UC-NRLF

| ||||||||||||||||||

후 30 I 5 I 5

THE MEDICAL

INSPECTION OF GIRLS

IN SECONDARY SCHOOLS

\title{
CATHERINE CHISHOLM
}



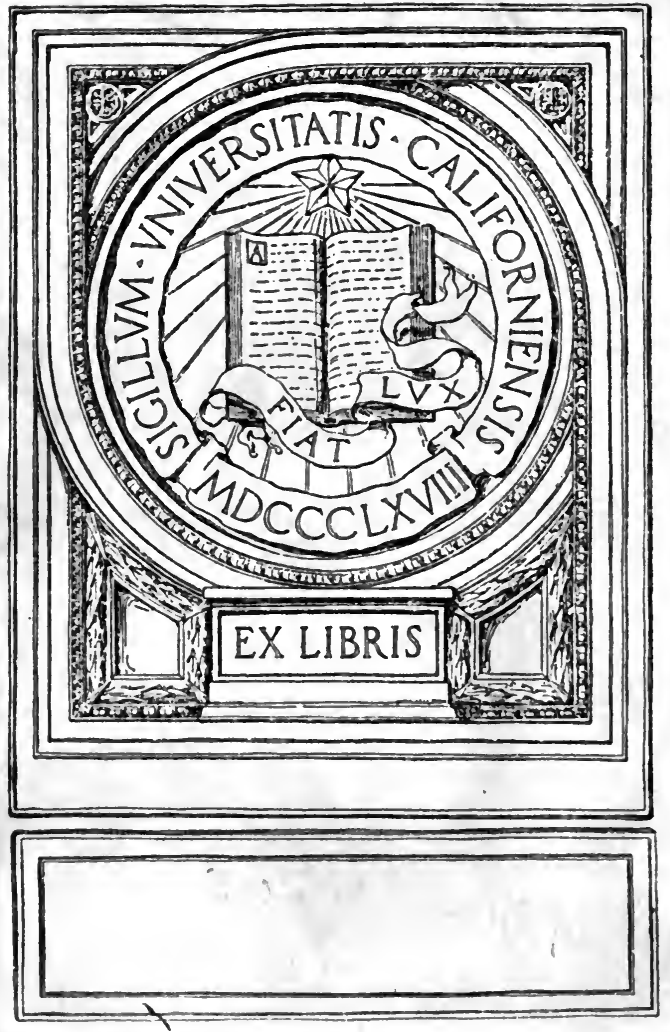



\section{Digitized by the Internet Archive in 2008 with funding from Microsoft Corporation}


THE MEDICAL INSPECTION OF GIRLS IN SECONDARY SCHOOLS 


\title{
THE MEDICAL INSPECTION OF GIRLS
} IN SECONDARY SCHOOLS

\author{
BY \\ CATHERINE CHISHOLM, B.A., M.D. \\ MEDICAL INSPECTOR TO THE MANCHESTER HIGH SCHOOL \\ FOR GIRLS
}

WITH DIAGRAMS

LONGMANS, GREEN, AND CO.

39 PATERNOSTER ROW, LONDON

NEW YORK, BOMBAY, AND CALCUTTA

I 9 I 4

All rights reserved 


$$
v_{3}^{B^{3 x^{3}}}
$$




\section{TO THE MEMORY}

OF

MY FATHER

\section{KENNETH MACKENZIE CHISHOLM}

$$
\text { M.D., J.P. }
$$

WHO AS TEACHER AND PHYSICIAN ADVOCATED

THE HEALTHY DEVELOPMENT AND EDUCATION OF GIRLS THIS BOOK IS IN GRATITUDE

DEDICATED 



\section{PREFACE}

THE high schools for girls which have come into existence since the Schools Inquiry Commission of the 'Sixties had the advantage of making a fresh start, of establishing a new tradition. Those of us who remember these early days know well that no small part of that tradition was a new respect for health and vigour of body as well as of mind. Indeed, one characteristic feature of the whole movement for the higher education of women has been the stress laid on physical training and hygiene, so far as these have been understood; in some of the pioneer schools medical inspection by a woman doctor was customary a generation ago, and for years in the "Girls' Public School Year Book" have appeared in many prospectuses the names of medical officers. But, at the present time, a marked impetus has been given to medical inspection in secondary schools by the Act establishing medical inspection in primary schools, and by the general public interest in the maintenance of health, and in the prevention of disease and physical disability. The problems of the school have also become more urgent: we have many delicate children brought to us for education; the standards of examination have risen, risen dangerously; parents and children 
are less able, certainly less willing, to put up with discomforts and difficulties, they rightly demand more attention to physical well being: while the national, the international, demand for efficiency is greater as the struggle for industrial success, and for the improvement of material conditions, becomes more severe. Under these conditions all who are responsible for the upbringing of young people, parents, teachers, administrators, depend on the medical expert more than did our fathers. School hygiene becomes more and more the foundation of our educational structure; while it is increasingly obvious that the medical authorities themselves must derive their experience, not only from the hospital and the consulting room, but from the school, the works, and the ordinary life of the citizen.

A large day school for girls, containing a great variety of types, and serving the needs of a busy urban community, presents opportunities for developing a useful system of medical inspection. It is because I have so keen a sense of the value to us in this place, and to education generally, of the work of my colleague Dr. Catherine Chisholm, that I have urged her to place on record some account of her plans and principles. We have found that a good deal more can be done than merely measuring and weighing the pupils, drawing up tables of results, advising parents as to eye defects, or the need of special gymnastics, and the like. We hope to be able to find out something that is really true and certain for us in our conditions as to school 
customs, methods and equipment, as to the effects of work and play, and even of administra tive regulations. Much has of course already been discovered through the medical inspection of primary schools; the effect of their appalling statistics must be far reaching in promoting social and educational reform. In secondary education we have still much to learn, and if careful medical inspection becomes general, as it is rapidly becoming, the evasive and thorny problems of the secondary school will secure some elements of a solution.

But if the medical officers are to help us teachers to solve our problems-and we need help sorely-we and they, experts both, must work together. The famous Scottish phrase as to the relations of Church and State, "Co-ordinate jurisdiction with mutual subordination" must be the rule for the relations of the school Head and the school Doctor. It is not an easy matter to carry out this rule in practice, and there are of course limits to its application.

A school medical officer cannot continue to advise school authorities who pay no attention to her recommendations; but a woman of sense knows that financial, personal, and administrative conditions may make it difficult, all but impossible, to carry out particular hygienic ideals in the everyday life of the school. Similarly, a head mistress, on whom the ultimate responsibility for the school must rest, may once in a way regretfully put aside the views of the medical authority as to a time-table, a menu, or 
the requirements of a scholarship competition. But it is always a risk to set aside the judgment of the expert: it is often unwise and always dangerous. One may do it occasionally, and risk the consequences for what may prove a greater advantage. Such occasions are, however, rare, and should become rarer, as the scientific basis of education is better understood.

In actual fact it is found that by good sense and sympathy, and give and take on both sides, the two authorities, teacher and physician, can work together, as they do in many schools, for the common purpose that urges each-the right development of the future citizen.

\section{SARA A. BURSTALL.}

Manchester High School for Girls,

October, 1913.

\section{AUTHOR'S PREFACE}

THis book was written in response to a request for one which would explain the methods and aims of Medical Inspection and be useful to the Head Mistresses, and authorities of secondary schools for girls where medical inspection does not yet obtain. The present volume does not aim at anything more than giving the lines on which the writer's practise is based. It is hoped that it fulfils in some measure the terms of the request, but the writer is conscious of its many deficiencies.

November 8, 1913. 


\section{CONTENTS}

INTRODUCTION . . . . . . . . . . . . I

I. MEdical Officer. . . . . . . . . . . 14

\section{EXAMINATION OF THE GIRL}

II. Measuring and Weighing . . . . . . . 30

III. EXternal APPEARANCES . . . . . . . . 42

IV. RESPIRATION . . . . . . . . . . . . . 59

V. Circulation . . . . . . . . . . . . 63

VI. Digestion . . . . . . . . . . . . . 73

VII. Nervous System . . . . . . . . . . . 80

VIII. Examination OF THE EAR . . . . . . . 9I

IX. Examination of The Eve . . . . . . 95

X. Adolescence . . . . . . . . . . . . . 103

\section{SPECIAL INSPECTIONS}

XI. REINSPECTIONS AND SchOlaRship EXAMINATIONS . . . . . . . . . . . . . . . IO8

XII. Class InSPECTION . . . . . . . . . 115

\section{INSTRUCTION}

XIII. Mothers, Pupils, Teachers . . . . . 129 


\section{SCHOOL HYGIENE}

CHAPTER PAGE

XIV. TIME-TABLE. . . . . . . . . . I5O

XV. DINNERS . . . . . . . . . . . . I57

XVI. VENTILATION-HEATING • . . . . . . I7I

XVII. Gymnasium and The Medical Officer . I86

XVIII. INFECTIOUS DISEASE • • • • • • . . I97 


\section{SCHOOL MEDICAL INSPECTION}

\section{INTRODUCTION}

THE conviction that without the full physical development of the body neither mental ability nor moral force can exert its fullest influence or attain to its highest state of efficiency, is the source from which the system of medical inspection of school children has sprung.

Though the Greeks aimed at producing the man fully developed, physically, mentally, and æsthetically, providing as the basis of their education, music, rhetoric and gymnastics, the moderns have but recently dropped their cherished idea that a scholar normally appears with bowed head, narrow chest, and pallid brow.

But at last, two facts are clearly recognized, and on them is based our present attitude to physical culture. The first is, that to enhance mental ability the body must be trained and not 
$\therefore$ SCHOOL MEDICAL INSPECTION

exhausted. The second, resulting from this, is the recognition that it is important to start as early as possible, and that if the best is to be obtained from the man, every care must be taken that he shall develop from childhood, nay, from birth, and even earlier, under the best conditions, and that adverse physical tendencies shall be checked at the earliest moment.

The Education Act of 1870 compelled every child to enter the schools. Many of them were ill-fed. Often through ignorance, occasionally through the carelessness of their parents, children suffering from various pathological but remediable conditions were attending school, though unable to profit properly from the instruction given. It became evident that the money spent in Education was to a large extent wasted. Various authorities began to take the matter up, and in 1891 the London School Board appointed a medical officer. In 1893, Dr. James Kerr, whose name stands out most prominently in the history of medical inspection of school children, was appointed to be the school doctor of the Bradford School authority.

Nine years later the Government, in passing the Education Act of 1902, made further appointments. In 1905, a report was issued on the Medical Inspection and Feeding of Children 
attending the Elementary Schools. The number of bodies having medical officers for educational purposes was by this time largely increased. In 1907, the Education (Administrative Provisions) Act was passed, providing for the systematic medical examination of all school children in the Public Elementary Schools.

We are already reaping the benefits of this Act. The reports of the medical inspectors are showing statistically that improvement in general physique, as evinced by the average heights and weights of the children, is clearly evident. The prompt notification to parents of defects found in their children has in many cases led to immediate treatment of those defects, and the consequent improvement of the children. The parent has now no longer the excuse of ignorance when he allows a child suffering from ill-health or physical defect to attend school. And the parents have been found very ready to respond to the calls for treatment made by the school authorities.

The result has been that benefit has accrued through the early notification to parents of defects present in their children.

Unfortunately, in many cases, the means of the parents preclude the possibility of the child's obtaining adequate attention except through the 


\section{SCHOOL MEDICAL INSPECTION}

already overworked out-patient department of the hospitals, or by the help of the Poor Law. In many towns, therefore, clinics have been provided for the treatment of certain of the diseases often found among school children.

Although medical inspection is now enforced by law in the Elementary Schools of England and Scotland, as yet medical inspection in the High Schools or Grammar Schools for boys and girls is by no means common. In these latter schools the introduction of medical inspection was originally commenced from different motives than in the Public Elementary Schools.

In the Elementary Schools, as has been shown, medical inspection was commenced in order to attempt to improve the obviously poor physique of some of the children, and to remove the evident disabilities from which they were suffering.

In the Secondary Schools most of the children appear to be well looked after and cared for, and the necessity for inspection on this score was not so evident. When, however, the education of girls was being reorganized and developed as a result of the movement for the higher education of women, the place of gymnastics and drill in the school curriculum had to be carefully considered. 
Frances Mary Buss recognized the fact that physical training was important in order that her girls might develop all that was best in them to the highest degree. She felt, however, that the girls must be carefully treated, or more harm than good would result. Therefore, more than thirty years ago she insisted on a medical examination taking place before physical exercise was undertaken.

It was only so lately as 1899 that Dr. Clement Dukes (whose work is so well known) commenced to examine every boy who entered Rugby. This was the first Boys' Public School to adopt the system of routine medical examination.

That Secondary School Teachers welcome and desire medical inspection is shown by the resolutions that their associations have passed. The Head Mistresses' Association declare that in their opinion such inspection is advisable.

The National Union of Teachers also thinks it advisable to have inspection in the Municipal and County Secondary Schools.

There are, however, yet comparatively few schools admitting children to secondary education where there is established systematic medical inspection.

In 1910, only 42 out of the 132 High Schools 
mentioned in the High School Year Book had a medical officer mentioned in the prospectus, and on inquiry it was often found that this officer was merely a medical referee in case of infectious or unexpected illness.

The figures collected by Dr. Alice Corthorn show that in 1910, out of 276 Secondary Schools, including Public, Private, and Convent, 92 had medical examination, I I had partial examination, and 19 had an examination by the drill mistress; further, 65 principals wished to have examinations but had none, and there were in addition 89 schools with no examination.

It is frequently urged, even by those who admit the advisability or even the necessity for medical inspection in the Public Elementary Schools, that such inspection in the Secondary Schools is totally unnecessary.

They declare that the parents of these children are able and willing to pay for advice and treatment for their children.

That it is the parents' duty to do this is true.

But the number of defects discovered on making a routine examination in a Secondary School of a good type shows, that through either ignorance or carelessness, many pathological cases, and many cases of abnormality are untreated. The parents are generally found 
ready and anxious to remedy these defects and abnormalities, when they are discovered. Thus the previous omission appears to be due to ignorance.

The Secondary Schools are of two main classes. There is the Grammar School or High School, which derives its funds, apart from the pupils' fees, either from an old foundation, or from a company founded to provide the education given in the schools. Some of these schools receive grants from the local education authority, and take a certain proportion of free scholars.

The other class is financed by the local authority to provide secondary education for the children of the town.

Many of the parents of the pupils in both classes are professional men with incomes none too large, or they are struggling tradesmen and business men. Many of the children are enabled to enter the schools by the means of scholarships and bursaries.

But though the parents will make great sacrifices to remedy a known defect, they cannot afford, nor do they yet appreciate the economy of, a periodical visit to the medical attendant to learn if all is going well with their children. 


\section{SCHOOL MEDICAL INSPECTION}

Thus it would appear to be advisable in the Secondary Schools, as in the Elementary Schools, to appoint medical officers to detect defects at an early stage.

Nowhere is there greater opportunity for a medical officer to do work of permanent social value than in these High Schools and Secondary Schools.

We are in this book more particularly concerned with the girls' schools. In these schools, the ages of the pupils vary from six years in the Preparatory forms, to nineteen among the senior students. Thus, though few children pass all their school life in the same school, the development of the large majority may be watched for many years at the most crucial period, through childhood and adolescence to full maturity. Often, indeed, the process may be observed in member after member of a large family.

It is important that the girls from these schools shall be turned out into the world mentally and physically as fit as their circumstances will allow. The work that they will have to do will be responsible and need all their capacity if it is to be done in the best possible way. Many will have to depend for their livelihood on their own exertions. The 
preparations for their life-work will in many cases, particularly for those going through a university course or a nursing training, be long and exacting. The tendency of eager, ambitious students is often by early over-pressure to spoil their later efforts. Perhaps this tendency is to be found more especially in girls' schools. The ambition of the girls is quickly stirred, their sense of duty and responsibility to those who are giving them opportunities is often keenly felt. They have fewer opportunities for distraction than their brothers. Their training and surroundings make them, even when keen on games and out-door sport, less likely to be carried away into indulging in them to the detriment of their studies. Moreover, every girl has some home duty or occupation, which helps to fill in her time and gives her, on the whole, less time for recreation than her brother. That this tendency to over-work exists in ambitious girls, or girls of ambitious parents, is shown by the numbers of those who in the earlier days broke down at the university or failed to bring to fruition the promise they had shown. These failures on inquiry will almost inevitably be found to result from an unwise system of work resulting from over-anxiety to excel. It is no good to win a good place at 
school or in the university if it is done at the expense of the body, and if success so impairs the health that justice cannot be done to the profession for which the scholastic work was merely the preparation.

The possibility of over-working at games and in the gymnasium must also be avoided. It is generally, though not always, a different group of girls who are likely to suffer in this way. One of the problems in a school having a gymnasium is to strike the right balance between encouraging physical development and checking that enthusiasm and interest in gymnastic work which makes excellence here an end in itself and a source of danger by overconcentration on this one branch of work.

Thus the care of the bodily development during the years when the girls are discovering and testing their capacity, when they are subject to great strain of growth and effort, and have not yet learned their limitations, is of the highest importance and full of interest.

But the medical officer in a school does not find the opportunities for valuable work limited to the inspection of individual girls. Details in the daily life of the school, advice on infection, school buildings, ventilation, heating, problems arising from the curriculum and discipline, all 
will, from time to time, come under his or her notice. There will be many opportunities, some formal, some informal, for giving hygienic teaching.

The social position of the girls in Secondary Schools is such that they will exert an important influence on the community in which they live. They are the teachers, the educators of the future, the civil service inspectors, the social workers, the nurses and women doctors, the wives of the professional, business, and legislating classes of their generation.

The attitude of such women to the question of public and private hygiene is of very great importance to the community. The presence and influence of the medical officer in the school where they are educated should and will accentuate the importance of a healthy sound body, and its dependance, not on fussy futile drugging, but on following broad hygienic principles, such as the provision of a sufficiency of air and food, the formation of habits of regularity and moderation in indulgence. Indeed, the formal instruction of the girls in sound wholesome teaching of physiology and hygiene should be a necessary part of the curriculum, and such instruction is best given by one having the authority of a medical training. 
It is probable that the children of the next generation, brought forth and cared for by former pupils of a school whose life is based on the co-ordination of pedagogical and medical experience, will start life under better auspices than the generations which have preceded it.

And it is just this conjunction of the experience of the pedagogue and the physician that is valuable and necessary to good education. More and more the teacher recognizes the necessity for training in psychology before he can understand how best to treat his subject and introduce into the receptive minds of his students the material he himself has assimilated. The senior wrangler may need much training in education before he is qualified to instruct the young in mathematics, and will always instruct the better after a study of psychology. Once we recognize the importance of the physical condition of the brain cell, its growth and development, the recognition of the physiological basis of education follows.

A medical officer in a girls' secondary school should be interested not only in general medicine, but in psychology, in education, in sociology. The work is more intimate, more concentrated than the work of the medical inspectors of elementary schools. If time can 
be given to it, the opportunities and research are many. The work is full of interest and value. Such an officer ought to aim at being more than a mere inspector, and have an influence which is felt in the atmosphere of the school as a whole, in the arrangement of the curriculum, in the health of the individual girl and in the homes from which the girls come. 


\section{CHAPTER I}

\section{MEDICAL OFFICER}

\section{DUTIES-ROOM-NOTICES-SECRETARY}

IF, then, it is advisable for the proper full equipment of the school that medical inspection should be undertaken, and undertaken with the objects spoken of in the previous chapter, the methods of carrying out the work must be considered.

It is taken for granted that in a girls' school the most suitable officer will be a woman. To one considering the matter without prejudice, it is evident that if the examiner is a woman the girls will find it easier to submit to the searching examination which is essential if the inspection is to be of any value.

On many occasions difficulties and problems arise in such schools which a woman is naturally more able to understand and with which she can more readily deal.

It frequently happens, for instance, that a 
case in which discipline is involved is reported to the medical officer for advice. It will be easier in many instances for a woman to get to the bottom of what may be causing the unsatisfactory conduct. The large majority of cases of really bad conduct are found to be due to some physical cause. This may be ill-health, unsatisfactory home conditions, unsuitable recreations. It is often possible for the medical officer who approaches the question without any bias caused by previous troublesome encounters with the girl, and who inquires into the whole matter from a health point of view, to find the cause of the trouble even after a sympathetic teacher may have failed. It is only a woman who could really set about investigating such questions. A great deal which is helpful to the mistress may be learned from a girl by a medical woman interested in psychology in a private interview with the girl involved. This is of course particularly true in the case of girls inclined to be hysterical. Such an interview would be impossible with a man doctor under the same circumstances.

Moreover, the medical inspector whose interest is in the school, and who works for the benefit of the school work, must be a member of the staff who can drop into the common room 


\section{I6 SCHOOL MEDICAL INSPECTION}

and discuss school problems with any of the mistresses without reserve. This, again, only appears possible with the woman officer. There must always be a certain amount of reticence and difficulty in discussing some school problems with a man. In medicine it is quite true that sex should not be regarded, but many things which the present-day lay-woman can talk freely about under necessity and in case of severe illness she finds difficult to mention when there is no urgency nor vital necessity.

The duties which a medical officer has to perform may be divided into-

1. The routine examination and re-examination of the girls.

2. The keeping of records and the collection of statistics and information about the normal child and variations from the normal type.

3. The supervision of remedial work in the gymnasium.

4. The giving advice to the Head Mistress on questions arising out of infectious diseases or other matters of school hygiene.

5. The instruction of $(a)$ the pupils and (b) the parents and guardians, in the hygiene of school life.

In arranging for the first of these duties, and the one which probably will take most of the 
time, different school authorities have adopted different plans, probably according to their conception of the scope of medical inspection.

Some authorities, chiefly concerned with the dangers of girls doing gymnastics and games when in a physically unfit condition, have adopted a voluntary system of inspection. In these schools the parents are notified that the proposed examination is to take place unless the parent or guardian signifies his or her objection. If permission to undergo the examination is refused the Head Mistress either asks for a medical certificate from the child's private medical attendant or refuses to allow the child in the gymnasium. Other schools, however, offer the examination, and if the parents refuse to allow the child to submit to it, no further action is taken in respect to that pupil. It is, in such cases, assumed that the parents accept all responsibility.

But in a school where medical inspection is instituted because health is known to be an essential for that development of mind and body which education superintends, and where the inspection is not simply a safeguard over A's or B's individual health, but a necessity to the school as a whole, the system must be a compulsory one. 


\section{I8 SCHOOL MEDICAL INSPECTION}

For this reason the expenses of the medical inspection ought to come out of the inclusive fees-that is, a special fee ought not to be charged for the medical examination. The compulsory entrance fee might be raised to supply the money. Many of the parents of children at the Secondary Schools have to consider every expense. They will often consider unnecessary an examination which is very important to the school. The examination is needed for the efficiency of the school work. Re-examination may often be even more useful to the mistress in helping her to decide on the proper treatment than directly beneficial to the girl's health. Especially is this the case where difficulties of discipline may have arisen. Therefore the fee ought not to be an extra. This inclusion of the medical expense in the general fee will make it less likely that requests for exemption will arise. Experience shows that parents are generally very glad to have their children examined. But it is often just the cases whom the Head Mistress is most anxious to have examined for the sake of the school and curriculum, who are inclined, under a voluntary system, to ask for excuse. To help her in such cases, and to keep the statistics of the school as a whole accurate, it is necessary 
that all the girls in the school should be examined.

In the prospectus of the school, therefore, it is well to state that there is in the school a system of medical inspection, and that each child is inspected at the wish of the Head Mistress. Due regard ought, however, to be paid to people such as Christian Scientists who have conscientious objections to medical treatment or examination.

The Examination Room in which the medical examination takes place ought to have special characteristics for the convenience of the work.

It ought to be a bright, cheerful, well ventilated room with good windows, if possible facing south, and capable of being opened. It is necessary that the room should be bright and attractive as the children are often nervous and a dark room is depressing.

Further, the room ought to be a model of what a hygienic room should be. Even if the girls and their mothers are in it only a short time, it is a pity that they should be in circumstances which one is explaining to them as unsuitable.

The size of the room is not of much importance, except, that for testing distant vision, one diameter of the room should measure six metres. 


\section{SCHOOL MEDICAL INSPECTION}

Eye-testing charts should be hung, framed, on the walls in convenient places. The windows should be supplied with well-fitting dark blinds in order that optic, aural, and throat examinations may be made.

The furniture of the room should be as simple as possible, fresh, attractive, and easily cleaned. It ought also to be as little official as possible, for we must remember the nervousness of the young people. The floor should be polished or covered with cork linoleum, and be frequently cleaned. The room should be heated with the heating apparatus of the school buildings, but there should also be a fireplace, as a fire may often be necessary when examining children only partly clothed, even if the weather is warm enough to do without the ordinary heating of the school.

A table or desk fitted with drawers with lock and key is needed. A couch for abdominal examinations is required. The high plinth used as apparatus in Swedish gymnasia is very suitable. These can be made by a local joiner at not much expense.

Cases to contain record cards, and two or three chairs, complete the necessary furniture of the room. Besides the furniture proper one needs scales and standard for weighing and measuring. 
Quite simple and useful ones can be provided on a stand for about $£$ I I $7 s .6 d$.

A convenient dressing-room near will be an advantage to the speed with which examinations are conducted, as a great amount of time is wasted if each child has to dress and undress in the examination room. No child but the one who is being examined ought, as a general rule, to be in the room with the examiner. The room ought to be kept quite private, and the intrusion of even the clerk who is assisting ought to be deprecated. Every child has the right to perfect privacy, and any delicate feelings ought to be very carefully considered and respected. Screens ought to be provided in case it is advisable on occasion to have a child detained in the room while another is being examined or some interview arranged.

Method of conducting the Examination.-When the girl has entered the school a notice is sent to the parents appointing a day and hour, as near the beginning of the term as may be, for the medical examination. It is advisable that the mother be urged to attend at the time stated. The presence of the mother lengthens the interview considerably, and when many girls have to be seen it appears to take up much valuable time, but that time is generally well spent. The 


\section{SCHOOL MEDICAL INSPECTION}

mother can often explain the routine of her daughter's life, tell of her previous medical history and describe her present state of health. Girls, especially of fourteen and fifteen, often try to persuade their mothers not to attend in order that they may have no restrictions laid on their bad habits of late hours and injudicious feeding which they may hope to conceal. But the interview with the mother is most valuable. One often learns much of the girl's home surroundings from the type of mother and the relations existing between mother and daughter. Moreover it is easier to speak of slight deformities, tendencies to weakness and actual defects without causing the unnecessary anxiety and alarm which a written communication, even when composed with care, may cause.

Details about personal cleanliness, suitability or care of clothing, if committed to paper would cause offence, while tactful comments will produce improvements later.

Together with the notices advising the parent of the child's inspection it is convenient to send a printed form asking for particulars of the child's previous medical history.

In this way, if the mother does not attend, one has the advantage of a reliable record of the past history. These particulars are entered 
on the child's record and these records are valuable in case of an outbreak of infectious disease when occasion to consider the necessity of isolation may arise.

It is most important to inquire into previous attacks of rheumatism, growing pains, and chorea before the child is sent into the playing fields or gymnasium.

After the inspection has taken place, if no relation or guardian has accompanied the child, a report of any defect or point needing attention must be sent to the guardian of the child as soon as possible. This can either be done in a formal notice or in a private letter from the Head Mistress. A report must also be given either verbally or on paper to the Head Mistress, and any special recommendation considered advisable sent to the form mistress or gymnastic mistress. The writer uses slips of paper typed for this purpose.

By these means, with the minimum loss of time, the child can receive special attention in her gymnastic work, and the form mistress has her attention drawn to defects arising from bad positions or unsuitable desks.

It is obvious that there will be a considerable amount of clerical work. If the time of the medical officer is not to be wasted 


\section{SCHOOL MEDICAL INSPECTION}

it is advisable that some member of the school staff shall act as clerk and keeper of the records. This is very necessary in the large schools where the number of girls to be examined is great. The clerk must be a careful, accurate, tactful, and discreet woman. She will have to keep the records, interview mothers, and prepare the girls to see the doctor in order that no time may be lost.

The time taken in examining the girls varies very greatly. A quarter of an hour to twenty minutes may be considered about an average time in a Secondary School. Some inspectors consider that they can examine a child in under ten minutes. But it is impossible to examine a girl carefully for the first time, to measure and weigh her, to test her eyesight and hearing, and to dwell on any points which may arise in so short a time. If the mother has attended, the time is apt to be longer. On the other hand, time is saved in writing out reports to be sent home. Re-examinations generally take much less time unless some special problem has to be investigated. Girls who come up to be seen just before leaving school may be seen very quickly, if a correct record of their weight has been kept each year. Those who are gaining weight and holding themselves well and have had no 


\section{MEDICAL OFFICER}

recent illnesses generally take up very little time.

The forms necessary, for convenience, in the secretarial work are all given below.

Preliminary notice of the existence of the medical inspection should be made on the prospectus.

I. Notice of the date and hour of proposed inspection, and invitation to be present.

II. Form asking for particulars of former illness.

III. Report to Gymnasium.

IV. Report to Form Mistress.

V. Report to parent or guardian.

VI. Record of girl made on card which is then catalogued.

VII. Chart of weight (see page 38 ). 


\section{SCHOOL MEDICAL INSPECTION}

\section{HIGH SCHOOL FOR GIRLS}

Ist Notice.

\section{MEDICAL INSPECTION}

Dear Madam,

I have arranged for your Daughter

(Ward) to see the School Doctor, according to School regulations, on at o'clock.

I trust this is a convenient day.

$$
\begin{gathered}
I \text { am, } \\
\text { Yours faithfully, }
\end{gathered}
$$

Head Mistress.

Re-examination Notice.

\section{HIGH SCHOOL FOR GIRLS}

\section{MEDICAL INSPECTION}

Dear Madam,

1 find it desirable that your Danghter

(Ward) should see the School Doctor on

at o'clock.

I trust this is convenient.

I shall be very glad to see you at the School, if you can be present.

$$
\begin{aligned}
& I \text { am, } \\
& \text { Yours faithfully, }
\end{aligned}
$$

Head Mistress. 


\section{MEDICAL INSPECTION}

\section{MANCHESTER HIGH SCHOOL FOR GIRLS}

\section{Dear Madam,}

Particulars of former illness.
Would you kindly write "Yes" against the following, if your Daughter (Ward) has had the complaint mentioned? And also fill up the last item, if necessary:-
(a) Scarlet Fever
(b) Diphtheria
(c) Measles
(d) Convulsions
(e) Chicken-pox
(f) Whooping-Cough.
(g) Rheumatic Fever Any other serious disease

The girl should bring this paper with her to give to the Doctor.

Yours faithfully. 


\title{
28 SCHOOL MEDICAL INSPECTION
}

Report to

Gymnasium.

Report to Form Mistress.
To the Gymnastic Mistress,

A.B. is suffering from

Needs special exercises as follows.

Medical Officer.

\author{
is absent
}

for

To Form Mistress,

Your pupil

Needs

\author{
C.D., \\ Medical Officer.
}




\section{MEDICAL OFFICER}

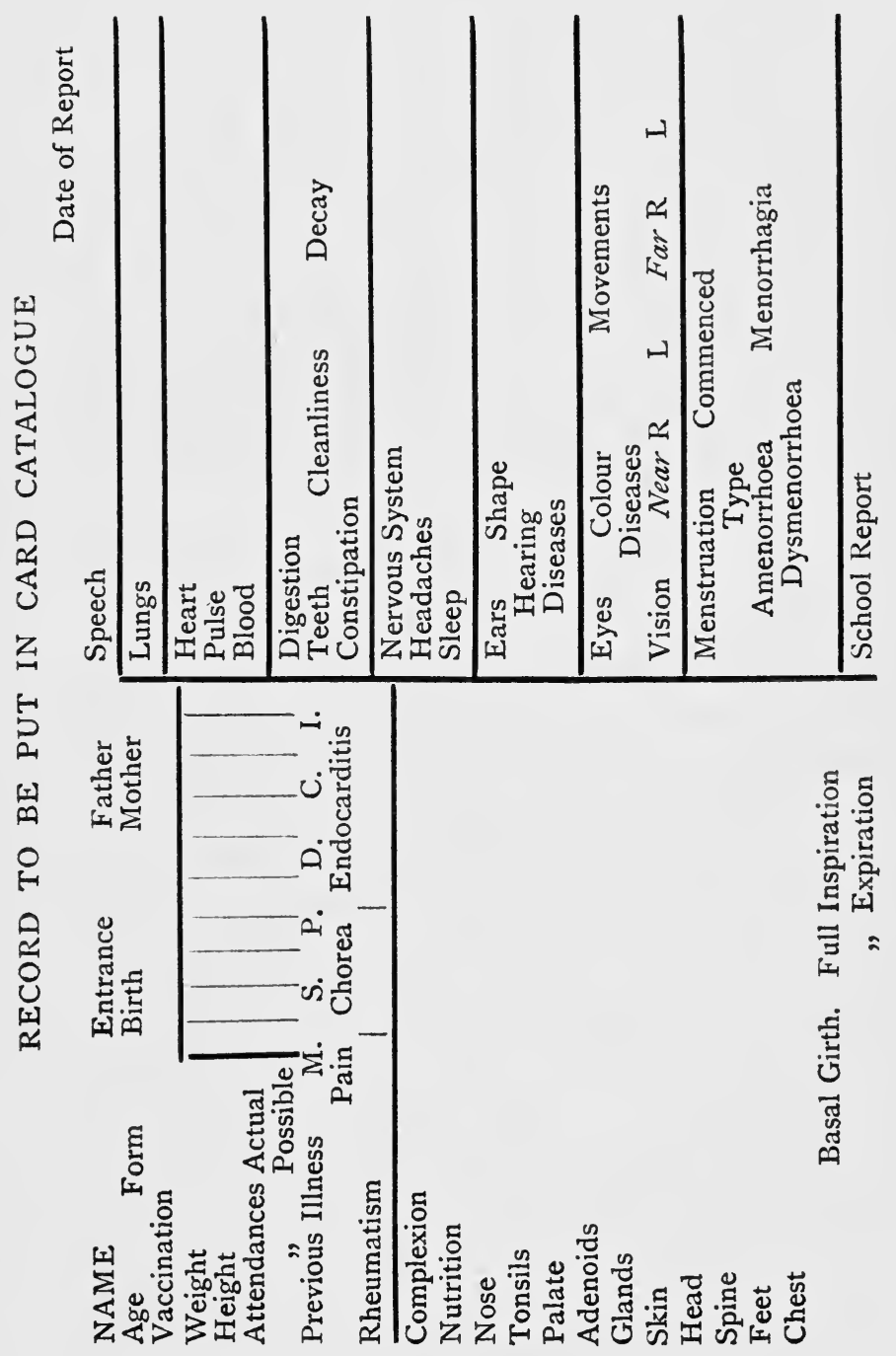




\section{CHAPTER II}

\section{EXAMINATION OF THE GIRL}

\section{MEASURING}

THE examination of the child commences with ascertaining her height and weight.

Statistics which have been scientifically collected show that on an average the heavier and taller children are the more intellectual. In a school where the forms are divided into higher and lower divisions according to their intellectual capacity it will be found that the division which is doing the most advanced work and doing the work best consists of girls who are on an average taller and heavier for their age than those in the lower division. This fact shows the importance of improving the girls' physical condition. We must, however, bear in mind that though the average weight of the girls in the upper divisions is greater than the average weight in the lower divisions, it does not follow that an individual girl is cleverer 
because she is overweight. Indeed, in the lower divisions there are often one or two very heavy girls who may be abnormally fat, perhaps because they are anæmic, or because they are suffering from deficient thyroid secretion. Such girls are phlegmatic and heavy. The proportionate muscular and bony development of the body and the amount of subcutaneous fat must be considered when judging the satisfactory weight for the individual.

The Anthropometrical Society in 1884 drew up tables showing the average weight and height for each year of age among. English girls and boys. These tables were drawn up from records of children of all classes of the community. As one would expect, children of the middle and upper classes, living under comfortable conditions and receiving as a class good wholesome food tend to have a higher weight than the average weight which is calculated from those of rich and poor, well-fed and starved.

Among the girls of a Secondary School in the north of England, in a town where the children in the elementary school were below the average, the average weight and height, but particularly the latter was above the Anthropometrical average. Of the candidates from 
elementary and private schools who obtained scholarships tenable at this school, those from the latter had a better average height and weight than those from the former. Thus, in judging of the weight social factors must be considered, and the importance to the child of early good environment is very clearly demonstrated.

The value of weighing and measuring the child lies in the fact that the regular and satisfactory increase in weight and height is a good criterion of the child's health.

It is, therefore, advisable to weigh her at regular intervals. It must be clearly recognized that the value of weighing and measuring the child lies in the help it affords, (I) in forming some idea of the child's physical condition. The opinion must be formed more from the proportion between height and weight being correct rather than from its relative approach to the normal average for girls of the same age in England.

In judging the condition from this later comparison we must, as has been observed, consider the social position of the girl and the part of the country in which she lives.

(2) As a guide in the future growth of the child. If the child is progressing steadily the height and weight will increase in a satisfactory ratio. 
It is therefore clear that the first record of the height and weight of the pupil will be a basis from which the future growth of the girl will be judged. Much exact information is gained when the girls are weighed each term. In a school where there is no medical inspection this should be done in order that there may be a definite criterion of the pupil's health, and the parents of a pupil, whose health is unsatisfactory, may have a fact demonstrated to them instead of receiving an indefinite observation which might fail to stimulate them into taking active steps to improve the conditions of the child's life.

Where the number of girls is very large, and especially if there is a medical officer who, during the term, sees any girl about whom the mistress may be anxious, it may be convenient and necessary only to weigh all the girls once a year. In the Manchester High School this is done in the summer term after the strain of the annual and public examinations is over. The girls are presumably then in their most tired condition. Any pupil losing weight at the end of the term should be re-weighed on the commencement of the next term. If no improvement has occurred, and the medical attendant has not been consulted it should be strongly 


\section{SCHOOL MEDICAL INSPECTION}

recommended that his advice should be sought. The school work should be modified and the girl weighed by the medical officer at regular intervals till her health improves. This proceeding need not in any way make the girl neurotic about her health, and does teach her that health is of importance. In some schools the annual or terminal weighing is done by the gymnasium mistress or the class mistress. It is necessary if the weighing is to be of any value that certain precautions be taken in order that these records may be exact and therefore useful.

The weights should always be taken at one time in the day, preferably during morning school. The girls should have on as few garments as possible in order that the records made at different times may be comparable. Clothing, shoes, etc., vary so much on different individuals, and indeed on the same individual from day to day that it is well to remove all clothing except combinations and stockings. A light cotton dressing-gown capable of being frequently washed can be worn during the inspection. The weight of these gowns will be practically always the same, any slight variation being so very small as to be negligible.

The time taken in removing the clothes and 
putting on the dressing-gown is not long, and the results are much more satisfactory. In the Manchester High School the annual weighing is done in the gymnasium, where cubicles have been made, in which the girls dress and undress. By using these, six or eight girls can dress or undress at the same time, and yet decently and in private and without waste of time. It is possible to weigh two or three classes of twenty to thirty girls in an hour. Some schools may find it more convenient to do the weighing when the girls go to the baths, but this is not so satisfactory, as in most schools all the girls do not learn swimming. It is advisable that one person should be responsible for all the weights and measures, as there is no doubt that the personal element enters and slightly alters the results of the operation.

The girls should sit well in the centre of the balance, or stand on it firmly. It is frequently necessary to be on the watch lest the girl be supporting some part of her person on the stand or the floor. The lever must be carefully watched and read, and the scales poised before commencing, to ensure accuracy. Experience teaches " ${ }^{2} \mathrm{C}^{\mathrm{E}}$ that it is necessary to emphasize all these points, as records taken have been vitiated by careless observation. 
In measuring, a standard with a projecting shaft is used. The standard must be quite straight. Many of the wooden ones tend to get warped, and then erroneous observations are made. The shaft must be set at a true right angle. The girl must stand quite straight, with her muscles taut. She must have no shoes, even gymnastic shoes cause varying error. Her hair ribbon or any coil of hair if placed on the top of her head must be loosened or removed.

The weight should then be entered on the card of each girl in the appropriate space, or, as has been found most useful, a chart demonstrating the gain by means of a graph should be filled in. This takes, however, some time, and it may be sufficient to keep only graphs of those girls not progressing satisfactorily.

The records of the individual weights and heights should be collected and tabled in forms, and the average height and weight of each form calculated. Any girl below the average weight or gaining insufficiently should be examined to see what causes the deficiency. Any form with height and weight below the average should be investigated (see chapter on Form Inspection).

Each year the form lists and averages should be copied and filed. They will constantly be 


\section{EXAMINATION OF THE GIRL}

needed for reference, and they form the basis of the statistics of the medical department.

On page 38 is a normal weight chart, according to the anthropometrical standard for girls of school age. There is also appended a list of the average weights and heights of the various forms in a High School.

Table Showing Comparison Between Heights and Weights of Each Form with Average Age of Form Compared with ANTHRopometrical Society's Standard.

\begin{tabular}{|c|c|c|c|c|c|}
\hline Form. & ge. & H.S. Hgt. & A. S. Hgt. & H. S. Wgt. & A. S. Wgt. \\
\hline 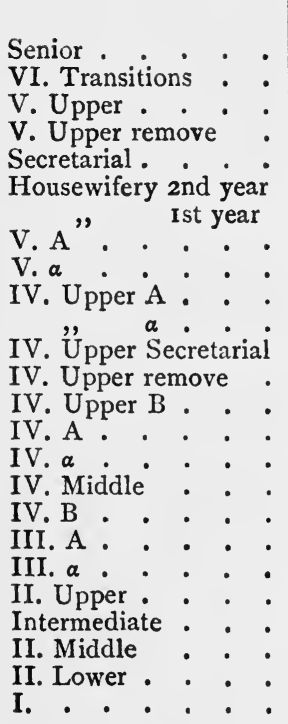 & $\begin{array}{l}\text { 18 } \\
\text { 17 } \\
17 \\
15 \\
16 \\
17 \\
16 \\
15 \\
15 \\
14 \\
14 \\
14 \\
15 \\
15 \\
13 \\
13 \\
13 \\
14 \\
12 \\
13 \\
115 \\
12 \\
10 \\
10 \\
8\end{array}$ & $\begin{array}{ll}\mathrm{ft} . & \text { ins. } \\
5 & 4 \\
5 & 4 \\
5 & 3 \cdot 5 \\
5 & 2 \\
5 & 2 \cdot 8 \\
5 & 2 \cdot 75 \\
5 & 1 \cdot 14 \\
5 & 3 \cdot 47 \\
5 & 2 \cdot 83 \\
5 & 1 \cdot 75 \\
5 & 2 \\
5 & 1 \cdot 84 \\
5 & 1 \cdot 24 \\
5 & 1 \cdot 57 \\
5 & 1 \\
5 & 0 \cdot 4 \\
5 & 0 \cdot 86 \\
5 & 0 \cdot 88 \\
4 & 10 \cdot 6 \\
5 & 0 \\
4 & 9 \\
4 & 10 \\
4 & 5 \\
4 & 5 \cdot 3 \\
4 & 2 \cdot 73\end{array}$ & $\begin{array}{ll}\mathrm{ft} . & \text { ins. } \\
5 & 2 \cdot 5 \\
5 & 2 \cdot 5 \\
5 & 2 \cdot 5 \\
5 & 1 \\
5 & 13 \\
5 & 2 \cdot 5 \\
5 & 1 \cdot 75 \\
5 & 1 ! \\
5 & 1 \\
4 & 11 \cdot 75 \\
4 & 11 \cdot 75 \\
4 & 11 \cdot 75 \\
5 & 1 \\
5 & 1 \\
4 & 9 \cdot 75 \\
4 & 9 \cdot 75 \\
4 & 9 \cdot 75 \\
4 & 11 \cdot 75 \\
4 & 7 \cdot 5 \\
4 & 9 \cdot 75 \\
4 & 6 \cdot 5 \\
4 & 7 \cdot 5 \\
4 & 3 \\
4 & 3 \\
3 & 10 \cdot 5\end{array}$ & $\begin{array}{ll}\text { st. } & 1 \mathrm{bs} . \\
8 & 9 \\
8 & 5 \\
8 & 10 \\
8 & 2 \\
7 & 13 \\
8 & 4 \cdot 4 \\
8 & 3 \cdot 5 \\
8 & 0 \cdot 13 \\
7 & 11 \cdot 5 \\
7 & 1 \cdot 4 \\
7 & 3 \cdot 8 \\
7 & 8 \cdot 65 \\
7 & 9 \cdot 12 \\
7 & 4 \cdot 92 \\
6 & 11 \cdot 43 \\
6 & 10 \cdot 32 \\
7 & 0.59 \\
7 & 0.25 \\
6 & 0.89 \\
6 & 8 \cdot 5 \\
5 & 8 \cdot 52 \\
5 & 13 \cdot 69 \\
4 & 12 \\
4 & 8 \cdot 46 \\
3 & 13 \cdot 75\end{array}$ & $\begin{array}{ll}\text { st. } & \text { lbs. } \\
8 & 4 \\
8 & 3 \cdot 5 \\
8 & 3 \\
7 & 8 \cdot 75 \\
8 & 1 \\
8 & 3 \cdot 5 \\
8 & 1 \\
7 & 8 \cdot 25 \\
7 & 8 \cdot 25 \\
6 & 12 \cdot 75 \\
6 & 12 \cdot 75 \\
6 & 12 \cdot 75 \\
7 & 8 \cdot 25 \\
7 & 8 \cdot 25 \\
6 & 3 \\
6 & 3 \\
6 & 3 \\
6 & 12 \cdot 75 \\
5 & 6 \cdot 5 \\
6 & 3 \\
5 & 1 \\
5 & 6 \cdot 5 \\
4 & 6 \\
4 & 6 \\
3 & 10\end{array}$ \\
\hline
\end{tabular}


38 SCHOOL MEDICAL INSPECTION

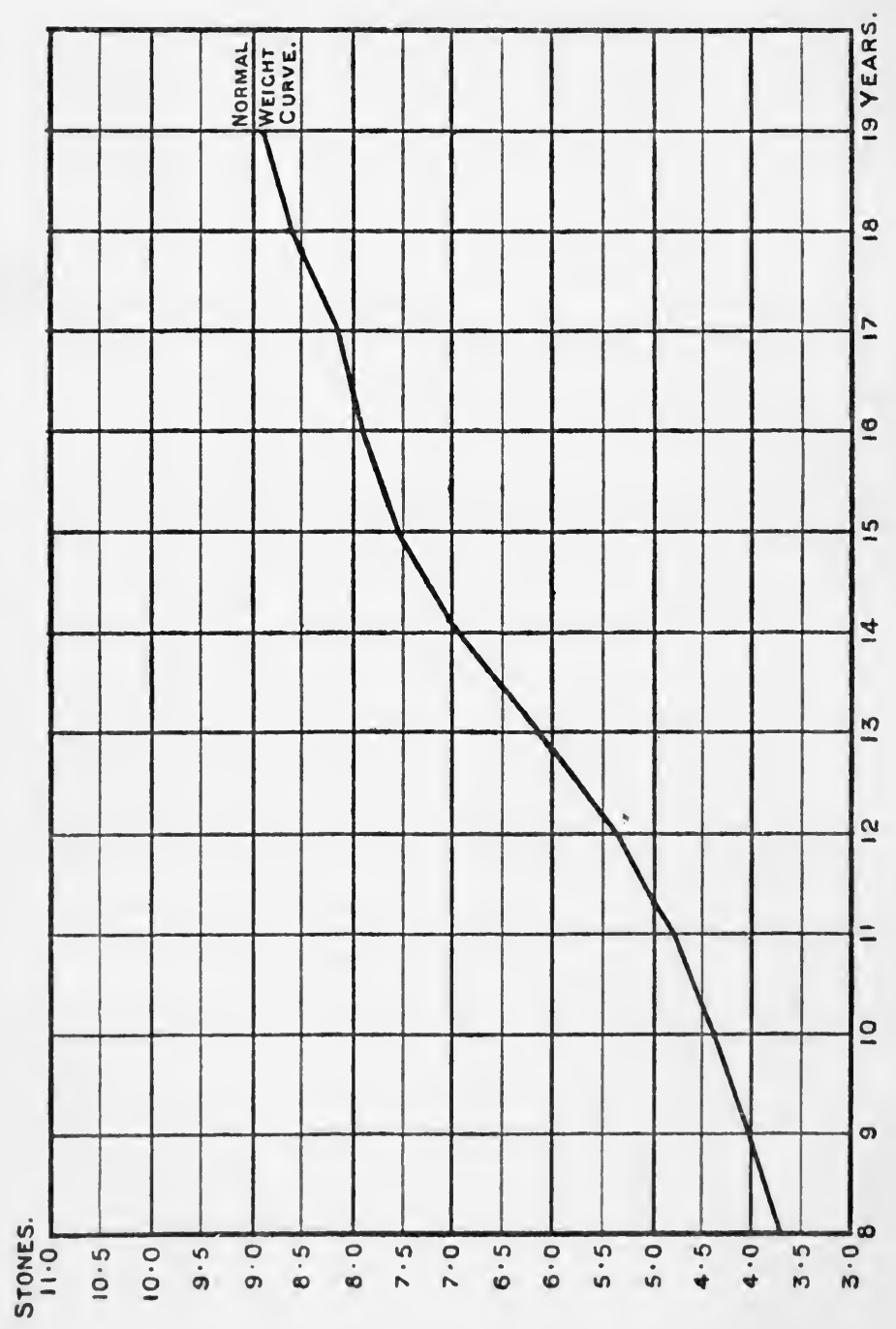


It must be remembered that the girls at the High School are dressed only in dressinggowns, and that the girls in the Anthropometrical Society's tables were clothed.

Table Showing Comparison Between Average of all Girls of Same Age at High School Compared with AnthropoMETRICAL SOCIETY's TABles.

\begin{tabular}{|c|c|c|}
\hline Age. & $\begin{array}{c}\text { Anthropometrical Tables. } \\
\text { Average Weight. - }\end{array}$ & High School Average. \\
\hline $\begin{array}{l}10 \\
11 \\
12 \\
13 \\
14 \\
15 \\
16 \\
17 \\
18\end{array}$ & $\begin{array}{ll}\text { st. } & \text { lbs. } \\
4 & 6 \\
4 & 12 \\
5 & 6 \cdot 5 \\
6 & 3 \\
6 & 12 \cdot 75 \\
7 & 8 \cdot 25 \\
8 & 1 \\
8 & 3 \cdot 5 \\
8 & 9\end{array}$ & $\begin{array}{ll}\text { st. } & \text { lbs. } \\
4 & 7 \cdot 3 \\
4 & 13 \cdot 3 \\
5 & 10 \\
6 & 4 \\
7 & 0 \cdot 6 \\
7 & 7 \cdot 5 \\
8 & 1 \cdot 2 \\
8 & 3 \cdot 9 \\
8 & 6 \cdot 25\end{array}$ \\
\hline
\end{tabular}

The High School averages of girls of the same age were calculated on the figures collected during two years in order to have a larger number with which to work, and therefore to get a more accurate result.

The growth of the girl is not at the same rate all the year round. The increase is greatest during the vacation. The necessity for vacations of ample length and of the proper division of terms is emphasized by the rate of increase in the holidays gradually slackening in term till at the end of term it may become 


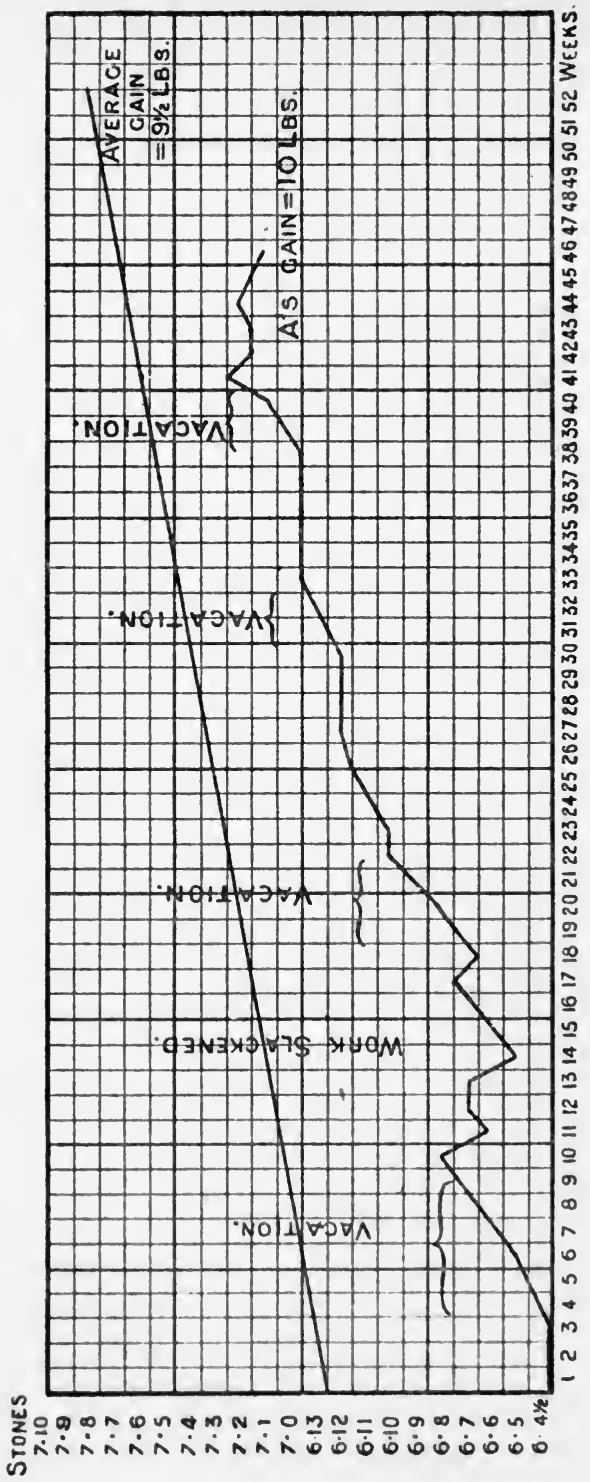




\section{EXAMINATION OF THE GIRL}

stationary or in overworked girls may become a loss.

In the autumn the gain in weight is greater than in spring, probably owing to the long summer vacation increasing the autumn weight and the long winter of work decreasing the spring one. The growth in height appears to be greater in spring..-

The table on page 39 shows the weekly weights of a pupil who was under weight, and therefore was weighed regularly. The advantage of the holidays and lightened work is shown. 


\section{CHAPTER III}

\section{EXTERNAL APPEARANCES}

\section{SKULL MEASUREMENT-EYE COLOUR- HAIR-COMPLEXION-BUILD}

Having made a record of the height and weight of the examined, it is next convenient to take any other anthropometrical observations which may be of interest to the examiner.

The colour of hair and eye, together with measurements of the head in the anteroposterior, biparietal, and bitemporal diameters may well be noted. Further measurements of the ears, the forearm, and upper arm may be recorded. These observations, particularly the latter, are not of practical importance and take up much valuable time. They may, therefore, be omitted, but where large numbers of children are examined, they provide points of interest to the student of anthropometry and may be useful for reference in future investigations.

The configuration of the body having been 
observed while the measurements were being taken, the girl is asked to bare back and chest, and any malformation or deformity is noted.

The condition of the skin will give information of the habits of the child. As a rule, the skin of the child attending the Secondary School is kept clean. Exceptions, however, occur. Often the body is kept too warm by the multiplicity of garments. This produces a moist condition of the skin and an unpleasant odour on the child who bathes only once a week. It is important to point out the benefits which accrue from the daily bath, or from a complete sponge down if a bath cannot be obtained.

Among adolescent girls there is often free action of the sweat glands. The pores of the skin are apt to get clogged with dirt and micro-organism, and a condition of acne often ensues. Scrupulous care in cleansing the skin by means of hot water and soap followed by plentiful sponging with cold water will improve the condition of the skin. Where pustules have formed, these should be cleared out with antiseptic treatment. It is well in such cases to examine the condition of the nails, and to warn the girl how infection is carried from one spot to another.

Occasionally a child is found suffering from 


\section{SCHOOL MEDICAL INSPECTION}

Impetigo Contagiosa. Such a child must, of course, be sent home and her parents notified. The child should be better in a very few days if she softens the scabs with water and applies some antiseptic ointment, but she should be advised to consult her own medical attendant.

Ringworm in girls is generally found on the skin as a red scaly spot which spreads at the margin whilst healing in the middle, thus appearing pale inside with a red circle round. If it is in the hair it produces a bald spot with a few bent little broken hairs. If the hair is soaked in liquor potassæ and examined under the microscope, the fungus is seen as a branching mycelium with spores arranged in groups or chains. Ringworm is very contagious, and in such cases the child must be isolated. No case should be considered cured till the hair shows no signs of the spores.

Scabies (Itch) may be found, though rarely, amongst children attending a Secondary School. It may be found in an exceedingly clean child of good family who may have contracted it during her journey to and from school.

This disease is caused by a parasite which burrows in the skin. The female burrows where the skin is thin-at the root of the fingers, in the flexures of the wrist or elbows. The male does 
not burrow. Intense itching is caused; a tiny vesicle is seen on the skin, which is often scratched owing to the intensity of the irritation. Pustules then often ensue. If they are not hidden by marks of scratching the course of the burrow can be seen on the skin and by searching with a pin, the acarus or itch may be found at the end of the burrow. The burrow shows itself as a short, thin, dark line, found in the most affected spots, i.e. between the fingers and in the flexures of arm and wrist. The dark line is caused by dirt catching on the raised top of the burrow. The latter is therefore more difficult to see in clean people.

Eczema of various kinds may be found.

Psoriasis is a fairly common skin disease. It is characterized by dry reddish scales found chiefly on the extensor surfaces, particularly on the elbows and knees. This is not infectious but ought to be treated vigorously and constantly. It will be found to be very persistent and to recur readily.

Children may be attending school with the eruption of any of the infectious fevers already out, and the school examiner may at any time come upon such cases.

When examining the skin, it is advisable to glance at the hair in order to note its condition. 


\section{SCHOOL MEDICAL INSPECTION}

This is very important in a girls' school. The hair is an important feature æsthetically, and care in brushing and washing ought to be bestowed on it. Many children suffer from scaliness of the scalp. This arises in two ways. The hair may be too greasy and heavy scales be detached and hang on the hairs, or the head may be exceedingly dry, and the epithelium be again detached. In either case, proper attention will greatly improve the condition. The condition of the hair is some indication of the health of the child. When the girl is thoroughly well, the hair tends to look well, bright and glossy. If the girl gets overtired, the hair often gets dry, straggling, and tired looking.

In every girls' school one is liable to come across some who have not paid sufficient attention to keeping the head free from parasites. In a school to which the pupils with the hair hanging loose come in public conveyances, there is a liability to infection, and the most careful may, in this way, contract it.

It is wise to insist that children attending such schools should wear the hair plaited or tied back in order, as far as possible, to avoid the danger. When examining the child it is necessary to be tactful in looking at the hair, as offence may be caused, or a nervous child be much hurt. It is 
perhaps easiest to glance at the hair when looking at the ears or when measuring the head. The presence of nits on the hair is easily noticed. They are found in greatest abundance just behind the ears. Children with any of these traces of pediculi must be excluded till the latter have quite disappeared. This will often be a tedious business and cause trouble, owing to many a mother's conviction that there is nothing alive in the hair and that nits are immaterial. Nits are always the results of parasites; the nearer the skull the fresher they are, and it is never safe to leave any in the hair, as one of them hatching may soon produce a fresh crop of nits.

The mother may be recommended some such simple device as washing the hair in paraffin or Lysol. The nits will, however, in most cases, have to be picked off the hair. A week is ample time in which even a bad case can be cured, but it will need many hours of careful attention to produce the result desired. It is always advisable to show the nit on the hair to the girl or her mother and then seal it up in an envelope in her presence. Trouble is less likely to be caused by an offended parent if evidence of the mischief is known to be in hand, for some mothers will wash the child's head and then take 


\section{SCHOOL MEDICAL INSPECTION}

her to a doctor in order to get his statement that the child's head is free from infection. If it is known that irrefutable evidence has already been secured, there is seldom trouble of this sort. Parents will, however, often insist on declaring that nits are unavoidable.

Though this stage in the examination is the point when such observations may best be made, it is not always advisable to point out these defects till the close of the interview, when the confidence of mother and child has been obtained, for thus the unpleasantness which might arise from mentioning the defect earlier will not interfere with the ease with which the remaining part of the examination is conducted. Having then glanced at the skin and hair, any marks or prominences on the surface of the body will be noted.

It is important to search for the presence of any enlarged glands. These may often be found along the sternomastoid muscle, above the clavicle or in the groin. The presence of these may be connected respectively with the condition of the hair or teeth, or with some injury in the lower limb. Any appearance of chronically enlarged glands should lead to a careful inquiry into tubercular tendencies, often the exciting cause of the enlargement, and to advice on the 
necessity of fresh air, nourishing food, and treatment of the glandular conditions.

At the age of puberty, an enlargement of the thyroid gland may be found. It is interesting to keep these cases under observation. Most of them gradually disappear in the ensuing three or four years. Any prominence of the eye or palpitation of the heart or tremors in conjunction with an enlarged thyroid would naturally be detected. It is seldom that cases of early exophthalmic goitre occur among school girls. If they occur it is more likely to be in the senior classes.

The appearance of the child's face is then carefully noticed. Signs of nervousness, twitching of the muscles, brightness of appearance, lethargy, heaviness, flabby muscles, sunken eyes, are also to be noted. Most particularly must the shape of mouth and nose be observed, the presence or absence of mouth breathing and any other facial sign of tonsils and adenoids. The throat should be examined, the tongue being depressed by a sterilized spatula. If there appears obstruction to breathing, the child is made to breathe up one nostril and down the other and, if necessary, the finger should be passed behind the soft palate to feel for the presence of adenoids. 


\section{SCHOOL MEDICAL INSPECTION}

Chest and Spine.-The examination of the spine and bony skeleton follows. This is a most important part of the examination. In many girls there is a tendency for curvature of the spine to be formed owing to quickness of growth or lack of proper muscular development. The results are both æsthetically and hygienically disastrous. In order that the spine can be thoroughly examined, the girl should be stripped to below the iliac crests. She should be in her stockings and without shoes. Any inequality in the length of the legs will be evident when she stands firmly on her feet.

The shape of the chest should be observed. At the same time it may be measured. A tape measure is passed just below the breasts and the measurement taken in full inspiration and deep expiration. The improvement in chest capacity after the girl has been in the gymnasium is in many cases marked. An increase from two and a half to four inches is frequently found. Any inequality of the two sides in chest measurement should be observed. Owing to compensation in carriage where there is dorsal curvature, the breast on the concave side of the curve will be most prominent.

The examiner should next stand at the girl's 
side and notice any kyphosis which may be present. From a position directly behind the girl the spine should be carefully observed. Any curve, either to the right or left in any part, any prominence of the ribs or protrusion of the angles of the scapulæ, any undue prominence of one hip or raising of one shoulder should be looked for. Having noted the position of the spinal curvature, if one is present, the next step is to put the girl in the best possible position, i.e. by manipulating the arms, to find out by pulling on the vertebræ in which direction the spine becomes straight. This is useful in devising the proper corrective exercises. Next, the girl should be told to put her hands high above the head and gradually lean over to a right angle and hang her arms down. The examiner can then look along the back and notice the prominence of the ribs along the spine. When rotation of the vertebræ has taken place, there will be prominence of the ribs on that side of the body. If rotation of the lumbar vertebræ has taken place, there will be prominence of one mass of the erector spinæ. After these observations have been made, the girl, having curvature, is classified in one of the following groups :-

I. Those whose spines may be straightened to normal by posture. 


\section{SCHOOL MEDICAL INSPECTION}

2. Those whose spines may be straightened out to some extent by posture but where deformity remains.

3. Those where the changes are radical and where posture gives little alteration.

It is necessary now to inquire into the causes which have contributed to these deformities in order that they may be removed as far as possible. In girls who have been growing quickly, particularly where the muscular development has not been good, the erect carriage of the body has become difficult. Stooping has' taken place, and gradually the easiest position has been assumed, and the spine has bent into abnormal curves. Prolonged standing may have caused the girl to find it easier to support all the weight of the body, for some time on one leg. A desk too low, or a bad light, or defective eyesight, may have caused a wrong position to be adopted when writing. A fondness for reading may have diminished the exercise necessary for the development of muscle, and induced a habit of sitting curled up on a sofa or chair. Prolonged exercise at the piano may have caused fatigue to the muscles, and a relaxation of the spine, or too long at the violin may, by the forced position of the arms, have produced its own type of 
spinal curvature. When inquiries have been made, and the cause of the curve diagnosed, asking the child to adopt the suspected position at once demonstrates the correctness of the opinion formed. If the child is asked to sit at the desk and write, the muscles at once pull on the spine, causing it to adopt the faulty position in cases where the curve has been caused by this means. This can be then easily demonstrated to the mother of the child. It is most important to get the co-operation of the mother in these cases. If she is shown the condition of the spine, and the importance of attending to its correction at once is pointed out, she is generally anxious to help. In slight cases, it is useful to mark with a grease pencil the spines of the vertebræ, and she will then readily appreciate the curvature. Emphasis should be laid on the necessity for a proper illumination, a suitable table, and for reminding the child when sitting or standing badly. The desk used by the pupil in school should be inspected. The class mistress should be informed of the girl's condition so that she may watch her. Any anæmic condition or the need for medical attention must be referred to the family medical attendant.

It is necessary that in the case of those girls 


\section{SCHOOL MEDICAL INSPECTION}

who are becoming bent through lack of strength due to anæmia and such conditions, care should be exercised in their drill. They must not be over exhausted, and yet muscular exercise is good for them. Free play in the open air would often be excellent, but they are just the girls who are listless and feel too exhausted to play. The daily routine of their lives should therefore be regulated. Some need time for rest, i.e. lying down in good positions after the morning's work. Few girls, however, need so much care as this. Those who are in the first class of curvatures, and the slighter cases in the second class, may with advantage do special exercises at school if the gymnastic mistress has time to arrange what are known as special remedial exercises. Any with more advanced mischief ought to have individual attention from a trained medical masseuse under her own doctor's supervision.

Feet.-Whilst examining the bony and muscular skeleton, it is wise to look at the feet. Feet are not now so frequently deformed by boots as used to be the case, but it is often necessary to enforce the advisability of well-fitting shoes with room for the toes in a normal position, with a heel not too high and sufficiently broad to support the foot adequately. The use of the gymnasium shoe for the whole day should be 


\section{EXTERNAL APPEARANCES}

deprecated, as the india rubber material prevents evaporation and the lack of heel tends to produce flat foot.

Weak ankles and flat foot are very common among school girls, and under sudden strain the ankle frequently gives way. Hæmorrhage takes place into the subcutaneous tissue, and, unless the joint is properly attended, the effects of the sprain last a long time and the joint is liable to give way again. Weakness of the muscles (the peroneal, the posterior tibial and the tibialis anticus) of the ankle joint is responsible for this condition and massage may be necessary.

These weak ankles tend to be found in cases of spinal curvature, where also, as shown above, a weak muscular condition is the cause. Moreover, by the weight being thrown unevenly on the foot owing to this muscular weakness, the arches of the foot tend to sag, and flat foot is produced. "The under part of the normal foot is hollowed out at the inner side to form with the ground a shallow cave, the roof of which is composed of a non-rigid spring composed of bones, joints, and ligaments. From a mechanical point of view the roof may be regarded as a series of arches disposed antero-posteriorly and diverging from the heel to the line of the heads 


\section{SCHOOL MEDICAL INSPECTION}

of the metatarsals, and the relation between the height and the span of the arches is such that those on the inner side are the weakest and those on the outer side the strongest." Kellett Smith.

Now, the sinking of the arches causes pain and deformity. Pain in the foot, aching in the bone, often ascribed to rheumatism, shooting pains in the legs, often spoken of as growing pains, may be due to the flattening of the arch. The deformity in marked flat foot is very evident. There is a deflection outward at the lower end of the tendo Achilles. (This, however, may be found when the ankles are weak and the arch of the foot still good.) The hollow under the inner side of the foot disappears. By placing the hand under the foot the absence or presence of this arch can be discovered. A more graphic and accurate effect can be got by taking an impression of the foot. This can be obtained by the pupil putting her foot in a basin of water and, after shaking off any hanging drops, firmly putting her foot on a piece of blotting-paper placed on the floor, and then throwing the whole weight of her body on the one leg. A quite satisfactory impression is got if only the blotting-paper is laid on a firm, hard surface. 


\section{EXTERNAL APPEARANCES}

Kellett Smith uses a printing frame for this purpose, which gives a more exact picture. The apparatus is a piece of wood with a piece of zinc fastened over it. The wood is surrounded

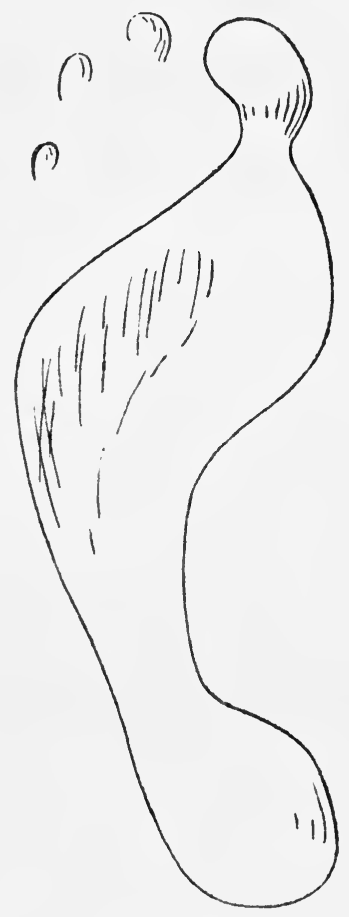

by a low frame and is divided down the middle by a movable wooden partition. Having inked the zinc surface, a piece of paper, sufficiently stiff not to crease easily, is placed over it. This 
58 SCHOOL MEDICAL INSPECTION

paper rests on the sides and the partition. If both feet are to be done, two pieces of paper are used, the inner edges of both resting on the movable partition. The foot is then placed on the paper, which is pressed on to the inked surface, and the impression of the foot is then readily obtained.

If the foot is found to be becoming flat-footed, or if there is any tendency to turn the ankles, appropriate exercises must be ordered, and the general health must be treated. Advice as to proper foot wear can be given. A great deal depends on the proper shape of the shoe and on proper support being given to the instep. A private course of massage and exercise and the wearing of a support may be necessary. Such advanced cases must be referred to the family medical attendant. 


\section{CHAPTER IV}

\section{RESPIRATION}

THE first steps in the examination of this system will already have been made in the general survey of the child.

The presence or absence of adenoids and the state of nasal respiration have already been noted, as well as the shape and expansion of the chest wall. It is both useful and interesting to measure the chest of the child on admission to the school and after she has taken part for some time in the physical exercises and games.

The measurements in centimetres or inches should be taken immediately below the nipple line or below the breasts in older girls. It is difficult to measure systematically by any method so that all cases can be compared, except after a deep inspiration and then again after a deep expiration. Both records should be kept. The next step should be to notice the equal expansion 
of both sides of the chest. The condition of the sternomastoid muscles often affords valuable information of any tendency to bronchitis or asthma, for there is hypertrophy in those cases where there is frequent expulsive attacks of coughing. It is necessary both when examining the children to notice, and when teaching breathing exercises to enforce, the complete filling of the whole chest with air. Inasmuch as the breathing of the young child is diaphragmatic, the tendency is to move the upper parts of the chest but slightly, with the consequence that the apices of the lungs move but slightly and are therefore the first to be affected with phthisis. If, however, the child is taught to expand the upper part of the chest, she forgets that she must also expand the lower part. All diameters of the chest must be exercised, the chest raised, expanded outwards and forwards. Further, care must be taken in teaching breathing exercises not to encourage an emphysematous condition of the lungs by holding them fully expanded during too long an interval. When the lung has been fully expanded, the natural elastic collapse of the lungs should be allowed to take place.

When the movements of the chest have been observed, the chest must be percussed and ausculated. Young children vary from adults in 
their breathing, being harsh and more bronchial in type.

Any suspicion of phthisis must be most carefully followed up. Particular attention must be paid to the apices of the lungs both in front and behind. By rounding the shoulders, the apices of the lower lobes can be examined more clearly. Here, often the first origins of tubercular mischief may be found. Fine crepitations, heard particularly at the end of inspiration, and a cough which is brought on by deep inspiration, must be regarded seriously. The crepitations, however, which are heard at the apices on deep inspiration in chlorotic cases must be remembered. It is advisable to re-examine frequently any child who is not gaining weight properly and to pay particular attention to the condition of the lungs. Inquiries into the temperature, feverishness at night, condition of the pulse and digestion must be made; and, if it appears necessary, further investigation must be made into their physical signs and symptoms.

Even slight signs and symptoms, which apparently disappear, must be remembered and the case kept long under observation.

A case of particular interest, showing the importance of watching carefully even very slight indications impressed the writer. A slight 


\section{SCHOOL MEDICAL INSPECTION}

apical crepitation and cough, which quite quickly disappeared, were observed in a girl. No sign later could be detected. A term after leaving school a year later, the cough again developed. Expert medical opinion gave a most favourable prognosis excluding phthisis. In six months the girl died of that disease. Too great care cannot be taken in respect to the hygienic surroundings of such girls where the signs are yet too indefinite to make the diagnosis clear.

Any persistent cough must be medically treated. A long uvula or an irritable throat with granulations, or perhaps enlarged tonsils, may be responsible. If it is expulsive and comes on in acute attacks without any chest or throat conditions to account for it, pertussis must be suspected. The whoop may not be heard till the third week of the disease and sometimes never develops. Whooping cough is acutely infectious and therefore such a cough should be investigated for a possible history of infection. The more acute diseases of the lungs as they cause the child to stay at 'home, are not likely to bring her under the notice of the school doctor, and therefore are not mentioned further. 


\section{CHAPTER V}

\section{CIRCULATION}

THE examination of the cardio-vascular system is of the greatest importance. This system is undergoing great developments during the years of Secondary School life, and is at the same time subject to great strain. It is a time of much muscular activity among the active of both sexes, and in girls particularly, the circulatory system, as well as the nervous system which regulates it, is becoming readjusted to a fresh wave of metabolic loss and recompense.

In schools in Munich re-examination at the age of twelve has been instituted, one of the reasons being the tremendous development of the circulatory system about that time. If carefully watched this very development may be of great benefit in the case of those who have already some heart delicacy. On the other hand, excessive exercise when the child is in an unfit condition produces dilation and strain, leaving permanent after-effects. 


\section{SCHOOL MEDICAL INSPECTION}

As soon, then, as a general survey of the body has been made, the examination of the heart is undertaken. Any cyanosis (blueness of the lips or skin), clubbing of the fingers, dilation of the superficial veins, will have been already noticed, also any excessive pulsation of the vessels. The rate, regularity, and tension of the pulse will be observed. If there is undue rapidity of the pulse, a glance at the neck will show if there is any enlarged thyroid present. The presence of an enlarged thyroid is fairly frequently found in adolescent girls, and is merely a physiological hypertrophy during the time of adolescence. If, however, there is any exophthalmos or marked quickness of the pulse or any tremor of the hands, the pupil must be referred for medical treatment. In examining the heart and circulation in children, the following peculiarities are to be noted (see Leslie Mackenzie).

"(a) The apex beat is higher and more to the left than in adults, being often found in the fourth intercostal space or over the fifth rib, and external to the nipple line.

"(b) The cardiac area or percussion often seems abnormally large, and caution should be exercised in the framing of any conclusion as to the presence or absence of hypertrophy. 
"(c) The rhythm of the heart is less constantly regular in children than in adults; very slight causes disturb the rate and regularity of the pulse, and accordingly these two are of little moment as an index of morbid conditions.

"(d) In rickety children the apex beat may, owing to deformity of the chest, seem to occupy an abnormal position.

"(e) During childhood, especially between the ages of seven and fifteen, the heart undergoes rapid changes in volume. About the fifteenth year the heart increases in volume by 100 per cent. This circumstance must be remembered more especially in the prognosis of all cardiac troubles that occur within the ages named."

Among the children attending Secondary Schools who receive careful home treatment, lesions of the heart appear much less frequently than in the children attending the Elementary Schools. This is due to the greater care with which they are protected from illness and treated when they are subject to it.

Affections of the heart may be divided into Congenital Malformation, Functional, and Organic diseases.

Congenital Malformations often cause early death before school begins. But where they are not very serious, the child may live through 
adolescence and gain adult age. The symptoms are cyganosis, clubbing of the fingers, and murmurs at the base of the heart, together with increase in the size of the heart through dilation, or hypertrophy. These children are particularly liable to pulmonary trouble, and any symptoms of rheumatism should cause much anxiety.

Organic disease of the heart in children generally takes the form of valvular lesions, the result of rheumatism. For this reason any case of valvular disease ought to be investigated for a history of rheumatism, presence of rheumatic nodules, chorea, or irregular attacks of joint pain. Any case of recurring tonsilitis, of pains in the joints, or chorea, ought to lead to a careful examination of the heart, and if there is any sign of trouble there, absolute rest must be enforced; or where there has been any heart trouble, any recurring pain must mean rest. This is very necessary, as there may be endocarditis (inflammation of the lining membrane of the heart), with very little evidence of what is going on, and extensive mischief lasting through life may ensue. The results of rest and care are so good that there ought to be no hesitation. Nothing needs more emphasis than the care which is necessary 
to one liable to rheumatism. The connection between Tonsilitis, Rheumatism, heart disease, and St. Vitus' dance ought to be known to all parents and teachers. No heavy exercise should be allowed in case of active valvular disease. On the other hand, where the mischief is in entire abeyance, where treatment has been careful, and where there is full compensation, gradually increasing exercise can be safely undertaken till the child can take the ordinary drill of children of her own age, and may safely take part in school games under supervision. Such cases, however, must be frequently examined, and the drill mistress must watch for any sign of stress. Gymnastic work for all pupils must be most carefully graded according to their capacity. It is not the mere presence of the murmurs which guides our treatment so much as the history of the case, the compensation established (as evidenced by the ease of breathing, absence of cyanosis, the steadiness and regularity of the pulse, absence of exudation under the skin, swelling or other signs of back pressure), and the opportunity for supervision.

A pure mitral incompetence in a healthy child, where further attacks of rheumatism can be kept at bay, gives a very good prognosis. 
If there is stenosis the prognosis is not so good. In any case, it is necessary to see that the child is warmly clad with flannel next the skin, winter and summer, and that the diet is suitably arranged and plentiful. It must be remembered that scarlet fever, measles, and diphtheria may leave behind them hearts weakened by endocarditis. The symptoms may be very slight-slight shortness of breath, slight palpitation, some pains in the legs and joints. The heart should always in these cases be carefully examined and rest enforced.

There remain to be mentioned functional disorders of the heart. These may be irregularity of action, either with very slow pulse or very quick pulse, palpitation or intermittent beats without any obvious cause. Such functional disorders are often found in anæmic, weakly children, or those suffering from gastric disturbance. In these cases, attention must be paid to the primary condition and the general health. Among girls, a certain number suffer from breathlessness, are very pale, their faces, in bad cases, having a greenish tinge; hence the descriptive term chlorotic. In such cases, we get a weak, thready, sometimes irregular and often quick pulse. These girls have a tendency to headache and dyspepsia. Often they suffer from 
constipation. Some do not look pale, may even have a good colour, but the slightest exertion tires them, and often, although their face has colour, the mucous membrane is pale. In such cases, auscultation will give a bruit over the large vessels in the neck. Such girls are suffering from a deficient supply of hæmoglobin in the blood. The red blood corpuscles are diminished in number, small, and contain less hæmoglobin than the normal. It is convenient to have a ready means of testing the blood in such cases. Such a method is by means of Talquist's Hæmoglobin Scale. The finger is disinfected, a bandage wrapped round it and the finger bent; a sterilized needle is plunged through the skin just below the nail. The drop of blood is absorbed by means of a piece of white blottingpaper and compared with a scale of colour provided.

The book containing the colour scale and blotting-paper can be acquired from Messrs. Allen and Hanbury's.

Girls suffering from chlorosis should have their work regulated and be advised to be put under a proper course of medical treatment, and should not do physical exercises unless under special circumstances, i.e. in classes suited to their capacity or under individual supervision, 


\section{SCHOOL MEDICAL INSPECTION}

and they ought to be out in the air and sunlight as much as possible.

A certain number of girls in early adolescence may be found suffering from primary anæmia. Such cases are pale and again breathless, but the hæmoglobin index is not so low as in the chlorotic cases, and varies more in the month. Whereas the chlorotic girls often suffer from amenorrhœa, the history in these cases will give profuse and frequent menstruation. These cases will be more thoroughly discussed under the heading "Menstruation."

Urinary System.-An inquiry into the action of the kidneys must always be made. The tension of the pulse and the presence of any subcutaneous swelling, particularly in the face, are noticed. It is not often that one meets with kidney trouble among school girls, but it is advisable to have the necessary reagents so that the urine may be examined where there is suspicion of kidney mischief. Where such mischief is present it often develops insidiously, and serious illness may result from neglected cases. Cases where there is malaise and a poor state of health with no good demonstrable cause should always be examined for traces of kidney trouble. When examining the urine of school 
girls, where a positive reaction for albumen is found, the possibility of leucorrhœa accounting for the deposit on heating must be remembered.

Incontinence of urine is a trouble sometimes met with among school girls. This troublesome condition may have lasted from birth, when it is often but not always the result of defective training-but it may suddenly supervene later in school life. The most usual form is nocturnal incontinence or emuresis. Medical treatment must always be suggested. The trouble is generally nervous in origin. Ill health, late hours, excitement, are often the exciting causes. Where there is difficulty in the daytime, an opportunity of relieving the bladder must be afforded and advantage of it must be taken between each lesson. It is necessary for the class mistress to know of such cases, as the children are often shy, and an intelligent mistress can do much to assist cases of this description. Sometimes, indeed, the mischief has originated in a shy child not being able to get to the lavatory when she desired. A distended bladder may have resulted, which would lead to incontinence or lack of control. Such cases point out the importance of a sufficient lavatory accommodation being supplied. 


\section{SCHOOL MEDICAL INSPECTION}

Retraining the bladder by affording regular periods for relief, whilst the child's physical condition receives attention, may soon re-establish control.

In such cases, examination of the urine and parts must first have shown the absence of local irritation. 


\section{CHAPTER VI}

\section{DIGESTION}

THE first step in examining this system of the body is most conveniently made when the throat is examined. At that time a glance can be taken at the teeth and tongue. The presence or absence of decay in either primary or permanent dentition must be noted. Very important is the evidence of care in keeping the teeth and mouth well cleansed. Food left lodging about the teeth undergoes fermentative changes through bacterial action-acids are formed which attack any part of the teeth which may have lost its protective enamel.

It is therefore most important in the first place to keep the teeth well cleaned, and secondly, to pay attention to the smallest sign of decay immediately it is observed. Therefore the custom of regularly visiting the dentist in order that incipient mischief may be early checked, should be encouraged. Decay in the primary 


\section{SCHOOL MEDICAL INSPECTION}

dentition should not be disregarded as insignificant because these teeth will soon disappear. It is denied by good authorities that such decay can attack an underlying healthy tooth, and the dentist is sometimes reluctant to remove a bad primary tooth in order that by remaining it may assist in the natural way the regular and even eruption of the second tooth.

But the presence of foul decaying matter in a tooth and the presence of a cavity in which food fragments can undergo fermentation may upset the digestion of the girl, and any slight tenderness in the decaying tooth may cause the food to be badly masticated. In any mouth where there are decayed teeth special attention must be paid to the very careful cleansing of the mouth.

In using the tooth brush it is important not to use one which has bristles so hard that they will injure the delicate margin of the gums. Still, the bristles ought to be able to penetrate between the teeth. The most satisfactory way of removing much of the matter lying round the teeth is by filling the mouth with water and thoroughly rinsing the teeth, drawing the water to and fro by suction action. It is advisable, if possible, to rinse the mouth thoroughly after every meal. To finish with a drink of pure water serves in some measure this object. 
Sims Wallace points out the importance of giving the young child at a very early date hard food so that his teeth and jaws may have some work to do. Parts which are not exercised do not develop well. He points out that the soft sloppy food so long given to children gives no opportunity for mastication. Consequently, the jaw does not develop, and the mouth becomes overcrowded with irregularly placed teeth. Moreover, these sloppy foods, being largely of starch foundation, leave plenty of material, prone to fermentative changes, round the teeth, and settling in the crevices conduce to early decay.

Mothers, therefore, should be instructed to give their younger children toast instead of bread and milk. Later, after they get their first molars at fourteen months and they are able to masticate, they can be given more solid puddings, boiled fish, fruits which require biting, such as bananas and apples, and even chicken occasionally.

The mouth must then always be left clean, and foods of a sugar or starch nature not given at the end of a meal unless the mouth is well rinsed afterwards, also soft puddings, jam and bread, and so forth, should always be followed by some clean fibrous fruit, such as an apple whose slightly acid juice will help to keep up the flow 


\section{SCHOOL MEDICAL INSPECTION}

of saliva, and the mastication of which will help to remove the matter round the teeth.

As the permanent teeth appear it is necessary to notice that they are not overcrowded, and that they are when closed in good opposition, so that biting and mastication may be satisfactorily performed. If they do not seem to be developing properly the dentist should be consulted.

In inspecting the mouth the number present is a criterion of the soundness of the teeth, and also shows if the child is at or about the proper stage of development.

The following table gives the approximate number of teeth a child should have at varying ages :-

\begin{tabular}{c|c|c|c}
\hline Age in years. & Temporary. & Permanent. & Total. \\
\cline { 2 - 3 } $6-7$ & 20 & 4 & 24 \\
7 & 16 & 8 & 24 \\
8 & 12 & 12 & 24 \\
9 & 8 & 16 & 24 \\
10 & 4 & 20 & 24 \\
$11-12$ & - & 24 & 24 \\
$12-14$ & - & 28 & 28 \\
$18-25$ & - & 32 & 32 \\
\hline
\end{tabular}

It is important to distinguish the primary teeth from the permanent set. The incisors and canines differ only in their smallness in the 
primary dentition. The hinder molars are larger than the front ones. The first upper primary molar has three cusps, the second has four. The first lower temporary molar has four cusps, the second five, three being external. The first permanent teeth to appear are the first molars which come before the central incisors.

Having examined the teeth, inquiries are made about the appetite of the child, the presence of pain or disturbance after food, the regularity, sufficiency, and quality of the meals. The importance of having a proper breakfast before leaving home in the morning is a point which, experience teaches, needs strong emphasis. Late rising and journeys to school often cause the breakfast to be neglected. Especially in those schools where the long morning session of nine to one o'clock is held it is very necessary for the pupils to have a good breakfast before leaving home.

It is not often that serious intestinal mischief is met with in school inspection. A history of diarrhœa should always lead to a careful inquiry into family history, previous health, and present gain of height and weight in order that a possible case of tuberculosis may not be neglected. Any suspicious case ought to be examined for enlarged glands. Cases of 


\section{SCHOOL MEDICAL INSPECTION}

appendicitis may be found, and it will occasionally be found necessary to point out to parents the necessity of getting medical attendance in cases of recurring colicky pains which they may have considered insignificant.

Constipation remains to be considered. On questioning patients in private practice one finds that constipation is a very common complaint. One is therefore the more struck by the comparative freedom from this complaint among school girls. An inquiry into five hundred school girls showed only fifteen per cent. suffered from this complaint. A great many must develop constipation later in life. Schools and particularly boarding schools have often been blamed for the development of this pathological condition owing to the lack of opportunity for the early morning evacuation of the bowels. In day schools the girls getting up late have to rush from breakfast to school. In boarding schools the number of convenient apartments have often been too few for the number of girls who have to be accommodated in the interval between breakfast and morning school. The necessity, however, for forming a regular habit of an action of the bowel each day must be emphasized. The bowel responds to such treatment, and the difficulties and troubles both 


\section{DIGESTION}

mechanical and toxæmic which follow on constipation may thus be averted. The habit of taking drugs to stimulate the bowel should be deprecated. A suitable dietary, including the free ingestion of fresh, pure water and fruit, should be suggested. Drug treatment of constipation should be under medical advice in order that the muscular condition of the intestinal wall may be improved in those cases (the large majority of cases of constipation) where from neglect the intestinal canal has lost its muscular tone. 


\section{CHAPTER VII \\ NERVOUS SYSTEM}

"THE nervous system of the growing child is the cardinal physiological system of educational life" (Leslie Mackenzie). The whole of the child's waking and sleeping life is ruled by the nervous system. School life is specially devised in order to produce its physiological development by means of exercising its faculties. For like all parts of the body exercise of its functions produces development. So also does over-exercise produce toxic symptoms and atrophy. Advanced nervous trouble is itself prohibitive of attendance at school. And therefore it is only the early symptoms with which we are here concerned. But as each development in the long ascent to the human level is sooner destroyed than its predecessor, inasmuch as it is more delicate in its development, it is particularly necessary to notice the first signs of any failure of the nervous system. Its lesions, once they occur, 
are repaired very slowly. During the time so far spent in examining the child many observations on the state of the central nervous system may have been made. Any gross effects of previous illness such as deformities resulting from infantile paralysis, any paralysis left by acute infectious diseases such as diphtheria, any squint or torticollis will have been observed.

The face is a valuable indication of the state of the nervous system. The tense twitching face of the highly strung child, the slack tired look of the overworked, the watchful eye, the quick movements which betoken the need for care lest over-pressure occur, and the pale tired hollow-eyed appearance of the already over-pressed compare unfavourably with the calm bright appearance of the healthy child.

The hands again are an important indication of the state of the nervous system. The trembling thin fingers of the nervous type, with fingers hyperextended or drooping, and the flabby hands, compare with the firm well-developed hand of the normal child. The hand with bitten finger nails often accompanies the corrugated brow of the over-excitable child. Among young children particularly spasmodic twitching movements are often noticed. One of the causes of convulsive movements in a child of school age, 


\section{SCHOOL MEDICAL INSPECTION}

and one which must always be carefully treated, is chorea. The percentage incidence is very low in the writer's experience in the Secondary School, but the results of neglected cases are serious. Moreover a child with choreic movements in a school often produces a crowd of imitators. The movements are rapid and incontrollable twitchings of all the muscles of the body. Chorea is most likely to occur between the ages of seven and twenty years of age. The movements often commence with twitchings of the face which become worse on attention being directed to the sufferer. Later the hands and arms twitch. Often the speech is affected. The child is restless. The symptoms may be very slight at first. The child may be scolded because she is awkward and clumsy; often she is irritable and cross. Any change in manner towards irritability associated with clumsiness should ensure an examination by the school doctor. If it is decided that the child is suffering from chorea all work should be stopped at once. Chorea is generally associated with rheumatism and consequently with heart trouble. Sometimes it follows acute fevers or it may develop suddenly after shock. But the condition is always serious and demands immediate physical and mental rest. 
All twitching convulsive movements of hands and face must be carefully observed. It is very unlikely that even minor epileptic children will be in Secondary Schools. It may be that some of the twitchings noticed are simply due to bad habits which must be checked at once or a habit spasm will result which may last through life. It may be that these twitchings are caused by some constant irritation or that some other exciting cause which may be removed can be found. One small child contracted the habit of constantly wrinkling up her lips like a rabbit. She had had a slight nasal catarrh, and some irritation to relieve which she had wrinkled her mouth, and finding some amusement or pleasure, continued the practice till she was unconscious when she did it. Only constant correction freed her from a most unpleasant habit.

Attendance at picture palaces produced in a small person of seven a ridiculous habit of blinking the eyes. A stop to the foolish plan of taking a young child to such entertainments was necessary before cure could be hoped for. In moments of excitement or tiredness long after cure, such habits tend to recur. Apart from habit, fatigue of the nervous system will produce twitching, particularly of the facial muscles. 


\section{SCHOOL MEDICAL INSPECTION}

This will be most often observed in the kindergarten and lower forms of the school. Such cases must have a holiday, and when they return to school have regulated hours and plenty of rest.

Mentally defective children often display aimless, sudden movements, but they are not generally convulsive in character. The general appearance of the child and inquiry into its mental development will lead to diagnosis. Feeble-minded children only occasionally come before the medical inspectors of high schools, and then they are mostly children with sluggish brains rather than actually defective ones.

Small children who may appear actually mentally defective have in our experience been found to develop wonderfully after careful removal of all physical defects such as tonsils and adenoids, or bad teeth, when a regular hygienic life with long hours for sleep and proper food has been given. This is especially so after a careful psychological investigation has been made and the easiest avenue to their minds has been found.

One set of cases, reported in the chapter on Form Examination, particularly revealed a possibility of awakening the intelligence of children who displayed many signs of 
deficiency. Dramatic action-by re-enforcing the ordinary paths of memory by numberless muscular acts each making co-ordinations and individual impressions, improved their work. The work was learnt with less effort. The result was less fatigue and a greater capacity to attack the next task. Thus careful observation of the mentally sluggish child by the Medical Officer is amply repaid.

Headaches.-The presence or absence or frequency of headaches must be investigated-

I. The most usual cause of headache is eyestrain. The headache is usually frontal or bitemporal. Eyes which are defective and causing headache need careful testing. Much discredit is thrown on the advice to get glasses by the child's being taken to some shop where she is fitted with glasses. A skilled oculist should be consulted. Astigmatism is often the cause of the continued trouble, and it is only set right when glasses which accurately correct the defect are obtained. (A separate chapter is devoted to eye conditions.)

2. Overcrowding the schoolroom or badly ventilated rooms at home where home-work is being done produces poisoning by $\mathrm{CO}_{2}$ and thus causes headaches. Gas or lamps quickly use up the oxygen, and if the family sit in a small 
room lighted by two or three gas jets, headache will naturally result, particularly in the young child occupied in mental work.

3. Closely related to this form of headache is the one produced by tonsils and adenoids, causing obstruction to the breathing, or a persistent nasal catarrh causing congestion and stuffiness in the head. Such headache is frontal in locality.

4. Digestive troubles and constipation may cause headache by the formation of toxins or by interference with the circulation causing a certain amount of cerebral anæmia. In these cases the teeth need careful attention-both to improve mastication, and to prevent septic conditions. The diet must be regulated and the action of the bowels corrected.

5. General bodily conditions like anæmia or some forms of heart disease produce headache. In girls' secondary schools the former is the more likely condition to be found.

6. Headaches are commonly found in children with rheumatic tendencies, who often complain of shooting pains in the head as well as constant aching back and front.

7. Headaches recurring at the monthly periods will be discussed later.

8. There are finally the headaches to which neurotic or nervous children are subject for 
no obvious cause. The nervous system is unstable, and excitement and late hours produce an overpowering headache often associated with sickness and prostration. Such headaches may be preceded by disorders of vision and sensory disturbances. They occasionally come on without any exciting cause. Such attacks of migraine increase in intensity for some hours and then gradually pass away. When the exciting cause of the headache is discovered it should be treated and removed if possible. After this is done the lives of the sufferers must be arranged for them on methodical and healthy lines. They should have fresh air, and opportunity for exercise. Their mental work must be limited and done under the best conditions and, important as is the necessity for long hours of sleep to all children, it is even more necessary for these children to have the opportunity for sufficient sleep.

Sleep.-It is during the examination of the nervous system that inquiry should be directed into the sleeping arrangements made for the child. It is here that there is often an opportunity to improve the conditions under which the child is doing her school work.

Day school children, with few exceptions, stay up much too late at night. 
The value of sleep in a child's life, and to its growth, cannot be exaggerated.

The following table given by Dukes in Clifford Allbutt's System of Medicine shows the minimum number of hours of sleep needed by healthy young children of school age.

AGE.

Under Io years

\begin{tabular}{|c|c|c|c|c|c|c|c|c|c|c|}
\hline de & oy & 'ears & & & • & . & • & • & & \\
\hline & 13 & , & • & . & - & . & . & . & . & $10 \frac{1}{2}$ \\
\hline & 15 & ", & . & - & . & . & . & . & . & 10 \\
\hline & I7 & ", & - & • & . & - & $\cdot$ & • & - & $9^{\frac{1}{2}}$ \\
\hline & 19 & ", & & • & - & - & • & - & - & 9 \\
\hline
\end{tabular}

He also particularly states that this scale is not sufficient during the time of puberty, when for a year at least this amount is insufficient. Yet it is with the greatest difficulty that we can get this time of rest enforced on the children. Children showing signs of strain or of growing particularly fast need extra hours of rest.

Mothers often allow their children to stay up late because they do not sleep. Children suffering from sleeplessness need to go to bed at the proper time even more than the normal child. Sleeplessness is often a sign of nervous exhaustion, and the nervous system is resting when the child is in bed even if she is not asleep. If the girl is sleepless it is well to inquire if she goes hungry to bed, or, 
on the other hand, if she has a meal too late at night. Either condition may cause sleeplessness.

There remains to be noted certain signs of nervous irritability.

The habit of biting the finger nails or picking bits of skin off the fingers, or rubbing various parts of the body is very disgusting and must be controlled.

Efforts must be made to get at the child's self-respect. The best physical conditions again must be provided. Plenty of sleep must be ensured, and, with the improvement in the general tone of the body, the child may gain sufficient nervous energy to control the habit.

Once a bad habit is contracted it is a difficult task to overcome it, and any mechanical aids, such as the wearing of glove fingers, or the painting of bitter aloes on the fingers, which appear to offer help, can be used with advantage in obstinate cases.

The opportunity of warning both girls and their parents of the importance of forming good habits, and at once discontinuing bad ones, should be taken. Training in self-control is of the highest importance to future happiness. The lack of it is the cause of many of the 


\section{SCHOOL MEDICAL INSPECTION}

neuroses and nervous breakdowns which occur in adult life.

Regularity of life and of function, of food and of pleasure should be enforced during childhood, but originality and self-management should be encouraged by the child's having as far as possible free time for self-expression. The child's individuality and taste may be consulted without allowing indulgence in the pleasures of the adult, in rich food, late hours, theatres, picture palaces and excitement which exhaust the nervous system. That the nervous system is still only developing in school life is scarcely appreciated by the lay mind, and excessive strain is often placed on a system which modern education itself taxes heavily.

If the medical officer can by tactful questioning discover whether wise methods are being adopted, and by judicious advice persuade those who are making a mistake to alter their ways, a great step will have been made, and the intrusion of the medical officer in school life more than justified. 
CHAPTER VIII

\section{EXAMINATION OF THE EAR}

IN the Secondary Schools the number of ear defects do not appear to be many.

Defects are found as the result of one or the other of the acute infectious diseases. Scarlet fever, measles, or influenza may have set up an otitis media, which has resulted in perforation and deafness in one or both ears.

Adenoids and tonsils, by obstructing the Eustachian tube, or setting up a catarrhal condition of that tube, may cause deafness.

The hearing power may be tested by means of (1) mechanical sounds, (2) the voice.

The most convenient mechanical methods are (a) a watch, (b) Galton's whistle, (c) the tuning fork.

When testing, the room must be quiet; each ear must be separately tested.

If a watch is chosen as the testing instrument, one whose loudness has been tested by normal individuals must be chosen. By doing this the 


\section{SCHOOL MEDICAL INSPECTION}

distance at which the ticking can be heard can be readily measured, and can be expressed in terms of a fraction of the normal. Thus if the normal distance is twenty inches, and it can only be heard by the pupil at ten inches, the fraction is $\frac{10}{20}$, and so forth, the necessity for contact being expressed as $\frac{C}{20}$, and if it can only be heard by pressing it to the head $\frac{\mathrm{P}}{20}$.

One should not be satisfied with one experiment as the pupil is often uncertain and inaccurate at first. Indeed, with young pupils, this is an unsatisfactory method.

In Galton's whistle a scale is so arranged that one can tell the exact number of vibrations given out when it is blown, and so the sensitiveness of the hearing can be tested.

The tuning fork generally used is the $\mathrm{C}^{\prime}=256$ vibrations. It is made to vibrate by striking the knee with one of the prongs. The fork is placed near, but not touching, the patient's ear till she declares she cannot hear it. The fork is then removed to the examiner's ear to see if it can still be heard to vibrate.

The most useful method of testing the hearing, because the most practicable and most successful, is by the voice. A whisper is better than 
ordinary speech. The pupil should have her face turned from the examiner. Each ear alternately should be closed by the finger of the pupil.

A word should be whispered and the pupil asked to repeat it. The distance at which the whisper is heard is then recorded. In very few if any individuals are both ears of equal power.

If the patient does not hear when thus examined the tuning fork can be applied to the skull, and if the sounds are then heard the auditory nerve is not affected, and the defect is in some of the accessory parts.

Having tested the auditory powers, the shape and appearance of the ear should be noted. Prominence or peculiarity in size, and any eczematous or other diseased condition will be observed.

The internal auditory meatus may then be examined. This is done by means of an ear speculum and a reflecting mirror. The aural speculum is a funnel-shaped tube about $I_{2} \frac{1}{2}$ inches in length. Light is projected in by means of a concave reflecting mirror. This mirror has an aperture through which the eye looks down. The mirror is held in position either by means of a spectacle frame or suspended from a band round the head. Good light-sunlight, electric light, or an argand burner is necessary. 


\section{SCHOOL MEDICAL INSPECTION}

The ear is pulled up and back and examined for wax, mucus, pus, eczema or narrowing of the canal. The speculum is then gently introduced. Any abnormality obstructing the view of the membrane or any abnormality of the membrane can now be examined.

Finally, if there is deafness further attention must be paid to the throat and nose, as such deafness may be caused by occlusion of the Eustachian tube. 


\section{CHAPTER IX}

\section{EXAMINATION OF THE EYE}

Is examining the eye a routine method ought to be adopted.

First the lids ought to be examined. Styes or Blepharitis (inflammation of the margin of the eyelids) often occur in delicate anæmic or tubercular children. They frequently accompany defects of accommodation. Conjunctivitis simple or chronic may be found.

Phyctenular conjunctivitis in an anæmic tubercular child may be found.

Keratitis, or inflammation of the cornea, may be found among children of school age, especially about the time of puberty.

Iritis is stated to be one of the eye diseases which attend the onset of menstruation. The writer has not come across any such cases.

After noticing the presence or absence of signs of disease in conjunctiva, cornea and iris, the movements of the eyeball are to be observed. 
An eye which habitually squints tends to become functionally useless and ultimately blind.

George Mackay, when describing test for strabismus ("Encyclopædia Medica"-Art. "Strabismus"), says: "The simplest means which can be employed without any apparatus is to direct attention to some small, remote, but welldefined object, preferably on a level with the eyes (or with the head thrown back it may be at a higher level, e.g. a chimney top). The observer should place himself before the patient in such a position that he can easily watch the eyes without interfering with their lines of vision to the object selected, and then rapidly slip the back of his hand or an opaque card in front of one eye of the patient. If the remaining exposed eye possesses sufficient power of fixation, it will remain unmoved; but if it instinctively turns towards the object of regard, it reveals at once the faultiness of its previous position. Let the cover next be quickly transferred from the first to the second eye, and note whether the former remains with fixed gaze on exposure or alters its position. If the muscular equilibrium of the eyes is perfect, no movement will be detected. If any movement of adjustment occurs, strabismus is at once revealed." Squinting is often caused by a defect in refraction. It is therefore important, in these 
cases particularly, to test the vision and get the child proper glasses where there are defects.

The vision should be tested for far and near sight. The range of vision is normally from infinity to the nearest point at which test types can be distinctly seen.

For practical purposes the far point is taken to be about twenty feet distant.

The child when being tested should be placed about six metres away from a board bearing Snellen's test types. The child covers one eye. If she can read all the letters to the line D6 her vision is normal. Each eye should be tested separately. The acuteness of vision is stated by placing as denominator the type which the child can read at a distance of six metres.

If a child can read $\frac{\sigma}{\sigma}$, that is the line which should be read at six metres when standing at that distance, it is well to put a convex lens in front of the eye. If with a No. I convex lens she can still read $\frac{6}{6}$, she has been using her accommodating muscle and is really hypermetropic or long-sighted.

If she cannot read 6 and can read 9 and is not helped by a convex but by a concave lens, she is probably long-sighted. If neither helps her she 


\section{SCHOOL MEDICAL INSPECTION}

is probably astigmatic and needs testing by retinoscopy.

Astigmatism may, however, be roughly tested by means of radiating lines in thick black type. If the child is astigmatic either the perpendicular or the longitudinal lines will appear blurred or grey according to where the defect in her lens is.

To test for near vision Jaeger types are advisable. The child of ten ought to be able to read the smallest type easily at a foot's distance from the face.

It will generally be found unnecessary to examine the eyes by retinoscopy as it is not the medical officer's business, at any rate, in Secondary Schools, to prescribe glasses. But it is advisable that facilities for darkening the room and examining the fundus by means of the ophthalmoscope as well as for checking the determination of refraction by means of retinoscopy should be provided.

To perform retinoscopy the room should be dark.

The lamp should be at one side of the head, leaving the face in shadow. The light through the retinoscopy mirror should be reflected in the eye. The pupil becomes red. If the mirror is rotated from side to side, a shadow encroaches on the red area. 
If that shadow when the mirror is rotated moves with the mirror the eye is myopic (shortsighted). If it moves against the mirror the eye is normal or hypermetropic (long-sighted), or very slightly myopic. If $\mathrm{a}+{ }_{5} \mathrm{D}$ causes the shadow to go with the mirror the eye is very slightly myopic. If $+I D$ causes the same effect the eye is normal. If more than $+\mathrm{I} D$ is necessary the eye is hypermetropic.

Even when the eyes have been tested and corrected, it is well that the child should be from time to time re-inspected, for the defects alter and need further correction.

It is also important to note that myopia is greatly increased by eye strain at near work and under bad conditions, and school work is blamed for much of the modern prevalence of this condition.

It is important that the kindergarten children and the children in the lower forms who have not the power to accommodate finely for near vision have big print and do not have fine sewing or handwork which needs discrimination of fine distances.

Lighting.-Adequate lighting of the schoolroom is essential to the preservation of the child's eyesight.

Sunlight has been mentioned as necessary to 


\section{IOO SCHOOL MEDICAL INSPECTION}

the growing child as it is to the growing plant. Therefore schools need a large extent of window space. For purposes of reading and writing these should be satisfactorily placed. They should throw the light from above on the left side and somewhat behind the girls in order that they do not work facing the sun nor while their shadows lie on their work. Cross lighting should be avoided as far as possible.

Where artificial light is supplied it is recognized that a diffused light sent out from concealed lamps is the most pleasant light. This is most easily done with electric lights which can be placed in mouldings, or the light can be sent out from opaque globes.

In choosing different illuminants the disadvantages of each kind must be considered. Ordinary gas burners use up much of the oxygen in a room. Incandescent burners do not use so much, therefore with them the atmosphere is more pleasant. These do, however, consume some of the oxygen, and share the disadvantage of the ordinary burner in overheating the room.

Incandescent burners also produce a very glaring light which needs to be subdued by a tinted globe.

Electric light neither heats the room nor burns up the oxygen, but in lighting a room 


\section{EXAMINATION OF THE EYE IOI}

with this luminant the intensity of the light must be considered and the position of the supply in relation to the pupils working with it. If table lamps are supplied greer-covered shades should throw down the light on to the working surface and so protect the eyes from the glare. It is quite unnecessary to use for table lamps so strong a light as is used for room illumination. It is both more expensive and most irritating to the eye when put into too close proximity. Bulbs should be renewed when they become dim. Old bulbs waste electricity without producing light. Thus they are extravagant as well as harmful to the sight.

These notes on lighting are added for the sake of suggesting to readers of the book that parents can be reminded of these points when homework is considered and so provide as good conditions as may be for their girls while preparing their lessons. There is no doubt that headaches often result from the endeavour to do work in a room where the lights may be over-brilliant or defective or badly situated so that the eyes are being strained all the time work is being done.

A further point affecting the eyesight of the scholars lies in the position of the black-board. An acting teacher pointed out to the writer the 


\section{IO2 SCHOOL MEDICAL INSPECTION}

effort of seeing the black-board when it was not placed in a suitable light. Daylight often strikes on the board at an angle which makes it shine for some of the children. The board should be placed so that all the children can see it without inconvenience.

If artificial light is used a light should be suspended close to and above the board. A shade should throw the light down on to the board and away from the class. 


\section{CHAPTER $\mathrm{X}$}

\section{ADOLESCENCE}

In designing the cards for the medical records a space is given to the menstrual history. This is of importance. Many erroneous ideas are held on the subject of the health of girls in adolescence. It is necessary that reliable statistics should be collected by independent observers, in order that our knowledge may be more exact.

The inquiries made should be tabulated under the headings:

I. Age at which menstruation starts.

2. Time the period lasts.

3. Interval between periods.

4. Regularity of periods.

5. Whether period is profuse.

6. Whether pain is present.

7. If pain is present,
(a) on which days.
(b) in what position. 


\section{SCHOOL MEDICAL INSPECTION}

It is particularly important for the girl's present and future prospects that her health should be watched during the years of adolescence. The normal girl at this time puts on weight, grows quickly and as is often particularly noticed in girls who have been thin and frail, improves remarkably in general health and physique. The normal girl is able to do an increasing amount of work and to engage in strong and strenuous physical exercises. She needs, however, to make up for the large demands on her physical and nervous energy, opportunities for long hours of sleep.

The onset of menstruation ought to make little if any difference in her daily life. She ought to be working well and playing well, but doing neither so vigorously or unwisely as to have to knock off at the time of her monthly period.

On the other hand, all girls who suffer either pain or profuse loss at the menstrual period must have exceptional treatment. Inquiries into the history of the onset of menstrual pain in those who have previously had a painless flow must be made and the cause if possible discovered. Menstrual disturbances should always be considered a pathological condition to be treated, and cured when possible, and never as an inevitable condition of feminine life. 
Such disturbance may be the result of some indiscretion in personal hygiene not necessarily occurring at the period time but which may have caused a temporary falling off from the usual standard of health. Neglect to wear sufficiently warm clothing, neglect to attend to the action of the intestines may have caused local pain. Some over-exertion or over-application to work or play may have produced the nervous exhaustion which makes pain more readily felt.

It is certain that such attacks of pain repeated from month to month become established as a habit. Sedentary occupations, too long standing or sitting in one position, may help to cause the inconvenience. The advice given should be in accordance with the causes. Anæmia and debility will call for rest and treatment, not only at the period time but in the intervals between. A history of sedentary habits and too long standing shows the need for exercise. It is a mistake to encourage all cases of dysmenorrhœa to stay in bed and rest.

Those cases which from the first have suffered pain should be referred to a doctor for medical advice. Such cases often suffer from local physical conditions and the pain which the patients suffer may often be at least relieved and sometimes cured. 


\section{Io6 SCHOOL MEDICAL INSPECTION}

During the first year of menstruation a large number of cases will be found to be irregular. The cases where the periods are far apart, if the health is otherwise good, may be disregarded. Where the periods occur too often or the flow is too profuse the patients ought to be treated at once.

The condition of anæmia which results if they are neglected leads only to their condition becoming more serious and a vicious circle being established. The frequent profuse period causes anæmia, the anæmia-through exhausting the muscular tissue of the body including that of the uterus causes a further profuse flow. If such cases are treated the results are often very good.

Most girls' schools recognize the necessity of allowing special privileges to those pupils who need them at the period time, and it is wise to allow and to urge pupils suffering from any degree of profuseness to have some days at home for rest if necessary. The gymnastic work should always be excused or modified for girls needing such special treatment.

Mothers of girls should be urged to explain as far as they feel able to do so the function of menstruation to the girls when they observe the development of breast and hair which points to 
the fact that the function of menstruation is about to be established. It is not right that the girls should be ignorant or learn these facts imperfectly from one another. If the mother does not feel able to give the information she should arrange for its being given by some other woman who can give it with authority.

If the information is given freely and openly there will not be the same temptation to discuss the subject privately and unwholesomely as sometimes happens among school girls. Once the subject is explained, the less the mother bothers the girl about the function the better. Of course it is wise to quietly observe the girl and notice if she appears to suffer at all. But menstrual suffering is generally to be discovered by a careful mother without questioning. Girls often are exceedingly reticent on this subject, and their reticence should be respected once the proper information has been given and they understand where help can be obtained if it is needed. 
CHAPTER XI

\section{SPECIAL INSPECTIONS}

\section{REINSPECTIONS-SCHOLARSHIP EXAMINATIONS}

How often ought girls in a Secondary School to be reinspected?

The object of school inspection being to keep the girls in good health and to check the development of abnormalities, the frequency of reinspections depends on the general observation which is directed to the girls.

In some schools routine reinspection is felt to be necessary each year. It is arranged in other schools that the girls shall be seen three times during their school life.

The scales may be held to give good evidence in the case of a girl who regularly gains weight that there is nothing seriously amiss. In those schools, therefore, where the girls are weighed at the end of each term, regular reinspection may safely be infrequent. Even with yearly 
weighings if the mistresses are carefully observing the girls, in class and gymnasium, and sending up for reinspection those they think are failing, the same opinion as to reinspection holds good.

It is well both for the satisfaction of the school, the completion of the school records, and the good of the girl herself, that an examination should take place just before she leaves school.

What rule is, then, to be established for the intervening time? In the case of girls, it is advisable to see them about the age of fourteen or fifteen in order to inquire into the due establishment of the uterine functions, and to regulate, if necessary, gymnastic work.

No other regular reinspections need take place. It is, however, found in practice that a considerable number of reinspections are constantly made. These are frequently in the case of the same set of girls, i.e. the more delicate ones.

All those who are found to be losing or gaining unsatisfactorily at the annual or terminal weighings should be seen, and the cause of either loss of weight, stationary weight or unsatisfactory gain should be sought. It may be necessary for the school work to be modified. These will be seen again at a greater or less 


\section{IIO SCHOOL MEDICAL INSPECTION}

interval of time according to the discretion of the examiner, in order to see that efficient measures have been adopted for recovery ahd to decide on the necessity of still further limiting or returning to the old curriculum.

The class mistresses will also from time to time be dissatisfied with the appearance or carriage of their girls. In this case also reinspection will be called for. The gymnastic mistress from time to time will notice curvatures or flagging physique for which she will request advice. The Medical Officer ought frequently to visit the gymnasium in order to pick out girls needing re-inspection.

In practice, therefore, it will be found that a large number of reinspections take place, though many girls may go undisturbed through the school from the entrance examination to the leaving one.

\section{Scholarship Examination}

In addition to the fee-paying pupils there are in the Secondary Schools a certain number of girls receiving free education.

One group is formed of students who have gained entrance by means of scholarships offered by the founders or governors of the schools. 
These girls come mainly from private preparatory schools.

In schools partly financed from the public purse a certain proportion of free scholars must be admitted from the elementary schools. There is naturally competition for these free places and scholarships, and there is a temptation, both to parents ambitious for their children's future, and to teachers of the elementary and private schools ambitious for their school's reputation, to push on their pupils to reach the standard of scholarship necessary for success. The age at which the competitions take place, viz. eleven and twelve, is a tender age when the powers of the girls are developing fast. Experience shows that it is a fatal policy to force these young people. The nervous system does not stand too many liberties being taken, and it may often be observed that children who have been overworked and overstrained so that their health suffers, may indeed gain their scholarship but not be able to profit by the course of instruction on which they should enter. They have been driven too hard. Either their health actually breaks down or they have to be allowed to mark time for a year before they can again enter on a full course of study.

In order, therefore, to lessen as much as 


\section{I1 SCHOOL MEDICAL INSPECTION}

possible this temptation it is useful to give credit for physical condition in making the awards of these scholarships. There is also the further reason in the case of the free-place girls inasmuch as the money is civic money paid for future results, and our work has proved that the stronger child has a greater chance of a higher mental equipment as well as of more favourable opportunity of developing it.

When considering the value of a good physique in these scholars we have to remember that the free-place children ought to take and do take good places in the school. They have to earn their living afterwards, therefore they must do well at the examinations in order to enter on well-paid careers at the earliest possible age. Their parents will not be able to afford to give them extra time at school, nor long and expensive holidays. So, for the sake of the public authorities who are sending them, only those of good physique should be chosen.

The examination of such candidates need not take much time. The procedure adopted at the Manchester High School is for a class mark A, B, $\mathrm{C}$ or D to be awarded to each scholar for general physique. The addition of + and - signs still further subdivides the candidates.

A consultation between the academic and the 
medical authorities always shows a remarkable coincidence in the marking. It is probably chiefly in the case of the doubtful candidates that the medical mark will make the difference between success and failure. A brilliant student may be able to work even handicapped by delicacy, a moderate one will fail when competing with the other children. The decision of the mark to be given depends largely on the correlation between the height and weight of the candidate. The presence of marked defects such as tonsils, adenoids, heart or lung weakness, and signs of physical neglect such as bad teeth, untidiness and carelessness of person are significant. It may seem unfortunate that a child should suffer the loss of her scholarship through simple matters of neglect. But the very presence of these signs shows the circumstances under which she will have to work, and will show that the ratepayers' money would not be spent to the best advantage.

The appearance of the face, pallor, anæmia, tiredness of aspect often bring out accounts of long hours of home-work and late hours such as girls of this age ought never to attempt.

All the observations made are reviewed and the mark given accordingly.

The effect of the examination, it is hoped, will 


\section{SCHOOL MEDICAL INSPECTION}

be to give every chance to the candidate to make use of her scholarship if she appears strong enough to hold it with advantage. Further, it is hoped that the knowledge of the impending medical inspection will stop early forcing with its suicidal results. 


\section{CHAPTER XII}

\section{CLASS INSPECTION}

IN organizing a large school the varying capacities of the students must be carefully considered. Youth is a time of preparation for the business of life. The competition to obtain maintenance in life is extremely difficult. The days are gone when it was comparatively immaterial how much a girl learnt at school provided that she was ornamental and useful at home. The time has come when the majority of girls must be prepared to earn their daily bread. The methods by which the middle-class girl can do this are strictly limited. Scholarship at least to a good university matriculation standard appears the necessary avenue to all the more lucrative employments for women, who have not to any great extent entered on business careers in this country nor on many of the active constructive employments of men.

The result is that there is pressure exerted 


\section{I16 SCHOOL MEDICAL INSPECTION}

on girls to strive for, and on mistresses to push their charges on to, matriculation examination at the earliest possible age. The standard of these examinations continues to rise, and though the able girls attain the standard with ease, to them is added the extra burden of higher alternative paper for the purpose of competing for the comparatively few scholarships open to women.

When we remember the eager conscientious spirit of the average school girl and her comparative absorption in her work, when we also remember that, unselfish as are most modern mothers in their demands on their daughter's time, the day-school girl must have a certain number of social and domestic ties, we realize that it needs much attention to prevent overstrain and to regulate work.

Thus we have the demand for a high standard on the part of the parents, and a willing response on the part of most of the girls. But we have to remember that only a certain number of girls are fitted physically or mentally for intellectual work of this character. There must remain a certain number whose taste naturally tends to more active practical careers and occupations, and who find the application necessary for scholarship examinations difficult. In addition there are also a large number whose intellectual 


\section{CLASS INSSPECTION}

ability is definitely limited, but who will do excellent work under carefully thought out arrangements. There remain also a certain number whose slightest effort must be carefully cherished and drawn out to produce any effects at all.

It therefore follows that one great advantage of the large school is that it provides sufficient pupils for the subdivision of forms, and for classes to be formed of children of approximately equal capacity. The highest efficiency of the working of such classes will depend on the correlation of the work set with the capacity of the pupil.

It is now an established fact that the mentally superior are taller and heavier on the average than their fellows. That is, they are physically superior. Thus in a school where the numbers are large enough and the organization good enough to allow subdivision of forms into separate divisions it will invariably be found that the average weight of the members of the more advanced division is greater, and the average height taller, than in the less advanced division. This will often be the case, even where the members of the more advanced class are younger and the work done by the division heavier. 


\section{SCHOOL MEDICAL INSPECTION}

It naturally follows, if we wish to improve the work of a form, we must if possible first improve its physical condition.

In a school where the forms are subdivided, girls of similar physical capacity tend to collect together. It is, however, only where the physical condition of each girl is carefully considered, and considered moreover in relation to the physical condition of the rest of the class, that the class will do its most efficient work.

The class in the school is a body composed of separate individuals who act and react on one another. Not only are the girls in a class more or less of the same capacity, but aslong as fashion, mutual impressions, and the formation of recognized customs, influence human beings, a set of individuals closely connected will have in common either good or bad habits and practices affecting their lives. For example, if three or four learn music the majority tend to do so. If some make a practice of going to social functions in the evening this soon becomes the fashion. If two or three are keen on games the form becomes athletic.

But from time to time the head mistress of a school becomes dissatisfied with the progress one set of girls who are working together in a form is making. The teachers give unsatisfactory 
reports. The mistress in the gymnasium records general slackness. The girls appear listless. Efforts may be made by the class mistress to find out what is wrong with the class. If the matter is investigated systematically it will frequently be found that either the physical surroundings of the form, the time table, or the health of the individuals need attention. That is, that the work is too hard, the surroundings for some reason unsuitable for that set of girls, though they may have been all right for the corresponding class in a previous year, or the girls may be unusually delicate. They may have been subject to an epidemic such as measles, which has left several of them below their normal condition, or the form may have been made up of girls looking strong and well, but may contain several who have previously been under weight and delicate, and therefore have no staying power though they now seem to be normal.

The Head Mistress in forming the class has naturally known of their previous work. She knows the mistress who is teaching them. The time table has been carefully thought out. She knows that some of the parents will be reluctant for subjects to be dropped. She is anxious to know whether she ought to urge on 


\section{I20 SCHOOL MEDICAL INSPECTION}

these girls to further efforts, or whether there is any hygienic error in their life which may account for their failure.

The medical examiner thereupon undertakes the special examination of such a form.

If an example is given of the procedure adopted by the writer both the results and the reasons underlying the work will be more easily explained.

A report is drawn up by the class mistress stating her special difficulties.

The cards giving particulars of the original observations made on each girl on her entry to the school and the account of her previous health, together with a copy of the statistics of the last routine weighing and measuring of the school are collected for references.

From these records it is discovered whether this class is composed of children whose health has previously been satisfactory or not-whether they are children who are now not gaining weight regularly and sufficiently-whether a certain number of them are satisfactory though the majority are failing-or whether the whole number fall under the standard.

A table is then drawn up showing for each girl her-
(a) Age. 
(b) Height and weight.

(c) Hours spent in bed and asleep.

(d) Hour of leaving home in the morning.

(e) Time taken in travelling to and from school.

(f) Time spent in practising music.

(g) Method of obtaining midday meal.

Any whose records are unsatisfactory are then noted for further examination.

The whole class is next paraded in the gymnasium. Any noticed to be pale or stooping and showing any signs of a crooked back are added to the list of special examinations.

The gymnastic mistress is then asked to put the pupils through certain exercises.

Their method of working is observed, whether they enjoy the physical movement of their limbs or, as may happen with overgrowing girls, if they do not seem to have vitality to respond to the demands made on them. The readiness with which they become fatigued is also a help in drawing up a report.

In addition to the exercises to which the girls are accustomed, various kinds of movements entailing quick response to unexpected commands or acuteness of special senses, such as eye and ear, are demanded of the girls, and observations made of the results. 


\section{SCHOOL MEDICAL INSPECTION}

The results of these observations are then embodied in a report and presented to the Head Mistress who, as a result, may modify in various ways the work of the form.

Thus it is often found on careful individual inquiry that certain of the pupils are working late, and that the others do so in order not to be left behind. As a result the class is becoming mentally weary.

Or it may be found, where the weights are unsatisfactory, that it has become the fashion in the class to despise the school dinner and bring sandwiches composed of materials insufficient for the midday meal. Details about feeding are much more frequently found needing alteration at these special examinations than in the routine ones. Here is an example of the way fashion or custom affects the form for the time being.

It is impossible to enumerate all the various conditions which call for interferences in every form examination which the writer has undertaken. Every examination appears to bring new factors to light. Sometimes very little can be done. Nothing will make stupid students bright, but experience of the alteration which takes place in a form after such an examination makes it evident to those who have tried it that this is a useful weapon for securing school efficiency. 
One or two actual examples of such form examination and its results are here given.

A class section $A$ in Form $X$ in 1910, was much worse than section $\mathrm{A}$ in Form $\mathrm{X}$ in 1909. It was found on examination that the average individual weight in that form was half a stone lighter, and height two inches under the height of the corresponding weight and height of the previous years. The special senses, eyes and ears, were tested and mistakes of inaccuracy and inattention were found rather than actual defects. In gymnastic work response to the word of command was slovenly. On inquiring into the habits of the class it was found that the majority were keeping late hours. Notes, informing the parents of these facts were sent round, and the help of parents as regards the regularity of meals and hours of rest asked for. The number of subjects studied was reduced and more time each day was given to gymnastic work and breathing exercises. The results showed at the end of the term, six weeks later, that the average number of marks gained per pupil had increased. The average of the top girl had improved from 72 to 78 per cent. Their physique generally was improved, and their gymnasium work which had been very poor advanced so that there was a keen struggle for the first place in the 


\section{I24 SCHOOL MEDICAL INSPECTION}

competition between the different sections of the form.

Again, a young form aged between ten and eleven were doing very bad work. They had an excellent mistress who was working exceedingly hard, but both she and the mistress who came to her form for special lessons found the class hopeless. One or two of the children seemed able to work spasmodically. Some were declared to be almost defective, particularly in their appreciation of arithmetic and geography. On examination it was found that the large proportion of threequarters of the class were below average weight. They differed widely in physique. They obviously differed widely in mental brightness. They were taken into the gymnasium. The drill mistress first of all gave them marching, then simple exercises they knew, then she gave them new exercises which they did not know. Four were easily differentiated as poorer than the others. One did not seem to get into any of the movements at all. Another could do response to a simple new command, but could not remember more than one or two movements if an exercise which they were expected to execute was described to them, or when they were taught a simple dance. The other two were also very slow, hesitating, and uncertain. A 
further four were obviously not so ready at picking up instructions as the rest of the form.

When the steps had been taught they did the dance to music, and one of the slow heavy girls was immediately seen to possess a marked sense of rhythm and nascent grace of movement.

On taking them back to the class-room, questioning elicited that studies with a dramatic appeal were the favourites with them and next to that came dictation, the difficult words of which they learned the night before and therefore gave the minimum of intellectual effort. Some few seemed quite bright and eager, but even the cleverest found it impossible to remember some simple verses with action accompaniments which had appealed to them very much and which they themselves offered to say but which they had not repeated for a couple of months.

Thus the obvious points were their poor physique (though it was interesting to remark that two of the dullest had quite good weights, see Chapter II.), their poor memory, their appreciation of drama and their fondness for mechanical work and the very evident difference in ability of the sixteen brighter ones and the eight duller ones. On the average these latter were older than the others. It was felt that the 
work would be much better done by removing the eight and giving them to another teacher. The aid of the parent was asked by the letter printed below with the omission of the names and the form of the mistresses.

\section{"Dear Madam,}

"Dr. Chisholm at my request has been conducting a careful inquiry into the physical condition of the form, which contains your daughter (ward). Their work was not up to the standard, particularly in Arithmetic, and the form mistress and myself felt anxious. Dr. Chisholm discovers, however, that three-quarters of the girls in the form are under weight, a very large proportion, so that we can hardly expect a high average of work.

"As to the question of remedies: food and bed depend of course on the home. I would suggest plenty of milk, jam, simple puddings, and chocolate, and that the children be made to keep to their early bed-time. The work we are modifying in accordance with Dr. Chisholm's suggestions, giving more manual and sense training. Next term I hope to arrange for a course of simple cookery lessons, which were found last year to help the Arithmetic in a weak form. I shall also try to split the form into smaller 
divisions, so as to admit of greater individual attention.

"I have, as on former occasions, to appeal to parents to work with us in these attempts to improve the health and work of a form. We trust that with the co-operation of home and school the difficulties which are hindering the progress of this form will be overcome.

"Believe me,

"Yours very faithfully,

"Sara A. Burstall."

The work, as suggested, was made more concrete-history and geography were made as dramatic as possible, and when possible visualized.

In teaching arithmetic more care was taken that, when possible, actual examples they knew should be used and actual measurements taken, and actual money used.

It was decided as soon as possible to give cookery lessons, as co-ordination of quantities and prices had in our experience helped a former class, such as actual engineering practice seems to aid boys in the assimilation of mathematical theories.

As a result of the former suggestions, before the application of the last, the form showed 


\section{SCHOOL MEDICAL INSPECTION}

improvement. The whole work of the form appeared to be stimulated. A proof of progress as convincing as any concrete example given to the class itself in its arithmetic work, came out in the results of the arithmetic examination paper. Here one of the dullest children gained a perfectly good 80 per cent. on a paper which though easy, contained among other questions a fairly difficult "bills of parcel" sum and a problem which needed careful thought for its solution. 


\section{CHAPTER XIII \\ INSTRUCTION}

\section{MOTHERS-PUPILS-TEACHERS}

THE inspection and examination of the girls aims at preventing their working or exercising when in an unfit condition. It also ensures the attention of the parents being drawn to defects established or incipient. But a medical inspector has opportunities for doing good prophylactic work by means of hygienic teaching. Apart from the importance of health being emphasized by the appointment of such an officer, every inspection attended by a parent or guardian gives an opportunity for emphasizing some important lesson, such as the importance of cleaning the teeth, of the daily bath, of fresh air, open windows, and good food.

It is not always, however, convenient for the mothers to attend inspections, especially when they are held in a morning.

The girls also, as has been already remarked, 


\section{I30 SCHOOL MEDICAL INSPECTION}

sometimes discourage the attendance of their mothers at the inspection. This may be done from a spirit of independence, or because they do not wish restrictions to be imposed on late hours, which they think can be avoided if mother and doctor are kept apart. Occasionally it is due to real shyness and reserve.

Whatever the reason may be the girls often gain their point, for the amenableness of the modern mother is as remarkable as the selfconfidence of the modern girl.

If the parent or guardian does attend, it is impossible to do more in the twenty minutes' interview than to emphasize a few points which seem most obvious. A few failings, bad habits, and tendencies, which are not quite easy to point out to an individual personally, can be mentioned more emphatically at a class or meeting, where the mother may obtain advice without feeling hurt at the application to her own particular case. It has, therefore, been found to be an excellent plan to invite mothers to tea in the afternoon, and afterwards to a lecture, which lasts about an hour, and is followed by an informal talk, when difficulties can be openly discussed. This has seemed to be a popular, and judging from the questions asked by the mothers, a very useful plan. The lectures ought to be clear and simple. 
They ought to cover the ground of the daily life and hygienic habits of the school girl, and can be very well illustrated by lantern slides. One, two, or three such lectures can be given in series. It is advisable to have at least one set each year in a school of any size. The same ground will have to be gone over more than once inasmuch as the pupils are continually coming and going, and each year there is a large number of new mothers who have not previously attended the lectures.

The writer has generally given two or three lectures in the Lent term. They have consisted of an introductory account of the value of health, the connection between physical and mental ability, the scope of school inspection, the necessity of co-ordination between home and school, between teacher, parent, and child. This is followed by definite instruction on the necessity of plentiful suitable food to the growing child. The processes of digestion are explained in simple popular terms-advice about quantity, quality, regularity, and variety of food is given. The value of exercise, games, and gymnastics in the development of the child's system is explained.

In a further lecture, the effect of bad positions in reading and writing can be shown by means of slides together with the effects of neglected curvatures, weak muscles, and flat feet. 


\section{I32 SCHOOL MEDICAL INSPECTION}

The need for a proper time-table being drawn up, with time left for the self-expression of the developing character, is explained. Finally, the importance of sufficient rest and sleep is emphasized.

In another lecture the principles underlying clothing are explained and the importance of warmth and simplicity of garments pointed out. Special reference to the hygiene of the menstrual period is also made in this paper.

Occasionally an address on more general subjects such as "Tuberculosis and the way to avoid it," "Modern methods of fighting disease" -will be found to be of much interest to the mothers and provide some variety from the constant repetition of details incident to school life.

Instruction to the Pupils.-That boys and girls, young men and women, should complete their education ignorant of one of their chief interests, i.e. the care of their own health and the knowledge of the functions of their own bodies, seems absurd.

If health is as important a factor in human happiness and progress as we believe it to be, if the future of the race depends on the conduct and knowledge of the present generation, common sense suggests that elementary physiology 
should have its place in all schemes of compulsory education. In the crowded state of the curriculum it is indeed difficult to find room for all the necessary subjects, and before we introduce any new subject we must make clear that it is worthy of the time it takes up, and that the course of study is one which gives the knowledge necessary to the conduct of life or is of educational value in training the mind. Elementary physiology fulfils both these requirements.

A child from her earliest days ought to be trained in good habits and a healthy mode of life, and it is necessary that when she attains the age when reason governs her actions, that she should know why restrictions, which may seem to her to be irksome, must be complied with. Ignorance, moreover, often causes totally unnecessary mental distress, and may lead to troubles which have disastrous effects lasting throughout life.

But physiology is also useful as a study in developing the intellectual faculties. It is a science which ranks with botany and zoology as a means of training in accuracy, clearness, and exactness of method. It is most fertile in producing object-lessons, and from it instructive illustrations can be drawn. It can be co-ordinated with many other subjects, and it is full of interest. 


\section{I34 SCHOOL MEDICAL INSPECTION}

It is suitable for teaching in all parts of the school, from the kindergarten to the matriculation form, if only it is taught wisely, and graded in accordance with the ages of the children in the classes. It is difficult to know why it has not been more widely used; unless it is from the old notion that it is indelicate to talk of one's own bodily construction.

However, in most Secondary Schools the curriculum is arranged to meet the requirements of matriculation and school-leaving examinations, and physiology is not a subject normally offered. If it were, a science mistress, a specialist in the subject, would present it to the girls. In schools where housewifery is studied a course of physiology is naturally included in the curriculum.

In schools where this is done, and where the time can be found, a syllabus, such as the one worked out by Alice Burn, M.B., D.P.H., and presented in a paper to a conference on diet and hygiene in public, secondary, and private schools, could with advantage be adopted.

This syllabus is given below. 
OUTLINE SYLLABUS FOR THE TEACHING OF ELEMENTARY PHYSIOLOGY AND PERSONAL HYGIENE IN SCHOOLS

\section{I \\ INTRODUCTORY}

I. The Physical Ideal.

(a) The general or national, expressed as physical fitness and efficiency for service.

(b) The particular or individual, expressed as joy in mere living. (This permits of varying expansion and illustration, according to age of scholars and type of school.)

2. The Mental and Physical Co-Relation.

(a) Perfect balance the highest aim; what are the fair demands of each?-Their efficient working adjustment requires study; how civilization has complicated an otherwise simple interaction.

(b) The perfection of the instrument; the high degree of physical perfection in the newborn ; the advent and advance of physical error as result of ignorance, adverse conditions, educational demands, etc. 


\section{I36 SCHOOL MEDICAL INSPECTION}

3. The Chief Controlling Factors in the Maintenance of Health.

(a) An understanding of the physiological ideal in general and in detail.

(b) The practice of the personal hygiene necessary to maintain it; a few preliminary illustrations.

(c) The significance of habit; "the prime purpose of automization is economy of energy"; habit entails no interference with freedom.

(d) The shortest road to efficiency; functional equilibrium established by habit, controlled and maintained without conscious effort, liberates energy and power for higher purposes.

(e) Perfect health consistent only with perfect hygiene; illustrate infringements and establishment of the "vicious circle"; emphasize need for study and practical application of knowledge.

$(f)$ The mental factor.

\section{ORDER AND METHODS OF STUDY}

i. General Review of the Body, Structural and Functional.

(a) What the body is made of ; the animal 
cell and its living characteristics; grouping of cells to form organs; organs grouped according to function into systems.

(b) Enumerate systems and briefly outline their functions; widely indicate their inter-dependence, and present a good mental picture of the unity of physical processes.

(c) The perfect physiological functionto secure maximum efficiency at minimum expense to organism. This is true of all function, both mental and physical. (Expand and illustrate according to class.)

(d) The physiological ideal, as expressed in the various systems and organs of special sense; co-relate all bodily function in terms of the "common good."

(e) Vis medicatrix naturae ; nature adaptable, amenable, and capable of great compensatory effort, but always exacts some penalty in the process; pain, the first expression of Nature's disapproval and then functional disablement.

2. Review in Detail of:-

(a) Systems and their functions.

(b) Organs of special sense.

(Outline lesson of one system, with its correlated hygiene, is appended.) 
(3) Personal Hygiene Deduced Concurrently with Study of Each System.

(a) The special urgency of the training and preservation by proper use of the special senses.

(b) Utilize factors in the school regime to emphasize practical points.

(4) Personal Hygiene Summarized.

(a) Work and fatigue.

(b) Sleep and rest.

(c) Air, exercise, and the circulation.

(d) Light and warmth.

(e) Clothing.

( $f$ ) Diet, digestion, and excretion.

(g) Care of skin, hair, teeth, hands, and feet.

(h) Hygiene of the eye, ear, mouth, nose, and throat.

(i) Correct breathing and lung expansion.

(j) Drill and gymnastics.

(k) Body postures.

(l) Deformities and remedial measures.

(m) Physical culture and harmonious development of muscle.

(n) Physical control and nervous stability.

(o) The hygiene which secures mental concentration.

$(p)$ The production of heat and control of temperature. 
(5) Common Ailments.

(a) Are symptoms of disturbed function.

(b) Do not treat symptoms, remove cause.

(c) The value of functional rest : Nature's great recuperative power if undistracted.

(d) The commoner ailments enumerated: their causes and the hygiene required to avoid them.

(e) Common-sense home treatment to aid in re-establishment of healthy function.

$(f)$ When to call in the doctor: prevention is better than cure.

(6) Public Health and Disease.

(a) Indicate broad meanings under functional, organic, and infection.

(b) Physical economics; immunity and resistance to disease; natural versus acquired; the best immunity is a high degree of resistance; acquired immunity more expensive to both individual and community.

(c) Our public health duty; how the individual is penalized by the community and vice versa; health radiates and permeates; replace infectious disease by infectious health. 


\section{I40 SCHOOL MEDICAL INSPECTION}

\section{OUTLINE OF A SYSTEM LESSON}

\section{THE PHYSIOLOGY OF DIGESTION}

( $A$ convenient means of systematizing lessons and securing uniformity of treatment is to take each system under the double heading of "The Physiological Ideal" and "The Hygiene Necessary to Maintain the Ideal." This provides scholars with an attractive peg upon which to hang the main facts of their subject-matter.)

I. The IdeaL.

A digestion which secures perfect nutrition and obtrudes its processes as little as possible upon the consciousness.

2. The Digestive Agents Enumerated.

Mouth, teeth, tongue, salivary glands, stomach, liver, pancreas, and intestines.

3. Trace Food and Chemical Changes Through Alimentary Canal.

(a) Mouth ; function of teeth, tongue, and salivary glands; secretion and preliminary alkaline digestion.

(b) Stomach: the food receptacle, its capacity, muscular and glandular nature; movement, acid secretions; stimulated according to nature of food introduced; function mainly mechanical mixture; a few 
early but important chemical changes; a little absorption.

(c) Liver-a big gland: its glycogenic function; the secretion and storage of bile; their digestive relations.

(d) Pancreas: its important digestive ferments.

(e) Intestinal tract: its special division with valvular communications; great glandular and absorptive surface : lacteal collection of nutrient material; involuntary peristaltic movements ; retention and passage of food material; excretion of waste.

4. Nutrition.

(a) The four stages which constitute nutrition: intake of food, digestion, absorption, and assimilation.

(b) Assimilation the most important of these; general factors which assist or retard assimilation.

5. Metabolism.

(a) The sum total of chemical changes that occur in living tissue.

(b) Combustion products given off by lungs, kidneys and skin compensated for by intake of food and oxygen.

(c) Excretion the final act in the metabolic round. 


\section{I42 SCHOOL MEDICAL INSPECTION}

6. The Physical Balance Sheet.

(a) The varying relations of income and expenditure in the child and in the adult; in health and in disease.

(b) Body weight : growth and development; good credit balance required in youth.

\section{THE HYGIENE OF DIGESTION}

I. The Ideal.

Keen appetite, simple taste, unconscious digestion and regular elimination.

2. Appetite and Hunger.

(a) Meaning, value, and regulation of appetite.

(b) Real versus artificial hunger; the cry of true insufficiency versus the cry of disordered function.

(c) Taste; may be controlled, educated or simplified; hunger finds the simplest foods appetizing; natural taste a good guide to food required.

(d) Natural appetite depends on exercise, air, and previous good digestion; appetite returns after digestive rest; value of abstinence and the long night rest; the late supper. 
3. FOOD.

(a) What to eat, when to eat, how to eat.

(b) Food values: general requirements of body in constituent proteid, fat, and carbohydrate proportions.

(c) Regularity of meal-times; digestive organs become creatures of habit, and prepare for the meal; adequate intervals.

(d) Good mastication a prime essential; salivary alkaline digestion in mouth is neutralized and arrested by acid secretions in stomach, hence importance of slow eating and thorough mastication.

(e) Relation of mastication to healthy development of mouth and throat organs and muscles.

(f) The rational order of the meal; secretion stimulated according to nature of food introduced; value of simple dishes; variety and simplicity in diet compatible; dilution by fluids unwise at early stage of a meal.

Even where it has not been found convenient to devote much time to the subject, it appears important to many educationalists that instruction in some parts of physiology, particularly 


\section{I44 SCHOOL MEDICAL INSPECTION}

sex hygiene, should be given before the girl leaves school. It is true that many mothers instruct their daughters well; others find the subject exceedingly difficult to mention to anyone, and particularly difficult to their own children. The personal element which makes the duty a pleasure to some mothers and daughters, is an embarrassment to others no less devoted. That this ought not to be may be true, but it is so. Further, many who would give the instruction are themselves not well instructed, and sometimes give bad advice with the most excellent intentions.

The method of giving advice by putting in the girl's hands one of the numerous books which instruct on sex subjects is also unsatisfactory. Many are written with such delicacy that an ignorant girl finds it impossible to learn the facts from them. Most of them are very badly written. As the result of such a method of instruction an almost unbelievable story is quite true. An educated woman who had studied physiology at school, and had read several of these books, including one of the best known, which instructs the young expectant mother, did not know on the day preceding the birth of her child, the method by which it was to enter the world. Perhaps it may be felt that she was a 
stupid person. Yet she had had considerable experience of the world, she was intelligent, for her position in life depended on her brain power, but she had not found out this elementary fact. Perhaps it may be said it was not necessary for her to know. Ignorance is not advantageous, and ignorance of facts which appear equally easy of discovery, but are really seldom mentioned by well-bred girls, even among themselves, often causes much mental suffering. If, then, instruction on these points is to be given, who is to give it? It is evident that no one can speak with as much authority on such matters as the medical officer. Moreover, less embarrassment is felt by teacher and by class, if one whose business in life it is to deal with these questions, speaks of them. It is much easier to attack such questions impersonally in class, but when the ground has been broken, it will be easy to invite questions which may be answered privately or publicly. It will be found that the girls have many questions which they desire answered, and the free ventilation of the subject tends to free it from the morbidity which sometimes affects it when it is discussed by the ignorant.

The question arises when shall this instruction be given. This depends largely on the curriculum 


\section{I46 SCHOOL MEDICAL INSPECTION}

of the school. A certain amount of knowledge should be given at the onset of adolescence. This, however, occurs at such various ages in girls that it may be convenient for the mother to be advised to give such simple explanations as she sees fit. When the girls happen to be inspected at this epoch, judicious inquiries will elicit if this has been done. It is when leaving school to become teachers, wives, and mothers, perhaps in two or three years, that such knowledge is necessary, and should be freely and fully given. Unnecessary attention should not be focussed upon it. It is easy to draw up a simple syllabus of about ten lessons on elementary hygiene.

The following is the one which the writer has adopted. It is illustrated by diagrams and slides:-

I. General Health. Its Value. Dependence of the various systems of the body on one another. The form and construction of the body. Frame work enclosing organs. Skin covering-Necessity for its care.

2. Digestive System.

3. Respiratory System.

4. Circulatory System.

5. Nervous System.

6. Muscular System.

7. Excretion. 
8. Reproduction. Anatomy of the Parts. Development of the function.

9. Growth and development of the child. Its birth and nurture.

Io. Simple talk on bacteriology and infection. Disinfection and cleanliness.

Sometimes more than ten periods of time are taken in going over the syllabus. The interest shown by successive generations of girls is very different. Some are very interested, others are more indifferent. It is particularly hoped that enough will be done to arouse interest in the subject and lead to further study of hygiene, particularly among the girls who are leaving school to help in the home.

Instruction to Teachers.-As the importance of good physical condition is steadily becoming more appreciated, teachers will be more carefully trained to watch intelligently the health of the children entrusted to them. It is very necessary, in order to get co-operation between the teaching and medical staffs that the teaching staff should all understand what the medical staff are working for, and how they are hoping to improve the health of the children. In the Training Colleges for Elementary teachers there is some instruction in school hygiene given. In the Secondary Training 


\section{I48 SCHOOL MEDICAL INSPECTION}

Colleges also, the present trend of practice is in the same direction. Many secondary teachers, however, enter school without any professional training, and many commenced teaching before training was as general as it is at present.

There are many observations which the intelligent teacher makes on the health of the children in her form, and having a medical officer on the spot encourages her to do so. She may fear a snub from the parents for interfering if she draws attention to some fact which may turn out to be insignificant, whereas she is sure of kind co-operation from the medical officer. Therefore meetings between the medical officer and the staff will make the inspection much more efficient; moreover the younger mistresses, who later may be in charge of schools where there is no inspection, may be glad of some course of instruction to help them to observe and guard the health of the children.

Some such syllabus as the following may be of advantage. In it there is no attempt to teach School Hygiene. It is merely an attempt to gain the co-operation of the teachers in school inspection, and to supplement what they may have studied elsewhere.

I. School Inspection. Its object. Its 
methods. Ways in which the Form Mistress may help.

2. Observation of the Child. Infectious disease. Incubation and Isolation. Premonitory signs.

3. Fatigue and recovery. Recreation. Rest. Exercise. Signs of nervous trouble. Fatigue. Chorea.

4. Weighing and measuring. How they should be done. Value of the knowledge thus gained.

If there were further opportunities these lectures could be extended. The headings given above are merely suggestions for treating the subject, and are not each intended necessarily to be fully treated in one lecture. 


\section{CHAPTER XIV \\ THE TIME TABLE}

WHEN women began to tackle the higher education problem they learnt the necessity for good teaching. They insisted on having good schools provided for the future generation.

The women who worked in these schools through demanding an equally good education for the girls as for the boys, were no slavish copiers of the systems in boys' schools. They evolved for their special need, special conditions of work. Thus they felt it wise to allow free time to the growing girl for the cultivation of those domestic arts and social graces which were to be in her future life her chief concern.

So they decided to spend the morning till one o'clock in study: the afternoon was to be free for domestic work, for exercise, for the mother's training in home duties which had been previously of so much importance and which it was still felt important to retain. 
Thus has arisen the High School tradition of work from 9 a.m. till I p.m. and freedom in the afternoon. From this, special difficulties as regards the question of health arise, but also special advantages.

The difficulties are largely due to the modification of the circumstances of girls' education.

The High School has, owing to the excellence of its teaching, the scholarships it offers, and the official stamp it confers on those who have been educated, killed off many of the previously competing private schools. The consequence is that many high schools draw their pupils from great distances. Girls start at an early hour, some at 7.45 or 8 to arrive at school at 9 to 9. I 5. And instead of breakfast at 8 to 8.30 and work from 9 till I with a break at eleven for milk and biscuits, many girls breakfast at 7 to 7.30 , take a long journey into town, and then have their morning work. Again, owing to the fact that many girls have now to study for some profession, they cannot afford the time to spend the afternoon as was originally intended in exercise or domesticity. Girls doing advanced work need special coaching, extra science and language teaching. For those who live at a distance there is the return journey. In addition, taking up time, are all the special subjects of art and music, sewing and the like. 


\section{I52 SCHOOL MEDICAL INSPECTION}

Thus many girls have full time-tables, morning and afternoon, and the apparent advantage of the long morning time-table with its free afternoon is lost.

To make matters worse, the multiplication of subjects and the demands of mistresses anxious for justice to be done to their own subjects frequently tend to crush out drill, gymnastic work, or games from the time-table of many girls, particularly if they themselves are not keen on physical exercise and do not demand some place for it.

Thus the very students who most need it, i.e. those working at high pressure either because they are very brilliant or because they are very poor intellectually, will miss what most they need if the time-table is not watched by one who has a special interest in their physical development. It sometimes needs the whole force of medical opinion to make a mistress or a parent realize that over-application is disastrous, or even to point out that over-application exists.

A sufficient amount of physical exercise must be provided for all classes and at suitable hours. Drill must be in the mornings, otherwise some members of the class would miss it, as they would not be able to return in the afternoon or would be reluctant to do so. It is evident, therefore, 
that the long morning time-table may be a serious trial to the less vigorous, particularly if they have to travel into town from any distance.

The elastic character of the High School time-table, putting as it does the important subjects in the morning and the accessory subjects in the afternoon, however, affords many useful opportunities for the modification of work according to individual requirements.

The afternoon subjects such as drawing, needlework, singing, and music can be dropped easily in cases where there is over-pressure or where open-air exercise or more rest is needed. Home lessons can be then done at school instead of the extra subjects, or the girl can be dismissed to get into the fresh air as quickly as may be. The possibility of thus being able to keep a delicate girl at regular study with girls of her own capacity instead of either allowing her to develop neurosis by unemployment and the contemplation of her own delicacy, or making her ill by futile efforts after a full curriculum, is highly valuable; and it is the problem of doing this that the high school system has helped the medical officer to solve.

But in every school acknowledging the supreme importance of physical fitness, whatever the form of time-table, whether it arranges work from 9 to 12 and 2 to 4 or gives the 


\section{I54 SCHOOL MEDICAL INSPECTION}

long school morning first, the adaptation of the hours of work to the capacity and hygienic needs of the form and also of the individual will be of great interest and of extreme value.

Co-operation between the medical officer and the teaching staff in these matters has produced, in the writer's experience, most encouraging and fruitful results.

Examples of the modification of the timetable of the form as a whole following medical inspection are given in the chapter to form treatment. Sufficient here to tell of individual examples.

Phœbe, aged fourteen, whose mother complains that she sleeps badly, is eating badly, and has headache, and is listless.

Medical inspection shows that her gain in weight is unsatisfactory. She is third from the bottom of her class list in weight, and has not gained weight during the term. She leaves home at eight o'clock after a hurried breakfast at 7.45. She stays dinner at school, and each afternoon has either sewing, singing, drawing, or extra French and mathematics, as she is backward in these last subjects, and her parents desire her to earn her living.

Physical examination shows no definite defect. 
Her eyes are normal, but she is somewhat anæmic. Such a girl should be stopped all extra subjects, such as sewing, singing, and drawing. Her extra French may be continued for a time, but consultation with her class mistress will probably result in her joining a lower class in mathematics.

She should be weighed every month and her progress noted. An early bedtime should be insisted on, and treatment of the anæmia referred to her family medical attendant.

Under such treatment her weight increases, her headaches diminish, and her school performance improves.

Priscilla, aged seventeen, a candidate for a scholarship, is noticed to be thin. Her weight has not increased since October, it is now February. Her mother records poor appetite and irritability of temper. Her mistress reports her work to be below the usual standard. Inquiry shows that the girl has been set by separate mistresses a large amount of homework including several essays. Being a keen student she has worked with excessive ardour.

All home-work is stopped. Her afternoon work is limited. Extra feeding and early bed are advised. The result is that in three weeks an increase of weight is recorded, together with 


\section{I56 SCHOOL MEDICAL INSPECTION}

improvement in well-being. After careful supervision of the amount of her work a brilliant place in her examination is secured.

Examples of such cases can be multiplied indefinitely. 


\section{CHAPTER XV \\ SCHOOL DINNERS}

As food and sleep are to the young animal the principal factors determining satisfactory growth, the question of feeding will come up constantly before the medical inspector. Particularly will this be so in a large day school where the pupils live at long distances from the school building. No girl can be expected to grow and develop, far less work well, unless adequately fed. It by no means follows that because a girl is attending a good High School or Secondary School that she is being properly fed. A special investigation, undertaken in such a school into the health of a set of girls numbering thirty, showed no fewer than six to be suffering from an inadequate supply of food. In some of these cases the actual amount of food was sufficient, if only the proper proportions of the constituents of a diet had been present; but as, even in these few instances, the proteid constituents were too 


\section{SCHOOL MEDICAL INSPECTION}

small all the six were suffering from starvation in some degree.

In the diet of the young the mid-day meal should be the principal one of the day. If from economic reasons, the evening meal has to be the chief meal of the day, the danger is that it will be taken too near the sieeping time, and therefore the night's rest be disturbed by digestive troubles. But whether or no the mid-day meal is the principal one of the day it is essential that after the journey to school and the long morning's work, the girl should partake of good nourishing food. For those who live near the school the problem is simple. For those who live at some little distance it is important to discover if the time allowed for the dinner interval is sufficient both for the double journey, and for the proper mastication of the meal. Much of the benefit derived from the food is lost if proper opportunity for digestion is not allowed. Some girls can continue to rush over their meals for some years; but inevitably the bad habits will in time produce their results. The more delicate girls soon break down in health under this strain. Arrangements must therefore be made for the feeding of those who live so far away that the dinner hour does not provide sufficient time for the double journey and the 


\section{SCHOOL DINNERS}

meal. In most cases it is not advisable that girls attending schools should have to procure meals at public restaurants. Among other evident disadvantages of this plan is the natural desire of children for the more attractive but less wholesome dishes, such as pastry and sweets, to the exclusion of proteid-containing food. Some children may also be tempted to economize on their food and spend the money in other ways. Provision must therefore be made at the schools for the dining of the scholars.

A large proportion of girls will desire or be made by their parents to bring lunch from home. This is often done from the necessity of economizing as much as possible. This policy is a foolish one. These meals are in most cases necessarily cold. In winter, at least, it is advisable that the mid-day meal should be hot. If a school provides a warm dinner it will not generally be found easy to provide facilities also for heating the food brought to school. In most cases the meal brought to school consists of sandwiches. The monotony of such a diet does not conduce to that lively anticipation of the meal which helps to promote digestion. Unless the girl is very hungry she will after a time hate her sandwiches. Ham, tongue, and meat, together with occasional fish sandwiches form the staple 


\section{ı6० SCHOOL MEDICAL INSPECTION}

of such meals. Hard-boiled eggs and cheese for those who can digest it, meat pies, and sausage rolls, may be added occasionally. To vary the monotony tomato and jam sandwiches are frequently brought to school. But the latter do not produce sufficient proteid constituents, and the girls must be told that they are insufficient, especially in cases, which do occur, where an evening dinner or high tea is not provided at home.

The really satisfactory method is for the school to provide, at as cheap a rate as possible, a good, nourishing, plentiful meal. This can be done so cheaply, when the school contains large numbers, that the cost of having dinner at school should be little more than that of the food brought from home. No attempt should be made to make profit on school dinners.

The school meal should be important educationally. Its influence should be hygienically and æsthetically valuable, especially to the less affluent girl or the one who comes from a less well-trained home. The table should be carefully laid, the meal should be served attractively and quickly, and the portions should not be limited. Experience teaches that a certain amount of discretion has to be used in the allotment of helpings, for many girls have large 
appetites which need satisfying, and may be shy of asking for a second helping. On the other hand, some girls are nauseated by large quantities served out on their plates. Whoever is responsible for serving the meals should see that a suitable mean in serving portions is adopted, and that girls are urged and given time to have the necessary second helpings.

Younger children need supervising at their meals both for the sake of their manners and their digestion.

Freedom may be given to the older ones; public opinion and home training will ensure the observation of table amenities. Freedom from restraint and opportunity for conversation will not only add enjoyment to the meal, but will also help digestive action. Pleasure is of the highest importance as a sauce to a meal. For this reason there is no more pernicious weakness in the feeding of a large community than a monotonous menu. That one should know exactly what meal to expect every Monday, Tuesday, and Wednesday, and know that the same dish may be served again more than once during the week takes away appetite, except from the strongest, and from those who are not naturally interested in food. It is desirable, especially. when providing for large 


\section{I62 SCHOOL MEDICAL INSPECTION}

numbers, when it can be done easily, to have a choice of dishes. "One man's meat is another man's poison," and though one does not wish to encourage fastidiousness, if a choice is given, individual tastes are gratified and neither choice nor variety need add to the expense of the dinner.

There is always a certain amount of faultfinding with institution or community meals, and often justly so. It is a difficult art to cater well for a large number, and unless the institution is fortunate in the appointment of the cook, the meals will not always be satisfactory. But when it is known that the meals are well served, school dinners should be useful in curing, or at least improving, too great fastidiousness in girls. Food is not so often refused when many dine together as in private life where the individual gets more attention, and portions ought not to be regularly left on the plate without inquiries by the authorities into the reason for such action.

There is no doubt that too much attention is often paid at home to incipient dislikes for certain dishes in small children. Again, the golden mean may be found between insisting on a child's eating something which absolutely nauseates her, and allowing her to pick and 
choose and finally reject one after the other the wholesome dishes provided.

In arranging the school menu it has already been decided that variety is essential to enjoyment. The character of the meal should also vary with the seasons-in winter, soups, suet puddings, and hot dishes-in summer, a choice of cold dishes, more fish, lighter puddings, and salads. Stewed fruits and green vegetables should frequently appear on the menu all the year round.

It appears to us inadvisable to allow soup to take the place of the meat course. The place of soup in the menu will be a question which ought to be settled on physiological principles. Clear soups generally contain little more than stimulating and appetizing ingredients. Their actual food value apart from stimulating absorption mainly depends on the bread or toast eaten with them. Lentil and pea soups, on the other hand, or broths containing portions of meat and vegetables, contain a certain amount of proteid material. This, however, is accompanied by a large proportion of the carbohydrate constituents of diet. It appears, therefore, more suitable when soup is served as an alternative where only two courses are partaken, that it should be instead of the sweet rather than 


\section{I64 SCHOOL MEDICAL INSPECTION}

of the meat course, and that the soup should be made of constituents which have food value.

In some schools there will be a demand for vegetarian meals. When these are supplied it is necessary to determine that the proper ingredients of a well-proportioned meal should be present. It is not sufficient to serve the vegetable portion of a mixed meal with the possible addition of bread. Nor are stewed tomatoes a satisfactory substitute for stewed steak. Cheese is a most useful vegetarian dish, and when children can digest it, is an excellent food, either eaten with bread, or toasted, or cooked with macaroni, or even with greens. Eggs treated in various ways, nuts variously prepared, and lentils can all be used in such meals.

It may be well to add a few notes on some of the details which practical experience has shown to be necessary in order that the full benefit may be derived from a scheme for the provision of school dinners.

The time taken for the meal ought to be at least half an hour to forty minutes from the commencement of the meal. After the long morning it ought to be served as promptly as possible after the termination of school. It is advisable, so that some check may be kept over the propensity to rush over the meal in 
order to get to play, that each girl should have her recognized place, and that the meal should begin and end formally. Opportunity, however, should be given to girls who have a free afternoon to catch as early a train home as possible. They should be allowed, if necessary, to come down a little early, be served first, and get away after a reasonable time.

Children who live at any distance ought to stay for their dinner rather than hurry off and journey back, making the interval between breakfast and dinner six hours or more. No child should leave for a train journey in winter without at least a bowl of nourishing soup if the morning has lasted till one o'clock.

The great difficulty in large dining halls appears to be to serve the meals quickly enough. The carvers ought to be quick and sufficient in number, and the waitresses should serve different girls first each day.

In a school with organized games, matches should not be arranged to take place too soon after dinner. Practical objections are often urged against such an ideal standard. The school time is so short, the time-tables are so complicated, that sometimes matches must be arranged in the noon hour.

In this case again we must ensure that proper 


\section{I66 SCHOOL MEDICAL INSPECTION}

effect is given to physiological teaching. Girls must learn the need of rest after meals. It is sometimes possible to arrange for girls playing matches to come down earlier than the others, and thus have some time at least for rest before the games are begun.

The after-dinner interval is very important. The girls should be encouraged to get out into the playground before the afternoon work is recommenced, but there ought to be chairs or forms for sitting on placed in the playground or in some airy room for the benefit of those who do not feel able to play. The majority will benefit by running about and playing games.

In every school there ought to be a few couches, Swedish plinths, or forms on which some of the girls can lie down for a time before beginning work again. Absolute rest, and for weakly girls with curvatures, a perfectly flat position for half an hour, is of great advantage, and we have noted the improvement in the afternoon work and general well-being, where this has been provided.

The tendency to gather together in groups and in small or stuffy rooms should be deprecated.

The dining-hall should always be well-ventilated and ought to be cleared of all the girls immediately after dinner. Some other place 
should be provided for their recreation. Doors and windows should then be opened widely, and an attempt made to free the building of the smell of food.

Many girls will be tempted to close windows or complain of draughts if there is not in the school a proper free system of ventilation. The more air is freely allowed in a building the less likely are we to have complaints of draughts.

The question of dinners has been discussed at some length, because practical experience has shown again and again how important is this matter of feeding. Time after time, when a girl has appeared to flag, has been losing weight or appearing listless, we have found that attending to her feeding at home, seeing that she takes her morning milk and arranging for food at school before she gets too exhausted by her work and school journeys to care for food at home, has made a difference, and improvement both in physique or school work has resulted. But school dinners must be well served and well cooked. Mothers and daughters are prejudiced in favour of home meals, and everything should be done to make such school dinners nutritious and educationally valuable.

The dining-room is, indeed, a valuable instrument-at the disposal of the medical officer. 


\section{I68 SCHOOL MEDICAL INSPECTION}

Governors of schools, even of High School standing, may sometimes provide much-needed, even essential, assistance to some of their scholarship and bursary students, if they are to derive the full benefit from the teaching provided, by allowing them in addition to the scholarship, free or assisted meals on the recommendation of the medical officer.

The school dinner is not the sole meal which needs regulation and careful provision, but it is under school control, and may be a vital factor in building up the physique of the students.

Appended are some of the meals provided at the Manchester High School for girls.

\section{SCHOOL DINNER MENU, LAST WEEK OF SUMMER TERM, I9II}

Monday.-Girls : Roast Lamb, Pressed Beef, Beetroot, Potatoes, Greens, Lemon Cheese Tart, Fruit Jelly, Sago Pudding; Mistresses: White Soup, Pressed Beef, Beetroot, Roast Lamb, Mint Sauce, Potatoes, Peas, Swiss Roll, Fruit Jelly, Sago Pudding; Meatless: Scrambled Eggs.

Tuesday.-Girls : Fish, Roast Beef, Potatoes, Greens, Mould and Fruit, Cambridge Pudding, Rice Pudding; Mistresses: Spring 
Soup, Fish, Roast Beef, Potatoes, Greens, Baked Custard, Mould and Fruit, Rice Pudding ; Meatless : Welsh Rarebit.

WedNesday.-Girls : Roast Lamb, Cold Beef Salad, Potatoes, Greens, Mould and Fruit Salad, Steamed Rhubarb Pudding, Sago Pudding; Mistresses: Brown Soup, Roast Lamb, Cold Beef, Salad, Potatoes, Marrow, Mould and Fruit Salad, Red Currant Tart, Sago Pudding; Meatless : Savoury Egg.

Thursday.-Girls : Fillet of Plaice, Galantine of Veal, Potatoes, Greens, Gingerbread Pudding, Chocolate Mould, Sago Pudding; Mistresses : Tomato Soup, Salmon Mayonnaise Salad, Galantine of Veal, Potatoes, French Beans, Pistachio Mould, Apple Charlotte, Sago Pudding; Meatless: Rice and Cheese.

SCHOOL DINNER MENU, FIRST WEEK OF LENT TERM, I9I 2

Tuesday.-Girls : Lentil Soup, Roast Mutton, Steak and Kidney Pie, Potatoes, Greens, Sponge Pudding, Cambridge Pudding, Rice Pudding; Mistresses: Lentil Soup, Roast Mutton, Steak and Kidney Pie, Potatoes, 


\section{I70 SCHOOL MEDICAL INSPECTION}

Greens, Sponge Pudding, Cambridge Pudding, Rice Pudding; Meatless: Irish Stew.

WednesdaY.-Girls : Pea Soup, Haricot Mutton, Roast Beef, Potatoes, Beans, Apple and Custard, Gingerbread Pudding, Rice Pudding; Mistresses: Vegetable Soup, Haricot Mutton, Roast Beef, Yorkshire Pudding, Potatoes, Sprouts, Rhubarb Tart, Gingerbread Pudding, Rice Pudding; Meatless: Chestnut Dish, Scrambled Eggs.

Thursday.-Girls: Potato Soup, Roast Beef, Sausage and Mashed Potatoes, Potatoes, Celery, Treacle Roly-poly, Prunes and Custard, Sago Pudding; Mistresses: Potato Soup, Roast Beef, Sausage and Mashed Potatoes, Potatoes, Celery, Pears à la Condé, Treacle Roly-poly, Sago Pudding ; Meatless : Macaroni and Cheese.

Friday. - Girls: Tomato Soup, Fish, Roast Mutton, Potatoes, Pears, Mince Tart, Plain Steamed Pudding, Fruit Sauce, Rice Pudding ; Mistresses : Tomato Soup, Fish, Roast Veal, Irish Stew, Potatoes, Artichokes, Mince Tart, Steamed Pudding and Fruit Sauce, Rice Pudding; Meatless: Rice and Tomato. 


\section{CHAPTER XVI}

\section{VENTILATION-HEATING}

THE site and surroundings of a Secondary School have in most cases been decided long before the school medical officer is appointed. But if that has not been done and new buildings are to be put up it is not likely at the present day that the necessity for sufficiency of light and air will be neglected. Some architects, however, in the desire to provide an artistic building err on the side of diminishing the window space, or in placing the windows too high up from the ground and leaving a depressing blank of wall all round the room. The medical officer will necessarily be interested both in the arrangement of plans, and in considering necessary and essential adaptations in a building already made. We have to remember in dealing with children, not only that light and air in a generous supply should be given, but that young children (and most adults) are wonderfully stimulated by sunshine. In England, and particularly where the writer lives in the north, it is unusual to get rooms made 


\section{SCHOOL MEDICAL INSPECTION}

unpleasant by too much sunlight, if only suitable provision for a thorough current of air is provided. In some cases, however, in the summer, especially in the afternoons, south and west rooms get very hot. Therefore all windows should be made to open wide in order to prevent the extra intensity of the rays passing through glass, and the windows should be provided with blinds, preferably green. Trees or other buildings should not be too near the school. In the playground and gardens trees are pleasant, but they should never be too near the house because they obstruct the light and air, and in a wet season make the building feel damp and cold. If suitably placed to the east and north they may be a protection to the house from searching cold winds.

It is most advisable in building a school to have it at some distance from the main road. The noise of traffic distracts the attention of the children, is an extra strain on the voices of the mistresses, and makes a large extra demand on the nervous energy of all using the building.

If the school has already been built on the main road where there is noise from the traffic, the relief from this toll on nervous energy will compensate the authorities for, even at considerable expense, laying down as quiet a roadway 
outside as can be laid. In our manufacturing towns, noise is one of the most nerve exhausting accidents of life. If we could eliminate smoke and reduce noise our health would be materially improved.

The building should, of course, be properly preserved from damp. A warm dry soil and subsoil should be chosen. Gravel, inasmuch as water flows through it so well, makes an excellent foundation if there is somewhere for the water to flow away. Rock, if drainage is properly provided for so that water does not lodge on the surface, is very good.

Clay is apt to lodge water and be cold.

A sloping site on a hill facing south or south-west is the best. On this the building should be put with its corners arranged to the four cardinal points.

Thus all the rooms at some

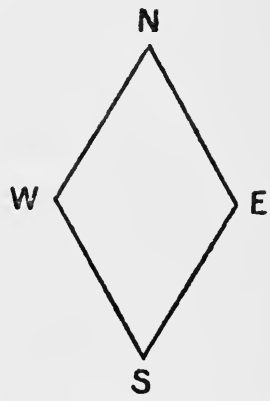
time in the day will get sunlight. No other buildings should ever come too near the school to obstruct direct light reaching the back walls. The following figure from Newsholme and Pakes' School Hygiene will show what is meant. With the building $\mathrm{A}$ at a fixed point and the 


\section{I74 SCHOOL MEDICAL INSPECTION}

light coming over from $\mathrm{D}$, the difference in the lighting is very evident.

Rooms $a$ and $b$ are badly lighted; even $c$ is not well lighted because no light gets on the back wall, but $a^{\prime} b^{\prime} c^{\prime}$ are all well lighted.

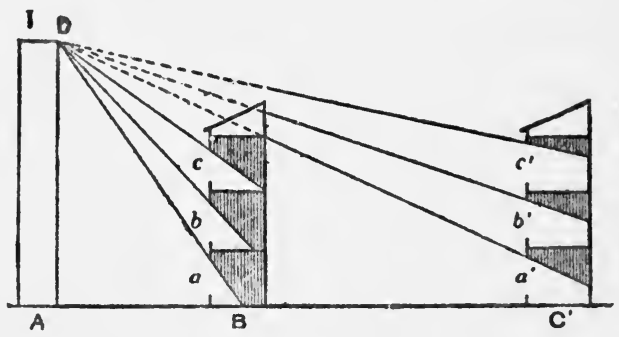

When the value of sunlight is considered, not only on the physical and mental condition of the children, but also as a cleansing and disinfecting agency, the importance of removing all possible obstacles to its free ingress is evident.

It would not be profitable here to discuss the various types of school buildings. Modern schools are likely to be built with all regard to every modern requirement. A certain number of schools, however, are still in adapted houses, and a certain number are housed in buildings which were built not within the last few years. But even in the newest buildings certain of the arrangements need constant observation in order that the hygienic conditions shall be satisfactory. 
The drainage system must periodically be overhauled, for even in modern systems defects arise through wear in the pipes and fittings. Cloak-room arrangements, particularly where adapted buildings are used, need supervision. There should be proper opportunities for drying and changing clothes.

The cloak-rooms ought to be sufficiently large for each child to hang her outdoor things on her own peg without being covered by the clothes of another girl. There should be accommodation for her outdoor shoes, and a bag in which spare stockings are kept. Colds are not caught by getting wet when walking, but bronchitis, rheumatism, and other ills follow sitting in damp clothes in a warm room, or putting on damp clothes when a railway or tram journey must be taken.

Heating and ventilation in a climate as variable as the English one cause much trouble before satisfactory conditions are secured.

Heating and ventilation are considered together because they are inter-dependent or, as it is more accurate to say, they affect one another materially.

Each separate room may have its own heating apparatus, or heating may be central, i.e. produced in a heating chamber, and the school 


\section{I76 SCHOOL MEDICAL INSPECTION}

heated by means of hot water or hot-air pipes from the central chamber.

Ventilation may be natural or artificial. By a natural or direct method of ventilation and heating, fires are lighted in the rooms, and the rooms aired by means of currents of air passing from the open window and door to the open chimney. This ventilation may be assisted by means of ventilators in the walls such as Tobin's tubes, Sheringham's valves.

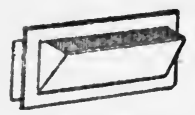

Sheringham's Valve.

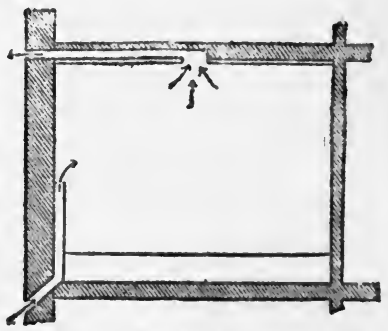

Tobin's Tubes with outlet in ceiling.

By permission from Newsholme and Pakes' "School Hygiene."

By the artificial method of ventilation air may be introduced into the building by one special source, be heated if necessary over radiators and passed on, and then pass out by outlet ventilators.

The points to be noticed in heating and airing a room are-

I. That the air of the room is at the proper 
temperature, i.e. $56^{\circ}$ to $60^{\circ}$ Fahrenheit. A thermometer should hang in every room, and the class and the mistress be interested in recording the temperature.

2. That too much moisture is not being abstracted from the air. A wet and dry bulb thermometer will show this. It is useful to have one in the corridors so that at any time it can be carried into the class-rooms. The record in the corridors will show the amount of loss of moisture from the air due to the heating of the air.

A number of children in a class-room where the ventilation is not good will themselves produce moisture, which in that case is an indication of the contamination of the air which is occurring.

The principle of the wet and dry thermometers is well known. Two ordinary thermometers are used. Round the bulb of one is passed a piece of cotton material which is continued into a vessel of water below the bulb.

The material absorbs the water and moistens the thermometer bulb. The water evaporates from the bulb and cools the mercury. If the air is dry, evaporation goes on quickly. If the air is moist it goes on much more slowly. If the air is saturated no evaporation takes place, and the 


\section{I78 SCHOOL MEDICAL INSPECTION}

reading of both thermometers is equal. There should be a difference of between three and four degrees. If the room is $60^{\circ}$ and well ventilated the wet bulb thermometer will read about $56^{\circ}$.

3. It is necessary to see that too much carbon dioxide gas is not present. Carbon dioxide is produced by the respiration of the individual. The adult inspires and expires about 30 cubic inches at each breath. As he breathes about 16 times a minute, and expired air contains 4 per cent. of carbon dioxide, he therefore exhales about 0.673 cubic feet of $\mathrm{CO}_{2}$ per hour. A child exhales slightly less than the adult, but inasmuch as tissue change is proceeding at a high rate there is little difference in the $\mathrm{CO}_{2}$ produced.

If the air in the room contains 0.6 per thousand of Carbon dioxide gas it is not fit to breathe.

Fresh air contains $0^{\circ} 4$ per thousand of carbon dioxide.

It is therefore evident that the number of thousand cubic feet of fresh air needed per hour per child equals the amount exhaled by the child divided by the difference between vitiated and fresh air, i.e. $\frac{0.6}{0.6-0.4}=3$.

The amount of $\mathrm{CO}_{2}$ in the air can be found very readily and with sufficient accuracy by the 
following method, which depends on the fact that where $\mathrm{CO}_{2}$ mixes with water and is shaken up, a milkiness appears owing to the precipitation of insoluble carbonate of lime. The depth of the milky appearance depends on the amount of carbonate formed, and therefore on the amount of carbon dioxide shaken up.

A series of bottles are taken having an exact capacity varying from 430 c.c. to 180 c.c. These are supplied with stoppers fitting accurately. Into them, when well washed, clean fresh water is poured. They are then taken to the room of which the air has to be tested, and then emptied completely and the stoppers replaced. They are then taken to another room. Into each bottle is quickly and carefully poured i 5 c.c. of lime water. The bottles are then well shaken up so as to mix the air and the lime water. The bottle in which milkiness first appears is then noticed.

The following table gives the amount of $\mathrm{CO}_{2}$ in the air-

Bottle where milkiness appears.

$\mathrm{CO}_{2}$ per cent.

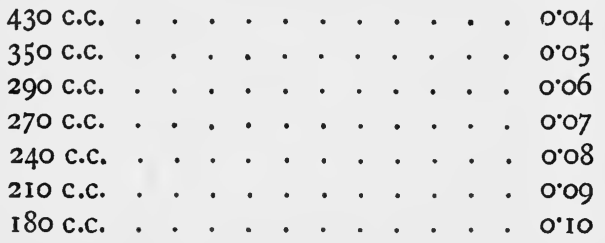




\section{SCHOOL MEDICAL INSPECTION}

If the bottle containing 290 c.c. shows milkiness the air of the room is deleterious. Indeed, any milkiness shown in any but the largest bottle must be regarded with suspicion.

If the medical officer discovers defects in the ventilation or heating of the building, steps must be taken to improve the conditions.

All systems of heating and ventilation have faults.

The natural method by means of fires and open doors and windows entails excessive heat for some and excessive cold for others. Moreover, teachers and girls must be fond of fresh air or the windows will never be sufficiently widely opened. If windows are open for a small distance there is a danger of a small current of air in a stuffy room giving the cold or muscular pain which a free current of air does not produce.

If the ventilation of such a room is assisted by the introduction of artificial ventilations, their apertures ought to be on a higher level than the children in order to prevent draughts being felt.

In a big school building it is much more satisfactory and more usual to have some system of artificial heating. This may be done by means of hot pipes placed throughout the building. 
If the school is heated by pipes unless there is a proper supply of fresh air a stuffy hot dry atmosphere will be produced which is enervating, soporific, and poisonous. It is very important in a school building to see that the air is not too warm and enervating where the children enter from outside. In a climate such as the English one it is very advisable to have fire-grates in all the schoolrooms even though the school is centrally heated. It often happens, even after summer has appeared, that some morning it is too cold to do without fires, and a small amount of heat will remove a chilly atmospheric effect. In a building heated by means of the central apparatus some time would be taken before the rooms could be warmed and then the tendency would be to overheat.

Moreover, there are always some rooms much colder in a building than others, and it may be necessary to heat some rooms without heating the whole of the building. There is no doubt that the presence of a fire often helps to improve the stagnant stuffy feeling experienced in rooms heated by hot pipes; especially will this be so if the chimney is provided with a Galton's ventilating shaft. By this means air from outside is brought by means of a shaft along the stove to an inlet above the mantelpiece. The heating of 


\section{SCHOOL MEDICAL INSPECTION}

the air in the shaft causes it to rise and enter the room. An outlet can be provided by means of a valve opening into the chimney.

The danger of closed stoves and hot-air pipes lies in the excessive dryness produced. Air at $6 \mathrm{I}^{\circ} \mathrm{F}$. will hold double the amount of water that air at $42^{\circ} \mathrm{F}$. will hold. The moisture is abstracted from the scholars with the result that they suffer from a tendency to catarrh, sore throat, etc. The change from dry air to cold damp air on leaving the building may be deleterious.

A method of discovering the humidity of the air has been described. The atmosphere in England generally contains 75 per cent. of moisture. The degree of moisture should not be allowed to sink below 58 per cent., there should therefore never be more than $9^{\circ}$ between the readings of the wet and dry bulb thermometer -and the readings should preferably be four degrees less in difference.

If the rooms are too dry bowls of water with a large surface of evaporation should be placed on the radiators or near the pipes.

If the school is heated by means of a mechanical system of ventilation and heating, whereby heated air is supplied as in the plenum system, the proper amount of moisture is restored 
to the heated air before it is sent on through the building.

There are two methods of mechanically ventilating a building-The air may be, as was mentioned above, pumped into the building or, by means of a central ventilating shaft the air may be drawn out. In these systems the windows and doors must not be kept open or the proper currents of air will be disturbed. The great advantage of these methods is that before the air is used it can be properly prepared, moistened, filtered, and heated. The difficulty of an unstable climate and the time taken to get such a system working counts as a minor disadvantage.

It is interesting to point out the statistical advantages of the mechanical over the natural system. The figures are taken from Carnelly, Journal of Pathology, November, 1893.

Mode of Heating and School Arr.

\begin{tabular}{|c|c|c|c|c|c|}
\hline Mode of heating. & \multicolumn{2}{|c|}{ Temperature } & $\begin{array}{l}\mathrm{CO}_{2} \text { per } \\
\text { Io,000. }\end{array}$ & \multicolumn{2}{|c|}{$\begin{array}{c}\text { Micro-organism } \\
\text { Bacteria. Moulds. }\end{array}$} \\
\hline $\left.\begin{array}{c}\text { Mechanical ventilation } \\
\text { by warmed air . }\end{array}\right\}$ & $5^{8 \cdot 6}$ & $40 \cdot 1$ & $12 \cdot 3$ & $17 \cdot 5$ & $I^{\circ} \mathrm{O}$ \\
\hline $\begin{array}{l}\text { Natural ventilation } \\
\text { and hot pipes }\end{array}$ & $58 \cdot 4$ & $46 \cdot 4$ & $16 \cdot 3$ & $96 \cdot 5$ & $I \cdot I$ \\
\hline $\left.\begin{array}{l}\text { Natural ventilation } \\
\text { and open fires }\end{array}\right\}$ & $58 \cdot 4$ & $44^{\cdot} 8$ & $19^{\circ} 2$ & I $53^{\circ} 2$ & $4 \cdot 8$ \\
\hline
\end{tabular}




\section{I84 SCHOOL MEDICAL INSPECTION}

Carnelly shows the importance of ventilation on school work in the following table showing grant earned and work done in the two types of school.

\begin{tabular}{|c|c|c|c|c|c|c|}
\hline Ventilation. & $\begin{array}{r}\text { Per } \\
\text { Reading. }\end{array}$ & $\begin{array}{l}\text { entage of } \\
\text { Writing. }\end{array}$ & $\begin{array}{l}\text { passes. } \\
\text { Arithmetic. }\end{array}$ & Grant. & $\begin{array}{c}\mathrm{CO}_{2} \text { per } \\
\text { ro,000. }\end{array}$ & $\begin{array}{l}\text { Micro. in } \\
\text { a litre of } \\
\text { air. }\end{array}$ \\
\hline $\begin{array}{l}\text { Mechanical. } \\
\text { Natural . }\end{array}$ & $\begin{array}{l}99^{\circ} 6 \\
95^{\circ} 6\end{array}$ & $\begin{array}{l}97 \cdot 8 \\
90 \cdot 4\end{array}$ & $\begin{array}{l}92^{\circ} 4 \\
84^{\circ} 2\end{array}$ & $\begin{array}{l}21 \cdot 8 \\
19 \cdot 6\end{array}$ & $\begin{array}{l}15^{\circ} 4 \\
22^{\circ} 2\end{array}$ & $\begin{array}{r}8 \cdot 0 \\
61^{\circ} 0\end{array}$ \\
\hline
\end{tabular}

This shows that the responsibility of seeing that the rooms are constantly well ventilated is an important duty of the medical officer. It is so easy for a small class to be put in a small room in an emergency and one and another member be added to the class, till the capacity of the room is overstrained. Or for a room which is not fit for the purpose to be adapted in some part of the building, or for a teacher to be impatient of open windows or ventilation. Actual testing of the condition of the air will silence many protests.

For practical purposes in most High Schools where the classes ought to be small and where the hours of each lesson are not long and the class-rooms are emptied between each lessons the natural system of ventilation with a combination of natural and artificial heating will be found 


\section{VENTILATION-HEATING}

most pleasant and convenient. The air ought under such circumstances to remain good. It will feel more natural, less dry and stale than it is generally found to be the case in many artificially heated and aired buildings, moreover there is no liability of the whole system being upset by one carelessly opened window. 
CHAPTER XVII

\section{THE GYMNASIUM AND THE MEDICAL OFFICER}

THE value of the gymnasium in the equipment of a school is of the highest importance.

In gymnasium and playing field the bodily development of the girls is promoted as is their mental power in the schoolroom. In both branches, physical and intellectual, growth comes with exercise and practice. In both we also aim at counteracting to some extent and in some degree defects which have already been formed, by paying special attention to the defective parts or subjects as the case may be.

The place of gymnastics and games in girls' education has long been challenged. Calisthenics or the cultivation of a beautiful deportment has always been studied in girls' schools. But the recognition of the necessity for muscular development in the girl was formerly not only considered unimportant but absolutely harmful. Special dangers to feminine functions were supposed to 
lurk in an active, well-developed frame, and not only the duties of maternity, but the safety of mother and child were felt to be imperilled by a strenuous devotion to athletics in girlhood. Further, the activities of gymnastics, the vaulting, the climbing, etc., were supposed to cause displacements of internal organs and miseries in later life.

Fortunately, Nature has provided us with numerous supports and ligaments holding the important organs in their places and a healthy development of our muscular fibres, a freer circulation of the blood and the improvement in respiration, contingent on bodily exercise, is more likely to prevent displacement of internal organs than to cause such a catastrophe. But that there are dangers for girls, as indeed there are for boys, in a gymnasium and in the playing fields, is certain, and in order that full benefit may be derived from their use and to prevent discredit falling on them, precautions must be taken.

Therefore each girl, before entering the school gymnasium, should be medically examined and any observation made about her health which it is necessary for her drill mistress to know in order to prevent harm accruing, should be communicated to her by the medical officer. Any modification of the drill normally undertaken by 


\section{I88 SCHOOL MEDICAL INSPECTION}

girls in a form in the case of an individual girl owing to the condition of her health should be considered jointly by the gymnastic mistress and the medical officer. Thus a girl with anæmia must be specially and carefully drilled if she enters the class at all. She may not be bad enough to exclude from the gymnasium altogether, or even to put in a special class, but she ought to be spared the more violent movements or prolonged efforts.

A girl with rheumatism must always be excused if she complains of any pains, and the mistress must be on the watch for these girls not looking well. Without fussing about their health, such girls are directed to do or to miss certain exercises. Thus they would only do part of the work done by the rest of the class.

It is wise in a girls' school to make it perfectly easy for a girl at any time to stop out from drill. But if permission is sought too often an examination by the medical officer may show that the girl is merely lazy and ought to be doing her drill with the others. When girls sit out from drill they ought to be provided with seats in which they can or must sit straightly. High Swedish plinths do very well for this. They can be made by a local joiner, and as they are needed for remedial work they should be found 
in any well-equipped school gymnasium. The question of providing work for girls sitting out sometimes arises and is difficult to settle. Idleness during the exertion of the others is morally bad; on the other hand, rest may be necessary.

No monthly abstention from ordinary drill need take place in the case of the normal girl. It is better to make no change for natural causes from a life which is normally well ordered.

Where, however, there is an abnormal loss at the period time, or where pain is very acute, abstention from games and drill, and in more severe cases from school itself is advisable. This question is treated in a separate chapter (see Adolescence).

Certain rules should be laid down for the regulation of drill by the medical officer.

As far as possible there should be some drill for each girl every day. The time-table often makes this arrangement difficult, but it is important in arranging physical work that the body shall be kept permanently fit and that extreme efforts should be avoided. Especially is it important for the younger children, that all the drill shall not be concentrated on one or two days with possible consequent overtiring of untrained muscles.

It is impossible here to go into the principles 


\section{SCHOOL MEDICAL INSPECTION}

underlying gymnastic work. We can only point out the two purposes of the ordinary school drill, and in some measure show how it can be used by the medical officer for class or form improvement.

Drill, then, is ( 1 ) recreative, (2) developmental. Recreative drill is used in school, particularly where there are no playing fields or where the playground is inaccessible for use to provide rest and relief from intellectual work.

The highest centres, fatigued with work, leave still active the lower centres regulating movement, action, physical activity. Bodily movement improves circulation, and promotes respiration. The blood current removes fatigue products, and the body is refreshed. Thus drill between lessons is recreative.

Such drill needs to be performed without much mental effort. Simple running about in the playground serves the purpose best, but it is open to many objections: too much noise and commotion may be caused; it may not be convenient to disband the class; or the weather may forbid. Again, there is a tendency in girls' schools for those who specially need the refreshment of such drill or running wild to walk sedately, with bent head and shoulders, round the playground. 
Hence it is well to arouse interest and pleasure and decrease mental effort in drill interposed between lessons, by means of music. Marching to music, dancing to music, drilling to music, pulls up the frame, throws out the chest, causes deep inhalations of breath intensified by pleasure and performed almost by reflex action. Such drill is a useful aid in treating forms whose members are inattentive and those whose members are easily fatigued by mental effort. The interposition of short periods of drill often produces a marked improvement in the work done in such classes.

Developmental Drill is a harder form of lesson. Periods devoted to such drill should count in arranging the curriculum as needing a large expenditure of mental energy.

Here the drill is arranged on scientific principles for the regular co-ordinated development of the whole body. Here each movement should be thought of by the performer, and the brain should consciously direct the movements. Such lessons must be carefully drawn up, and there is no doubt that the Swedish system of exercises fulfils these purposes the best. Here music by making the movements mechanical is a hindrance rather than a help.

The precision of such drill and the somewhat 


\section{I92 SCHOOL MEDICAL INSPECTION}

stiff action which has been adversely criticized as adverting from this system may be corrected by folk dances which bring out in charming fashion the inate grace which is latent in most girls even at the most awkward age. These graceful musical exercises are also a relaxation from what ought to have been a hard mental as well as physical exercise.

There will probably only be time for one or two such classes during the week. But the daily recreative classes and games ought to keep the muscular condition in tone for these stronger efforts.

In considering the difficulties of special forms it will be found from time to time that the developmental or serious drill lesson may again help us in dealing with them. Classes with troubles of a disciplinary character, classes with careless inattentive habits, classes containing individuals with poor powers of co-ordination each need a special syllabus of work directed psychologically to deal with its own special needs.

Thus some forms need a sharp military type of drill in which the girls are very hardly worked. Some need exercises which give practice in coordination of eye, ear, and muscle. Some need training in quickness of response by frequent change of order and less routine action 
in their exercises. The gymnasium is not used to its full benefit where only the muscular system is developed.

In a gymnasium with a well-trained and qualified mistress, the medical officer will not interfere with the ordinary lessons further than by sending notes about individual girls who need special care or consideration. The special lessons for special classes will be suggested by the medical officer, and afterwards the mistress will draw up a scheme the development and success of which will be watched with interest by both mistress and school doctor.

But a special department of gymnastic work, which is undertaken by many large schools, is the remedial work.

The amount of remedial work which can be done in a school gymnasium is strictly limited. No severe case of any kind ought to be attempted there. The amount of individual attention needed by such cases cannot be given in fairness either to teachers or pupils.

Any tendency to stoop, any commencing lateral curvature, prominent scapula, poorly developed chests can all be treated by exercises specially suggested by the medical officer to suit each case.

Experience shows very marked improvement 


\section{SCHOOL MEDICAL INSPECTION}

in such cases even with one or at most two remedial classes a week. The girls are put through the selected exercises and movements by a trained mistress, and are given exercises to do themselves at home.

Flat feet and weak ankles also may be improved by suitable special exercises.

Slight cases of muscular weakness left by anterior poliomyelitis may also be beneficially helped.

This remedial branch of the gymnastic work is well worth encouraging. Curvatures due to bad position if neglected will produce as their least harmful result an unpleasing appearance, but as before mentioned organic interferences may result. Much can be done in the early stages both to prevent and remedy such conditions.

To conclude, the influence of the medical officer will encourage many a girl to enter the gymnasium who would not be allowed to do so if her parents were not satisfied first, that she was physically fit, and secondly, that the work done in the gymnasium was not beyond the powers of the girls working there.

Games.-Games are now an established feature of the Secondary Schools. As in the gymnasium so in the playing field, the medical officer finds 
valuable assistance in improving the health of the pupils. Games provide a natural method of developing the body, improving the circulation, training the eye and ear and the co-ordination of the muscles, and sensations of the body.

Because the method is natural it arouses interest and joy in the children. Inasmuch as the games are played in the open air and with interest, they are in many respects superior to gymnastic exercises for bodily development.

The mistresses in the girls' school are still too often inclined to regard with suspicion the participation of girls in sports and games. They claim that games take up an undue proportion of the girls' interest, that they make them unfit for their work, that they are dangerous and subject the girls to accidents.

In truth, by improving the health of the girls and giving them healthy interests they improve the standard of their work. Where games are looked on with suspicion only those who are over-keen tend to take part in them. The result is that they do the minimum of good with the maximum of harm, for games need regulation. Girls who indulge in them should do so regularly. It is great effort spasmodically performed which produces ill effects. It is when the over-excitable, unchecked by the steadier element and 


\section{I96 SCHOOL MEDICAL INSPECTION}

unsupervized by interested mistresses, have everything their own way that accidents occur.

Further, girls must be subject to some risks, at some time of their lives, and they will be all the more able to overcome them and rise to emergencies if they have been trained in the playing field.

One great disadvantage girls suffer as a rule when compared to boys. That is, they risk colds far more frequently than boys owing to the frequent unsuitability of their clothing when they are playing. Boys when playing cricket, football, or lacrosse, have a suitable dress which entails changing at once when the game is finished. Girls too often play in their ordinary clothes with perhaps a short skirt instead of the usual long one. The result is that they often have too many clothes on when they play, and keep on those clothes damp with perspiration for some considerable time. There should always be in connection with the playing field of a school a pavilion with changing rooms and a bath, so that the girls may get a change and a rub down before going on to their perhaps distant homes.

If these precautions were taken, if only those played who were considered fit, and if all those played there would be better work, less excitement, and a generally all-round beneficent effect from a regular use of the playing field. 


\section{CHAPTER XVIII \\ INFECTIOUS DISEASE}

Young children are peculiarly liable to certain infectious diseases. Inasmuch as many children are carefully guarded at home and do not come into contact with others till school life begins, the number of children susceptible to infection in a school is generally very large. The greater the precautions against infection, the greater the number of susceptible children in the school.

Some mothers feel that measles and chickenpox at least, and perhaps whooping cough, must be encountered sometime, and they may as well be got over. But this is not a fair view to take. The effect of infectious disease is often very serious on the growing organism of the child. Even slight attacks of measles, unless carefully treated, may leave permanent disablement of one or another organ behind. A young teacher of the writer's acquaintance was left permanently crippled in her professional life by serious 


\section{I98 SCHOOL MEDICAL INSPECTION}

deafness resulting from an attack of measles so slight"as to have apparently needed no treatment at all.

The medical records of the forms show that a large proportion of the weaker divisions have suffered severely in their early years from the infectious diseases. This appears to show both that delicate children quickly contract infectious disease and also that infectious disease tends to hamper the children later in life.

Thus the school authorities are interested in keeping all chances of infection out of the school.

Children showing any signs of ill health must be watched and any trace of the premonitory signs of infectious disease must be referred for medical advice.

Sometimes these illnesses cause symptoms so slight that the mothers have not suspected what may have caused the malaise from which the child has been suffering. Even scarlet fever and diphtheria may have caused symptoms so slight that the mother may have thought it unnecessary to call in medical aid, and may have kept the child at home for a few days and sent her back to scatter infection broadcast among children who may suffer as severely as the first did slightly.

On their return to school after temporary 
absence, therefore, the class mistress should carefully inquire into cases of illness and report suspicious ones to the head mistress. At the commencement of each term certificates of freedom from exposure to infection should always be presented.

Suspicious cases reported to the head mistress will then be referred to the medical officer. In cases of sore throat, where there is fear of scarlet fever or diphtheria, either from the symptoms or from its prevalence in the town, a swab ought to be taken and brushed on the throat and examined bacteriologically. It is well to remember that to do this without the permission of the parent and against his wish may be by law regarded as an assault.

It is never well to unduly hasten the time of return to school after infectious illness. Apart from the risk of infection for the other children, the fever, or some other factor in the illness, may have so exhausted the child that the long isolation period may be the means of the child's returning to school in a better condition, and may ensure a recovery uncomplicated by the various sequelæ which so often hamper children later on. In some cases, however, the long isolation period does seem a waste of precious time. But the interests of the majority 


\section{SCHOOL MEDICAL INSPECTION}

must be safeguarded, and the times of isolation ought to be strictly adhered to.

In order to ensure that as much care as possible is taken to prevent infection entering the school, the various class mistresses ought to be interested in the health of their children and to be able to recognize the premonitory signs of the various infectious fevers.

Infectious fevers are always the result of the invasion of the body by some pathological microorganism. By absolute cleanliness of the school and the furniture and by an efficient system of ventilation, much trouble may be avoided. The germs of the diseases gain access to the body either by direct infection from patient to patient or by indirect infection, i.e. by means of some object or article of clothing touched or infected by the patient. That is, some diseases may be only acquired by contact with the sick, others may be carried by a healthy person.

The germs or micro-organism having entered the body, develop, and a certain period passes during which the patient is not infectious and shows no signs of disease. This period varies considerably in the various diseases, and is known as the "period of incubation." After this period the patient begins to show symptoms of illness and generally at once becomes 
infectious. These symptoms may come on insidiously and simulate other diseases as in measles, or they may begin suddenly as in scarlet fever.

After a further period, varying according to the disease, a rash often develops, "the illness then proceeds along its normal course till the time of recovery begins.

The following are the premonitory signs of the infectious diseases with which the mistress should be familiar.

In chicken pox the premonitory symptoms are practically absent. The disease is often very mild, and the first thing noticed are the minute blebs which are irritable and cause scratching. These are found all over the body, face, and head. Generally spots in all stages from simple blebs containing watery matter or pus to scabs may be noticed at the same time.

In diphtheria the onset is not very sudden. The sore throat comes on gradually. The glands of the neck become enlarged. A membrane of a greyish white colour is formed on the throat. The temperature is not necessarily very high. The patient generally, however, looks very white and ill. All cases of membranous sore throat ought to be regarded with suspicion.

Infection may remain in the nose and throat 


\section{SCHOOL MEDICAL INSPECTION}

of a patient for a long period of time, and it is most important that freedom from infection should be most carefully determined before the child returns to school.

In measles the onset is slow. The first symptoms are a cold in the head, running at the eyes and nose. In the mouth Koplec's spots may be seen. These are often found with difficulty, and are bluish spots on the buccal mucous membrane. On the fourth day, during at least two of which the patient has been highly infectious, the rash appears. This is a blotchy rash occurring on the face, hands, and other parts in spots, and soon covering the whole body with a purplish mottled appearance.

In mumps there is pain in the ear together with enlargement of the parotid gland causing swelling of the cheek. This may be affected on one or both sides. There is generally but not always a feeling of malaise.

Scarlet fever begins suddenly, often with sickness. The rash appears on the second day of the illness. The throat is sore, the skin hot and the pulse quick. The spots are discrete dots placed closed together, and giving the appearance of a bright red flush. The rash appears first on the chest. Round the mouth the skin remains quite white, giving a typical 
appearance. After some days the skin begins to peel. Peelings after a feverish attack and sore throat ought to be regarded with suspicion.

Whooping cough is infectious from the first, but the typical cough does not arrive till the second or third week. The cough is characteristic. It consists of a violent coughing attack which culminates in a sudden crowing inspiration. The cough is often accompanied by vomiting. The cough is not always quite typical. But it is advisable to regard as suspicious any violent cough which is severe enough to produce vomiting.

The following table is in general accord with " a code of rules for the Prevention of Infectious and Contagious Diseases in Schools," issued by the Medical Officers of Schools Association (J. and A. Churchill), and is printed for reference.

When several cases of epidemic disease have occurred in the school, every precaution must be taken to prevent the disease spreading.

If the cases have mostly arisen in one class, it is advisable if possible to isolate the class. This means of course that the children and their clothes and possessions shall be kept separate from their fellows. They should arrive and disperse some time before or after the rest of the school. If they stay for meals 


\section{SCHOOL MEDICAL INSPECTION}

\section{INFECTIOUS DISEASES.}

\begin{tabular}{|c|c|c|c|c|c|}
\hline \multirow[b]{2}{*}{ - } & \multirow{2}{*}{$\begin{array}{l}\text { Incubation } \\
\text { period. }\end{array}$} & \multicolumn{2}{|c|}{$\begin{array}{c}\text { Date of the definite } \\
\text { illness on which the } \\
\text { eruption }\end{array}$} & \multirow{2}{*}{ 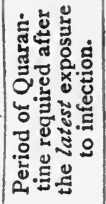 } & \multirow{2}{*}{$\begin{array}{c}\text { Period of } \\
\text { infection ceases. }\end{array}$} \\
\hline & & Appears. & $\begin{array}{l}\text { Begins } \\
\text { to fade. }\end{array}$ & & \\
\hline $\begin{array}{l}\text { Asiatic } \\
\text { Cholera }\end{array}$ & $\begin{array}{l}\text { A few hours } \\
\text { to ro days, } \\
\text { usually } 3 \text { to } \\
6 \text { days }\end{array}$ & 一 & 一 & I2 days & $\begin{array}{l}\text { In seven days } \\
\text { from complete } \\
\text { cessation of } \\
\text { diarrhœa. }\end{array}$ \\
\hline $\begin{array}{l}\text { CHICKEN } \\
\text { POX }\end{array}$ & $\begin{array}{l}\text { Io to } 16 \\
\text { days }\end{array}$ & $\begin{array}{l}\text { Ist day and } 3 \\
\text { following days }\end{array}$ & $\begin{array}{l}\text { about } \\
4^{\text {th }}\end{array}$ & 20 days & $\begin{array}{l}\text { When every scab } \\
\text { has fallen off. }\end{array}$ \\
\hline DIPHTHERIA & 2 to Io days & 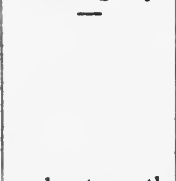 & & I2 days & $\begin{array}{l}\text { In } 4 \text { weeks, if no } \\
\text { discharges and } \\
\text { no albumen, and } \\
\text { if bacteriological } \\
\text { examination of } \\
\text { nose and throat } \\
\text { be negative. }\end{array}$ \\
\hline $\begin{array}{l}\text { GERMAN } \\
\text { MEASLES } \\
\text { (Rötheln) }\end{array}$ & $\begin{array}{l}7 \text { to } 18 \text { days } \\
\text { or even } \\
\text { longer }\end{array}$ & 2nd to $4^{\text {th }}$ & $\begin{array}{l}4^{\text {th }} \text { to } \\
7^{\text {th }}\end{array}$ & 20 days & $\begin{array}{l}\text { In not less than } \\
\text { Io days from } \\
\text { appearance of } \\
\text { the rash. }\end{array}$ \\
\hline INFLUENZA & $\begin{array}{l}\text { I to } 4 \text { lays, } \\
\text { usually } 3 \text { to } \\
4\end{array}$ & 一 & - & 5 days & $\begin{array}{l}\text { In } 3 \text { days after } \\
\text { the temperature } \\
\text { has become } \\
\text { normal, and all } \\
\text { catarrhal dis- } \\
\text { charges have } \\
\text { ceased. }\end{array}$ \\
\hline MEAsLes & $\begin{array}{l}\text { ro to } 14 \\
\text { days }\end{array}$ & $\begin{array}{l}\text { 4th day. The } \\
\text { patient is } \\
\text { highly infec- } \\
\text { tious for } 2 \\
\text { days before } \\
\text { the rash ap- } \\
\text { pears. }\end{array}$ & $\begin{array}{l}5^{\text {th }} \text { to } \\
7^{\text {th }}\end{array}$ & 16 days & $\begin{array}{l}\text { In wot less than } \\
2 \text { weeks from } \\
\text { appearance of } \\
\text { the rash. }\end{array}$ \\
\hline MUMPS & $\begin{array}{l}\text { ro to } 22 \\
\text { days }\end{array}$ & & - & 24 days & $\begin{array}{l}\text { In not less than } \\
3 \text { weeks, and then } \\
\text { only when I week } \\
\text { has elapsed since } \\
\text { subsidence of all } \\
\text { swelling. }\end{array}$ \\
\hline Placive & $\begin{array}{l}2 \text { to } 8 \text { days, } \\
\text { in rare cases } \\
\text { up to } 15 \\
\text { days }\end{array}$ & 一 & 一 & 21 days & In one month. \\
\hline
\end{tabular}




\begin{tabular}{|c|c|c|c|c|c|}
\hline & \multirow{2}{*}{$\begin{array}{l}\text { Incubation } \\
\text { period. }\end{array}$} & \multicolumn{2}{|c|}{$\begin{array}{l}\text { Date of the definite } \\
\text { illness on which the } \\
\text { eruption }\end{array}$} & \multirow{2}{*}{ 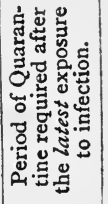 } & \multirow{2}{*}{$\begin{array}{c}\text { Period of } \\
\text { infection ceases. }\end{array}$} \\
\hline & & Appears. & $\begin{array}{l}\text { Begins } \\
\text { to fade. }\end{array}$ & & \\
\hline $\begin{array}{r}\text { SCARLET } \\
\text { FEVER }\end{array}$ & $\begin{array}{l}\text { I to } 8 \text { days, } \\
\text { usually } 3 \text { to } \\
5\end{array}$ & 2nd & $5^{\text {th }}$ & ro days & $\begin{array}{l}\text { When examina- } \\
\text { tion reveals no } \\
\text { b r o k e } n \text { - off } \\
\text { diseased hair. } \\
\text { When desqua- } \\
\text { mation and sore } \\
\text { throat and albu- } \\
\text { minuria disap- } \\
\text { pear, but never } \\
\text { in less than } 6 \\
\text { weeks. }\end{array}$ \\
\hline $\begin{array}{l}\text { SMALL-POX } \\
\text { TYPHOID } \\
\text { FEVER }\end{array}$ & $\begin{array}{l}\text { I2 to r } 4 \\
\text { days } \\
7 \text { to } 2 \text { r days, } \\
\text { usually Io } \\
\text { to } \mathrm{I} 4\end{array}$ & $\begin{array}{l}3 \text { rd or } 4^{\text {th }} \\
8 \text { th or } 9 \text { th }\end{array}$ & $\begin{array}{l}\text { 9th or } \\
\text { roth } \\
\text { 2rst }\end{array}$ & $\begin{array}{l}16 \text { days } \\
23 \text { days }\end{array}$ & $\begin{array}{l}\text { When every scab } \\
\text { has disappeared. } \\
\text { Indefinite (ty- } \\
\text { phoid carriers). }\end{array}$ \\
\hline TYPHUS & $\begin{array}{l}5 \text { to } 14 \text {, very } \\
\text { variable }\end{array}$ & $5^{\text {th }}$ & I4th & 14 days & After 4 weeks. \\
\hline $\begin{array}{l}\text { WHOOPING } \\
\text { COUGH }\end{array}$ & 7 to 14 days & $\begin{array}{l}\text { The characte- } \\
\text { ristic whoop- } \\
\text { ing may not } \\
\text { appear for } \\
3 \text { weeks al- } \\
\text { though the } \\
\text { patient is in- } \\
\text { fectious before } \\
\text { then. }\end{array}$ & 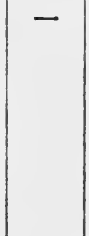 & 2I days & $\begin{array}{l}\text { In } 5 \text { weeks from } \\
\text { commencement, } \\
\text { provided all } \\
\text { charact eristic } \\
\text { spas m o d i c } \\
\text { cough and } \\
\text { whooping have } \\
\text { ceased for at } \\
\text { least two weeks. }\end{array}$ \\
\hline $\begin{array}{r}\text { YELLOW } \\
\text { FEVER }\end{array}$ & $\begin{array}{l}3 \text { to } 6 \text { days } \\
\text { and in rare } \\
\text { cases } 13\end{array}$ & - & - & I5 days & 一 \\
\hline
\end{tabular}

The above-named quarantines (usually fixed at about two days longer than the recognized incubation period of the disease in question) can be considered safe only if thorough disinfection be carried out at the commencement of the quarantine period. This should in all cases be done under the guidance of the medical attendant. It is important also to note that the quarantine period can begin only from the date of the latest exposure. It is often necessary to delay considerably the commencement of a child's quarantine period after exposure to infectious disease, because the patient has been insufficiently isolated, or has been isolated for a shorter time than is required by the Code, so that repeated exposures arise. It is only from the latest exposure previous to the complete recovery of the patient that the quarantine period dates. 


\section{SCHOOL MEDICAL INSPECTION}

they must have them apart. If cases still continue to develop, as may easily happen with such diseases as measles (where the child is acutely infectious before the disease has declared itself), the class must be sent home during the longest incubation period dating from the last exposure to the disease.

Possession of exact information as to previous illness suffered by the children may make it possible to take a less drastic course and to exclude only those who have never suffered from the illness which is at any period epidemic.

It is often important, particularly among the older girls, that as little time shall be lost by forced absence as can be done with safety. On the other hand, some diseases such as German measles and mumps have long incubation periods. In these cases it is possible, if the girls are being carefully watched and only one or two cases have appeared in definite crops (i.e. at the end of each incubation period from the last outbreak), to let the children continue at school till a few days before time for the next outbreak to appear. Then the class can be sent home till the period of danger is over.

No child should be allowed to return after suffering from or being exposed to an infectious disease without showing a medical certificate 
declaring that according to the incubation and isolation periods of the foregoing table, the danger of the infection is at an end.

The question of closing the school entirely arises when the infection is not confined to one class.

Measles, influenza and diphtheria spread very quickly through a school. The early stages are insidious, and not always at once recognized. The effects of these diseases may be so disastrous that it is advisable, if a large number of cases occur, to close the school.

There is less need of hesitation in the Secondary than in the Elementary Schools. If the Elementary Schools close the children still meet in their common playground, the street, and infection is very rife.

In the case of children in the Secondary School the stopping of the schools is more likely to lead to the separation of the scholars for a time. But with care on the part of parent, teacher, and medical officer it is exceedingly seldom that closure of a school should be necessary.

When an epidemic breaks out in a school the parents of pupils in the form affected should be warned of its presence in order that they may be on the look-out for the early premonitory signs. 


\section{SCHOOL MEDICAL INSPECTION}

If such precautions are taken it will be found that the danger of infection is greatly minimized and that much valuable time is saved. Within the last few years the number of cases of infectious disease in the schools has very much decreased. This must be in large measure due to the precautions which are taken, the cost of which in time and trouble is amply repaid.

THE END 


\section{GENERAL LIBRARY}

UNIVERSITY OF CALIFORNIA-BERKELEY

\section{RETURN TO DESK FROM WHICH BORROWED}

This book is due on the last date stamped below, or on the date to which renewed.

Renewed books are subject to immediate recall.

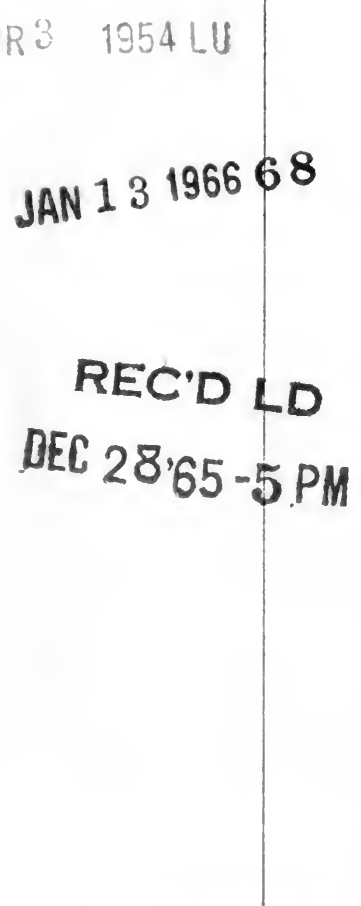




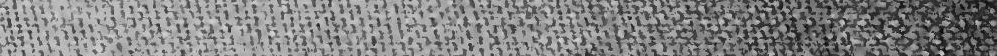
1.1 41.4.

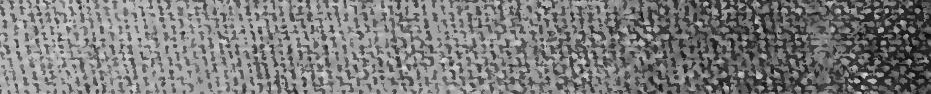

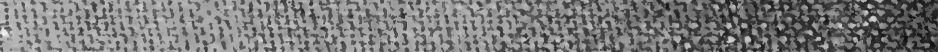

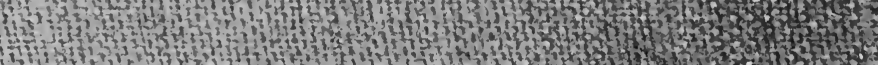

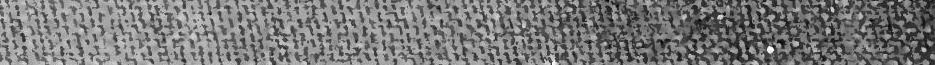

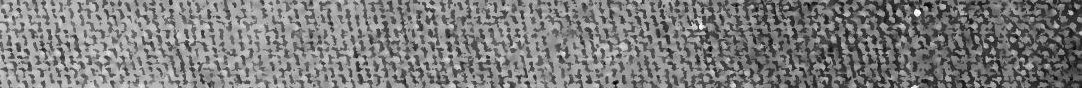

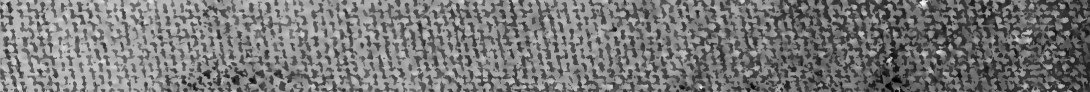

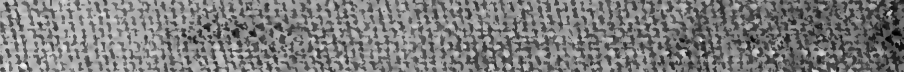

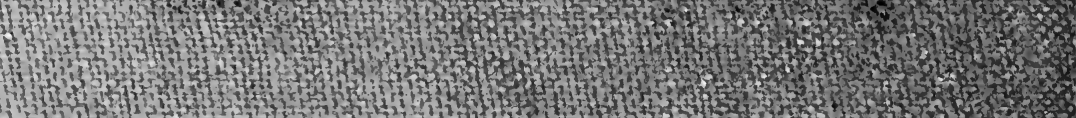

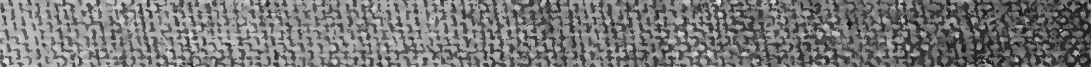

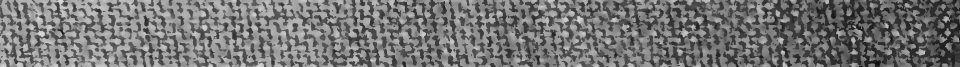
f. H.

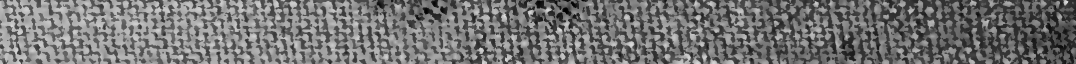
1. 3.

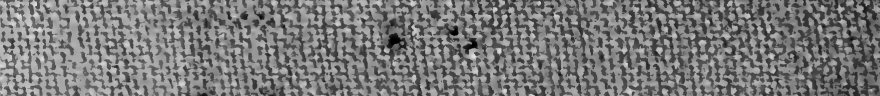
2. 3 .

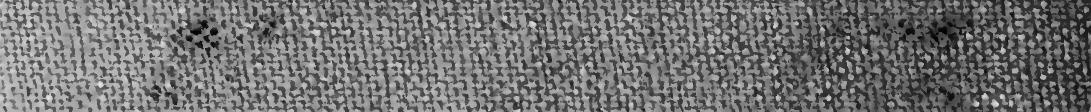

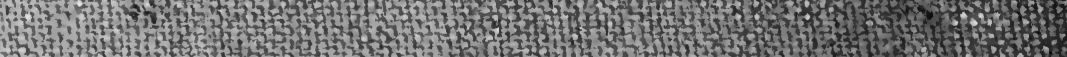
2. a tiv3 STH 